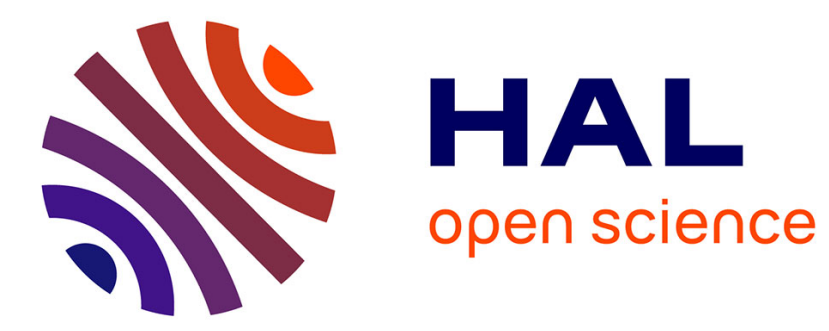

\title{
Repurposing Primaquine as a Polyamine Conjugate to become an Antibiotic Adjuvant
}

A. Norrie Norrie Pearce, Dan Chen, Liam Edmeades, Melissa M Cadelis, Azza

Troudi, Jean Michel Brunel, Marie-Lise Bourguet-Kondracki, Brent R Copp

\section{- To cite this version:}

A. Norrie Norrie Pearce, Dan Chen, Liam Edmeades, Melissa M Cadelis, Azza Troudi, et al.. Repurposing Primaquine as a Polyamine Conjugate to become an Antibiotic Adjuvant. Bioorganic and Medicinal Chemistry, 2021, 38, pp.116110. 10.1016/j.bmc.2021.116110 . hal-03368219

\section{HAL Id: hal-03368219 \\ https://hal.science/hal-03368219}

Submitted on 6 Oct 2021

HAL is a multi-disciplinary open access archive for the deposit and dissemination of scientific research documents, whether they are published or not. The documents may come from teaching and research institutions in France or abroad, or from public or private research centers.
L'archive ouverte pluridisciplinaire HAL, est destinée au dépôt et à la diffusion de documents scientifiques de niveau recherche, publiés ou non, émanant des établissements d'enseignement et de recherche français ou étrangers, des laboratoires publics ou privés. 


\title{
Repurposing Primaquine as a Polyamine Conjugate to become an Antibiotic Adjuvant.
}

A.Norrie Pearce ${ }^{\mathrm{a}}$, Dan Chen ${ }^{\mathrm{a}}$, Liam Edmeades ${ }^{\mathrm{a}}$, Melissa M. Cadelis, ${ }^{\mathrm{a}}$ Azza Troudi ${ }^{\mathrm{b}}$,Jean Michel Brunel, ${ }^{\mathrm{b}}$ MarieLise Bourguet-Kondracki, ${ }^{\mathrm{d}}$ and Brent R. Copp ${ }^{\mathrm{a}} *$

\author{
${ }^{a}$ School of Chemical Sciences, The University of Auckland, Private Bag 92019, Auckland 1142, New Zealand \\ ${ }^{\mathrm{b}}$ Aix-Marseille Universite, INSERM, SSA, MCT, 13385 Marseille, France. \\ ${ }^{\mathrm{d}}$ Laboratoire Molécules de Communication et Adaptation des Micro-organismes, UMR 7245 CNRS, Muséum \\ National d'Histoire Naturelle, 57 rue Cuvier (C.P. 54), 75005 Paris, France
}

\begin{abstract}
In our search for new antibiotic adjuvants as a novel strategy to deal with the emergence of multi-drug resistant (MDR) bacteria, a series of succinylprimaquine-polyamine (SPQ-PA) conjugates and derivatives of a cationic amphiphilic nature have been prepared. Evaluation of these primaquine conjugates for intrinsic antimicrobial properties and the ability to restore the antibiotic activity of doxycycline identified two derivatives, SPQ-PA3-83 and SPQ-PA3-10-3 that exhibited moderately strong intrinsic activity against the Gram-positive bacteria Staphylococcus aureus and the yeast Cryptococcus neoformans. None of the analogues were active against the Gram-negative bacterium Pseudomonas aeruginosa. However, in the presence of a sub-therapeutic amount of doxycycline (4.5 $\mu \mathrm{M})$, both SPQ-PA3-4-3 and the SPQ-PA3-10-3 displayed potent antibiotic adjuvant properties against $P$. aeruginosa, with MIC's of $6.25 \mu \mathrm{M}$. A series of derivatives were prepared to investigate the structure-activity relationship that explored the influence of both a simplified aryl lipophilic substituent and variation of the length of the polyamine scaffold on observed intrinsic antimicrobial properties and the ability to potentiate the action of doxycycline against $P$. aeruginosa.
\end{abstract}

\section{Keywords}

Antibiotics; antimicrobial; primaquine; polyamine; potentiation

\footnotetext{
* To whom correspondence should be addressed. E-mail: b.copp@auckland.ac.nz (B. R. Copp).
} 


\section{Introduction}

The emergence of multi-drug resistant (MDR) bacteria has become a serious global issue triggering increased rates of morbidity and mortality in those affected, with associated negative impacts upon public health and the economy. The declining number of clinically effective agents available to treat these infections has critically compromised therapeutic options and has highlighted the urgent need for novel strategies with new mechanisms of action to combat the diversity of antimicrobial resistance mechanisms exhibited by these MDR pathogens. ${ }^{1-4}$ The use of antibiotic adjuvants or potentiators which can breathe new life back into ineffective drugs is an attractive strategy which can be explored to subvert the drug-resistant phenotype..$^{5-8}$

In recent years, the bacterial membrane has been receiving considerable interest as a non-specific anti-infectious target with potential for bactericidal activity. Progress in the investigation of membrane-active agents has determined that those that best disrupt membrane integrity are typically both lipophilic and positively charged. In particular, centrally positioned, positively charged diamines are able to interact electrostatically with the negatively charged lipids on the surfaces of bacterial membranes while the insertion of bulky terminal hydrophobic units into the lipid layer leads to increased membrane permeability, depolarization with disruption of the transmembrane proton gradient, loss of cell wall rigidity, integrity and lysis. ${ }^{9}$ These attributes bestow the inherent capacity upon these agents to serve as chemosensitizers to enhance the effectiveness of other antibacterial agents. Reports have confirmed that natural polyamines ${ }^{10-12}$ and polyamine derivatives such as the natural product ianthelliformisamine $(\mathbf{1})^{13}$, the (bis)thiourea analogue $\mathbf{2}^{14}$, and acylpolyamines ${ }^{15,16}$ can prejudice membrane integrity and sensitize bacteria to antibiotics.

During our ongoing investigations into the biological activities of polyamine-containing compounds, ${ }^{17-21}$ we found that a library of substituted indolglyoxylpolyamines exhibited mild to modest intrinsic antimicrobial activity. ${ }^{21}$ The most active, 6-bromoindolglyoxylamido-spermine (3) demonstrated good antimicrobial activity against two Gram-positive bacterial strains Staphylococcus intermedius (MIC $3.125 \mu \mathrm{M}$ ) and Staphylococcus aureus (MIC $6.25 \mu \mathrm{M}$ ) and moderate to strong antifungal activity towards Candida albicans (MIC $17.2 \mu \mathrm{M}$ ) and Cryptococcus neoformans (MIC $1.1 \mu \mathrm{M}$ ). This compound was then evaluated for the ability to enhance the antibiotic activity of doxycycline towards Pseudomonas aeruginosa ATCC 27853. Despite having no intrinsic antibiotic activity against $P$. aeruginosa itself, a combination of 3 at $6.25 \mu \mathrm{M}$ with doxycycline at $4.5 \mu \mathrm{M}$, a concentration at which doxycycline alone is ineffective (MIC $>45 \mu \mathrm{M}$ ), was able to restore the action of the antibiotic.

Mechanism of action studies were performed to measure permeabilization, characteristic of membrane perturbation, and to verify the loss of the bacterial transmembrane proton gradient force which enables pathogens like $P$. aeruginosa to actively pump antibiotics out of the cell via drug efflux systems. The results of these studies established that rapid disruption of the bacterial membrane and loss of integrity coupled with strong depolarization occurred indicating that $\mathbf{3}$ was also able to dissipate the proton concentration gradient and inhibit efflux pumps. Unfortunately, this lead compound also exhibited low selectivity with undesirable cytotoxicity to rat skeletal muscle (L6) and human embryonic kidney (HEK-293) cell lines. 
<smiles>COc1c(Br)cc(/C=C/C(=O)NCCCNCCCCNCCCNC(=O)/C=C/c2cc(Br)c(OC)c(Br)c2)cc1Br</smiles><smiles>S=C(NCCCNCCCCCNCCCNC(=S)NCC(c1ccccc1)c1ccccc1)NCC(c1ccccc1)c1ccccc1</smiles><smiles>O=C(NCCCNCCCCNCCCNC(=O)c1c[nH]c2cc(Br)ccc12)C(=O)c1c[nH]c2cc(Br)ccc12</smiles>

Figure 1. Structures of polyamines 1-3.

Intrigued by these findings we decided to test a primaquine-polyamine hybrid, which had previously been synthesized as a possible anti-malarial candidate, and had demonstrated modest results, but which had not displayed adequate in vivo activity. Herein we present these preliminary data, and the preparation of a library of analogues for a structure-activity relationship study that explores the influence on intrinsic antimicrobial and antibiotic adjuvant properties of both a simplified hydrophobic pendant substituent and the consequence of chain length of the polyamine core. In this way we could span a wide range of lipophilicities and modifications in order to identify the minimum pharmacophore necessary for intrinsic antibiotic activity as well as for the ability to increase antibiotic susceptibility in resistant strains of pathogens.

\section{Chemistry}

The preparation of the library of SPQ-PA analogues was straightforward and uncomplicated and all analogues follow the synthetic scheme shown in Scheme 1. The initial step was the synthesis of the Boc-protected polyamine scaffolds 4a-e (Fig. 2) which has been previously described. ${ }^{20,22-24}$ Five polyamines were prepared with chains of varying lengths, commencing with spermine (polyamine PA3-4-3) and continuing through PA36-3, PA3-7-3, PA3-8-3 and PA3-10-3 designed to examine the influence of chain length, lipophilicity, steric bulk and spatial positioning of the positive charges on bioactivity. 


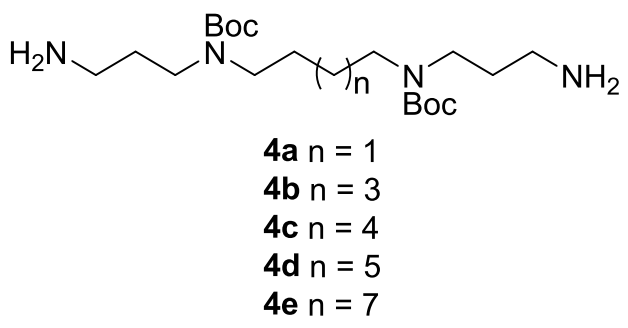

Figure 2. Target polyamine scaffolds 4a-e.

The library of SPQ-PA analogues was synthesized first. In order to couple a polyamine scaffold to primaquine it was necessary to convert the amine substituent into a carboxylic acid functionality. Thus primaquine bisphosphate was first converted to the free base by dissolving it in $\mathrm{CH}_{2} \mathrm{Cl}_{2}$ and washing the organic layer with $1 \%$ aq. $\mathrm{K}_{2} \mathrm{CO}_{3}$, following which the resulting free-based amine was reacted with succinic anhydride in anhydrous $\mathrm{CH}_{2} \mathrm{Cl}_{2}$ to give the succinylprimaquine acid intermediate 5. This intermediate was subsequently reacted with the Boc-protected polyamine scaffolds 4a-e by HBTU/DIPEA or CDI-mediated coupling in DMF affording the Boc-protected diamides 6-10 in yields of 70-81\%. Deprotection of the Boc-protected diamides was carried out using either TFA in $\mathrm{CH}_{2} \mathrm{Cl}_{2}$ or $4 \mathrm{M} \mathrm{HCl}$ in dioxane to yield the target analogues 11-15 as their di-TFA or di-HCl salts in $87-97 \%$ yield.<smiles>COc1cc(NC(C)CCCN)c2ncccc2c1</smiles>

Primaquine
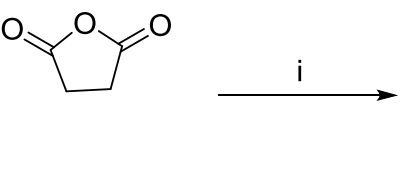<smiles>COc1cc(NC(C)CCCNC(=O)CCC(=O)O)c2ncccc2c1</smiles>

SPQ (5)<smiles>[3H]C#CC</smiles>

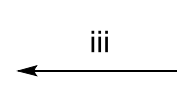<smiles>[R]NCCCN(CCC(C)(C)CCN(CCCN[R])C(=O)OCc1ccccc1)C(=O)OCc1ccccc1</smiles>

$11 \mathrm{R}=\mathrm{SPQ}, \mathrm{n}=1$

$12 \mathrm{R}=\mathrm{SPQ}, \mathrm{n}=3$

$13 \mathrm{R}=\mathrm{SPQ}, \mathrm{n}=4$

$14 \mathrm{R}=\mathrm{SPQ}, \mathrm{n}=5$

$15 \mathrm{R}=\mathrm{SPQ}, \mathrm{n}=7$

$R=S P Q, n=1,3,4,5,7$

(6-10)

Scheme 1. General method for the preparation of the SPQ-PA conjugates 11-15. Reagents and conditions: (i) $\mathrm{CH}_{2} \mathrm{Cl}_{2}, \mathrm{~N}_{2}, \mathrm{rt}, 12 \mathrm{~h}$; (ii) 4a-e, HBTU, DIPEA DMF, or CDI, DMF, $\mathrm{N}_{2}, \mathrm{rt}, 12 \mathrm{~h}$; (iii) TFA/ $\mathrm{CH}_{2} \mathrm{Cl}_{2}, \mathrm{~N}_{2}, \mathrm{rt}, 2$ h or $4 \mathrm{M} \mathrm{HCl}$ in dioxane, $\mathrm{N}_{2}, \mathrm{rt}, 4 \mathrm{~h}$. 
We sought to compare the intrinsic antibiotic and antibiotic adjuvant activities of the SPQ-PA conjugates with a corresponding library of amine-polyamine conjugates comprising progressively simpler nitrogen-containing aryl groups for structure-activity investigations. These analogues were prepared using the general scheme outlined in Scheme 1. The initial amido-acids were synthesized from the desired nitrogen-containing aromatic amine and succinic anhydride to produce an amido-acid fragment with a succinyl spacer as described above, capable of being coupled to a Boc-protected polyamine. The targeted conjugates were then prepared by HBTU, EDC.HClHOBt, or EDC.HCl-DMAP mediated coupling of the capping amido-acids with the Boc-protected polyamines 4a-e to afford Boc-protected diamides in yields of 24-100\%. Boc deprotection was achieved using TFA in $\mathrm{CH}_{2} \mathrm{Cl}_{2}$ to give compounds 43-62 (Fig. 3).

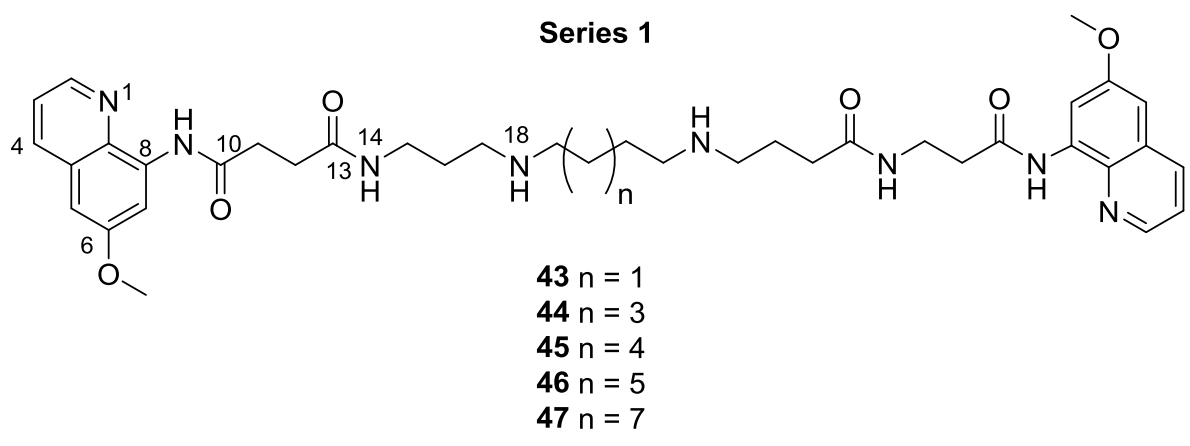

\section{Series 2}

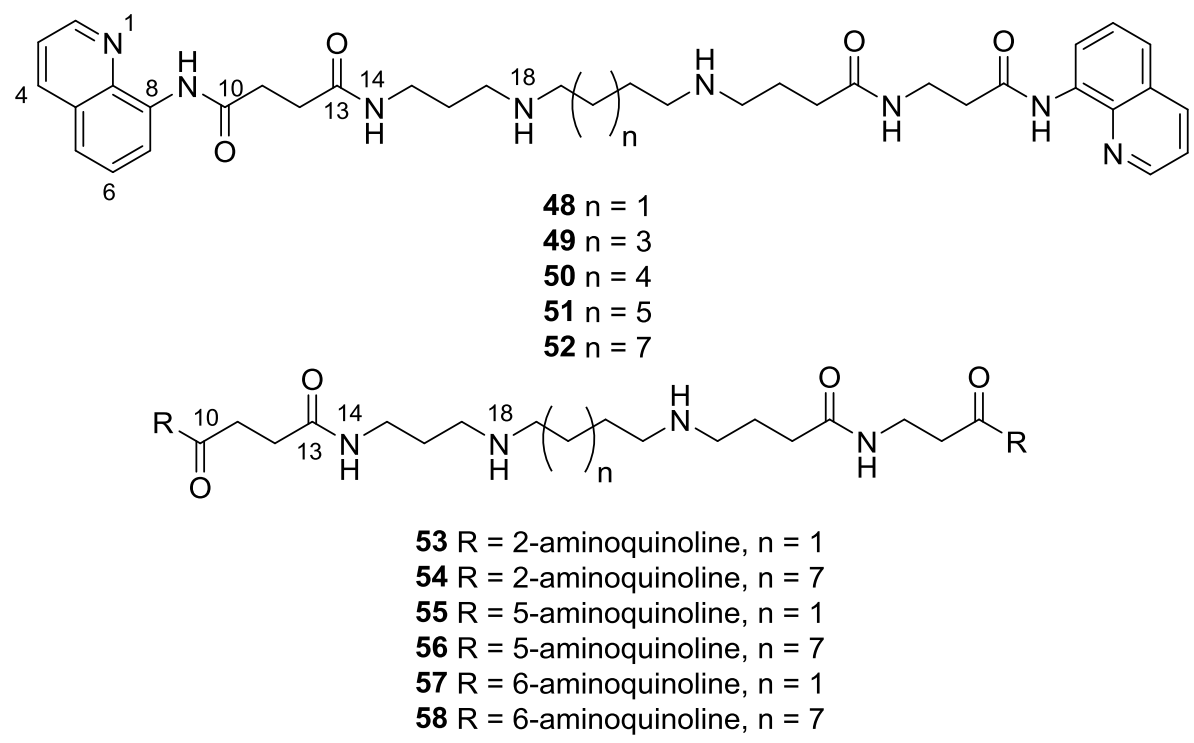

Series 3<smiles></smiles>

$$
\begin{aligned}
& 59 X=N, Y=H, n=1 \\
& 60 X=N, Y=H, n=7 \\
& 61 X=H, Y=N, n=1 \\
& 62 X=H, Y=N, n=7
\end{aligned}
$$

Figure 3. Structures of the SPQ-PA derivatives 43-62. 


\section{Biological Results and Discussion}

\subsection{Bioactivity of $S P Q$ analogues}

The intrinsic antimicrobial efficacy of the set of succinylprimaquine-polyamine (SPQ-PA) analogues 11-15 was evaluated against a variety of microorganisms including Gram-negative (Pseudomonas aeruginosa, Escherichia coli, Klebsiella pneumoniae and Acinetobacter baumannii) and Gram-positive bacteria (Staphylococcus aureus) as well as two yeast strains (Candida albicans and Cryptococcus neoformans) (Table 1).

Initial screening of the SPQ-PA conjugates showed that these compounds exhibited only modest or no intrinsic activity against the bacterial pathogens, except for derivatives 14 (SPQ-PA3-8-3) and 15 (SPQ-PA3-10-3) that revealed moderately potent MIC's of 13.7 and $3.3 \mu \mathrm{M}$ respectively against $S$. aureus. However, all compounds except 11 (SPQ-PA3-4-3) demonstrated potent activities against the yeast $C$. neoformans (MIC 33.4, 1.8, 0.4, 1.7, $1.7 \mu \mathrm{M}$ respectively for analogues 11-15). Of note was the lack of efficacy against Gram-negative organisms, likely due to the presence of a second outer cellular membrane, which typically confers extra protection against many antimicrobials. We observed with some interest a clear structure-activity trend strongly indicating that progressive lengthening of the polyamine chain increased antibiotic activity, as only $\mathbf{1 4}$ with the octyl mid-section chain length (SPQ-PA3-8-3) and 15 with the decyl chain length (SPQ-PA3-10-3) demonstrated any activity against $S$. aureus. Compound $\mathbf{1 1}$ (SPQ-PA3-4-3) which possessed the least hydrophobic alkyl chain length with only four carbons was essentially inactive in all assays. Gratifyingly, we observed no cytotoxicity against rat skeletal muscle (L6) or human embryonic kidney (HEK-293) cell lines, and no hemolytic activity towards human erythrocytes in any of these compounds (data not shown). These results clearly illustrated a strong correlation of increasing antibacterial potency with the increasing lipophilicity of the polyamine scaffold whilst retaining selectivity towards bacterial membranes and sparing mammalian cells, the decyl chain length showing significantly more activity over the shorter acyl chains. This is consistent with previous reports affirming that the spacing between the positively charged groups is strongly linked to selectivity and intrinsic antibiotic activity. ${ }^{12,15,16,25}$

With the initial screening in hand, we then set about exploring the main objective of our investigation, which was to evaluate this set of compounds for their ability to act as adjuvants to overcome the resistance mechanisms of $P$. aeruginosa that enables it to evade the antibiotic efficacy of doxycycline.

As shown in Table 1, none of the SPQ analogues demonstrated any intrinsic activity against $P$. aeruginosa, so we found to our interest, that all analogues restored, to varying degrees, the susceptibility of $P$. aeruginosa to doxycycline when they were combined with just $4.5 \mu \mathrm{M}$ doxycycline, a concentration at which doxycycline alone is ineffective (MIC $>45 \mu \mathrm{M}$ ) (Table 2). Compounds 11 (SPQ-PA3-4-3) and 15 (SPQ-PA3-10-3) in particular, both exhibited significant MIC's of $6.25 \mu \mathrm{M}$ demonstrating especially promising potential, followed by the intermediate chain lengths of $\mathbf{1 2}, \mathbf{1 3}$, and $\mathbf{1 4}$ with more modest MIC values of 25,50 , and $25 \mu \mathrm{M}$ respectively. 
Table 1. Antibacterial and antifungal activities of SPQ-PA analogues 11-15 and derivatives 43-62.

\begin{tabular}{|c|c|c|c|c|c|c|c|}
\hline \multirow[t]{2}{*}{ Compound } & \multicolumn{7}{|c|}{ MIC $(\mu \mathrm{M})$} \\
\hline & S. $a^{a}$ & P. $a^{b}$ & E. $c^{c}$ & $K \cdot p^{d}$ & A. $b^{e}$ & C. $a^{f}$ & C. $n^{g}$ \\
\hline 11 & $>33.4$ & $>33.4$ & $>33.4$ & $>33.4$ & $>33.4$ & $>33.4$ & 33.4 \\
\hline 12 & 28.0 & $>28.0$ & $>28.0$ & $>28.0$ & $>28.0$ & $>28.0$ & 1.75 \\
\hline 13 & $>27.7$ & $>27.7$ & $>27.7$ & $>27.7$ & $>27.7$ & $>27.7$ & 0.43 \\
\hline 14 & 13.7 & $>27.4$ & $>27.4$ & $>27.4$ & $>27.4$ & $>27.4$ & 1.71 \\
\hline 15 & 3.34 & $>26.7$ & $>26.7$ & $>26.7$ & $>26.7$ & 26.7 & 1.67 \\
\hline 43 & $>33.9$ & $>33.9$ & $>33.9$ & $>33.9$ & $>33.9$ & $>33.9$ & $>33.9$ \\
\hline 44 & $>33.0$ & $>33.0$ & $>33.0$ & $>33.0$ & $>33.0$ & $>33.0$ & $>33.0$ \\
\hline 45 & $>32.5$ & $>32.5$ & $>32.5$ & $>32.5$ & $>32.5$ & $>32.5$ & $>32.5$ \\
\hline 46 & $>32.0$ & $>32.0$ & $>32.0$ & $>32.0$ & $>32.0$ & $>32.0$ & $>32.0$ \\
\hline 47 & 3.89 & $>31.2$ & $>31.2$ & $>31.2$ & $>31.2$ & $>31.2$ & $>31.2$ \\
\hline 48 & $>36.2$ & $>36.2$ & $>36.2$ & $>36.2$ & $>36.2$ & $>36.2$ & $>36.2$ \\
\hline 49 & 17.6 & $>35.1$ & $>35.1$ & $>35.1$ & $>35.1$ & $>35.1$ & $>35.1$ \\
\hline 50 & $>34.6$ & $>34.6$ & $>34.6$ & $>34.6$ & $>34.6$ & $>34.6$ & $>34.6$ \\
\hline 51 & $>34.1$ & $>34.1$ & $>34.1$ & $>34.1$ & $>34.1$ & $>34.1$ & $>34.1$ \\
\hline 52 & 33.1 & $>33.1$ & $>33.1$ & $>33.1$ & $>33.1$ & $>33.1$ & $>33.1$ \\
\hline 53 & $>36.2$ & $>36.2$ & $>36.2$ & $>36.2$ & $>36.2$ & $>36.2$ & $>36.2$ \\
\hline 54 & $>33.1$ & $>33.1$ & $>33.1$ & $>33.1$ & $>33.1$ & $>33.1$ & $>33.1$ \\
\hline 55 & $>36.2$ & $>36.2$ & $>36.2$ & $>36.2$ & $>36.2$ & $>36.2$ & $>36.2$ \\
\hline 56 & $>33.1$ & $>33.1$ & $>33.1$ & $>33.1$ & $>33.1$ & $>33.1$ & $>33.1$ \\
\hline 57 & $>36.2$ & $>36.2$ & $>36.2$ & $>36.2$ & $>36.2$ & $>36.2$ & $>36.2$ \\
\hline 58 & $>33.1$ & $>33.1$ & $>33.1$ & $>33.1$ & $>33.1$ & $>33.1$ & $>33.1$ \\
\hline 59 & $>39.5$ & $>39.5$ & $>39.5$ & $>39.5$ & $>39.5$ & $>39.5$ & $>39.5$ \\
\hline 60 & $>35.8$ & $>35.8$ & $>35.8$ & $>35.8$ & $>35.8$ & $>35.8$ & $>35.8$ \\
\hline 61 & $>39.5$ & $>39.5$ & $>39.5$ & $>39.5$ & $>39.5$ & $>39.5$ & $>39.5$ \\
\hline 62 & $>35.8$ & $>35.8$ & $>35.8$ & $>35.8$ & $>35.8$ & $>35.8$ & $>35.8$ \\
\hline
\end{tabular}

${ }^{a}$ Staphylococcus aureus ATCC 25923 with streptomycin (MIC $21.5 \mu \mathrm{M}$ ) and chloramphenicol (MIC 1.5-3 $\mu \mathrm{M}$ ) used as positive controls and values presented as the mean $(\mathrm{n}=3)$.

${ }^{\mathrm{b}}$ Pseudomonas aeruginosa ATCC 27853 with streptomycin (MIC $21.5 \mu \mathrm{M}$ ) and colistin (MIC $1 \mu \mathrm{M}$ ) used as positive controls and values presented as the mean $(\mathrm{n}=3)$.

${ }^{\mathrm{c}}$ Escherichia coli ATCC 25922 with streptomycin (MIC $21.5 \mu \mathrm{M}$ ) and colistin (MIC $2 \mu \mathrm{M}$ ) used as positive controls and values presented as the mean $(\mathrm{n}=3)$.

${ }^{\mathrm{d}}$ Klebsiella pneumoniae ATCC 700603 with colistin (MIC $0.22 \mu \mathrm{M}$ ) as a positive control and values presented as the mean $(\mathrm{n}=2)$.

${ }^{\mathrm{e}}$ Acinetobacter baumanii ATCC 19606 with colistin (MIC $0.22 \mu \mathrm{M}$ ) as a positive control and values presented as the mean $(\mathrm{n}=2)$.

${ }^{\mathrm{f}}$ Candida albicans ATCC 90028 with fluconazole (MIC $0.41 \mu \mathrm{M}$ ) as a positive control and values presented as the mean (n $=2$ ).

${ }^{\mathrm{g}}$ Cryptococcus neoformans ATCC 208821 with fluconazole (MIC $26.1 \mu \mathrm{M}$ ) as a positive control and values presented as the mean $(\mathrm{n}=2)$. 
Further investigation of the ability of compounds $\mathbf{1 1}$ and $\mathbf{1 5}$ to restore the antibiotic activity of doxycycline against other Gram-negative pathogens, Escherichia coli, Klebsiella pneumoniae and Acinetobacter baumannii was undertaken, and the results summarized in Table 3. As established for P. aeruginosa, neither of these conjugates exhibited any intrinsic antibiotic activity towards these bacteria, but did demonstrate some modest synergistic activity with doxycycline. Compound $\mathbf{1 5}$ with the decyl chain length was identified as the most effective adjuvant against $E$. coli requiring an $\mathrm{MIC}$ of $12.5 \mu \mathrm{M}$ to restore the action of doxycycline at a fixed concentration of $4.5 \mu \mathrm{M}$ followed by 11 with a weaker MIC of $50 \mu \mathrm{M}$. No activity was observed towards $A$. baumannii and neither derivative demonstrated any substantial ability to sensitize K. pneumoniae to doxycycline, compound 15 exhibiting a MIC value of $50 \mu \mathrm{M}$, with compound 11 being completely inactive. This confirmed our observation that generally the longer chain lengths were optimal.

Table 2. Doxycycline potentiation activity of SPQ-PA analogues 11-15 and derivatives 43-62 against $P$. aeruginosa.

\begin{tabular}{|c|c|}
\hline Compound & $\begin{array}{c}\text { Conc. }(\mu \mathrm{M}) \text { for } \\
\text { potentiation }^{\mathrm{a}}\end{array}$ \\
\hline 11 & 6.25 \\
\hline 12 & 25 \\
\hline 13 & 50 \\
\hline 14 & 25 \\
\hline 15 & 6.25 \\
\hline 43 & 200 \\
\hline 44 & 300 \\
\hline 45 & 300 \\
\hline 46 & 300 \\
\hline 47 & 300 \\
\hline 48 & 566 \\
\hline 49 & 100 \\
\hline 50 & 200 \\
\hline 51 & 200 \\
\hline 52 & 100 \\
\hline 53 & 566 \\
\hline 54 & 517 \\
\hline 55 & 300 \\
\hline 56 & 517 \\
\hline 57 & 566 \\
\hline 58 & 517 \\
\hline 59 & 617 \\
\hline 60 & 559 \\
\hline 61 & 617 \\
\hline 62 & 559 \\
\hline
\end{tabular}

${ }^{\text {a }}$ Concentration $(\mu \mathrm{M})$ required to restore doxycycline activity at $2 \mu \mathrm{g} / \mathrm{mL}(4.5 \mu \mathrm{M})$ against $P$. aeruginosa ATCC 27853. 
Notably however, the synergistic activity with doxycycline towards $P$. aeruginosa did not coincide with the general preference for increased spatial positioning between the positive charges as observed for the intrinsic biological activity. As the $\mathrm{MIC}_{50}$ values of $6.25 \mu \mathrm{M}$ were comparable between the shortest spermine SPQ-PA34-3 (11) analogue and the longest SPQ-PA3-10-3 (15) scaffold, with weaker variable values being shown in the intermediate chain lengths, it became apparent that the potentiating activity was not completely lipophilicitydriven. The inference that interaction with membrane protein targets also plays a part is yet to be determined but cannot be discounted.

Table 3. Doxycycline potentiation activity of SPQ-PA conjugates 11 and $\mathbf{1 5}$ against E. coli, K. pneumoniae and A. baumannii.

\begin{tabular}{|c|c|c|c|}
\hline \multirow[t]{2}{*}{ Compound } & \multicolumn{3}{|c|}{ Conc. $(\mu \mathrm{M})$ for potentiation ${ }^{\mathrm{a}}$} \\
\hline & E.c. & K. $p^{c}$ & A. $b^{d}{ }^{d}$ \\
\hline 11 & 50 & $>200$ & $>200$ \\
\hline 15 & 12.5 & 50 & $>200$ \\
\hline
\end{tabular}

${ }^{a}$ Concentration $(\mu \mathrm{M})$ required to restore doxycycline activity at $2 \mu \mathrm{g} / \mathrm{mL}(4.5 \mu \mathrm{M})$.

${ }^{\mathrm{b}}$ Escherichia coli ATCC28922

${ }^{\mathrm{c}}$ Klebsiella pneumonia ACCC13443

${ }^{\mathrm{d}}$ Acinetobacter baumannii AYE

\subsection{SAR design of Series 1-3}

Motivated by these results, we sought to prepare a series of novel conjugates that would enable to optimize the molecules to gain potency, pathogen selectivity and to identify the minimal motif required for activity (Fig. 3). The SAR of the SPQ-polyamine conjugates was explored in three series of compounds, designed to become progressively simpler as deconstruction progressed and functionalities were systematically removed in order to assess the importance and contribution of each feature. As cationic amphiphiles act by perturbing the bacterial membrane, some tolerance for rigid structural requirements may be expected, so any significant variation in activity could point to the possible participation of other membrane protein targets. ${ }^{26}$

In Series 1 the 6-methoxy-quinoline pendant group was retained but the role of the 4-amino-pentyl linker to the succinylpolyamine chain was investigated by omitting it completely so that the activity would report on the contribution of this functionality. As the $\mathrm{p} K_{\mathrm{a}}$ of the aniline nitrogen at position eight on the quinoline moiety is very low (unmeasurable) ${ }^{27}$ and therefore unprotonated at physiological $\mathrm{pH}$, it has no influence on the number of cationic species. This series was synthesized as the polyamine 3-4-3, 3-6-3, 3-7-3, 3-8-3, and 3-10-3 configurations for close comparison with the SPQ analogues 11-15. Thus, we could interrogate the influence on activity of increased chain length, and therefore increased lipophilicity confining the two positive charges of the polyamine core, whilst retaining the mandatory cationic amphiphilic nature.

In Series 2, we not only removed the 4-amino-pentyl motif, but also modified the quinoline ring by eliminating the electron-donating 6-methoxy substituent to determine whether stereoelectronic variation was permitted at 
this position, as well as exploring any positional bias of 2, 5, 6, and 8-quinoline regioisomers. The 8-substituted quinoline, as for Series 1, was synthesized with all five polyamine chain lengths, while the other regioisomers were prepared with the 3-4-3 and 3-10-3 chains only, keeping in mind the observed adjuvant activities of SPQ compounds 11 and 15.

The final series (Series 3) was designed to assess the significance and requirement for steric hydrophobic bulk as a feature for activity by substituting 2 - and 3-subsituted pyridine rings in place of the quinoline moiety. The resulting analogues would represent the minimal possible pharmacophore in the series, sporting the least bulky possible nitrogen-containing aromatic end group, while also omitting the 4-amino-pentyl substituent, but retaining the essential cationic and lipophilic features of the polyamine scaffold for activity. These compounds were also prepared only with the 3-4-3 and 3-10-3 chains.

\subsection{Biological activity of the SAR analogues}

Examination of the intrinsic activity of these derivatives revealed that consistent with the original SPQ-PA results, none exhibited antibacterial properties against the ESKAPE bacteria except for 47 (Series 1) and 49 (Series 2) with MIC's of 3.9 and $17.6 \mu \mathrm{M}$ respectively towards S. aureus (Table 1). These conjugates both maintained the 8-substituted quinoline core, indicating significant preference for this functionality. To our interest, compound 47 (Series 1) was identical to SPQ-PA3-10-3 (15) in structure, retaining all of the features except for the absence of the 4-amino-pentyl substituent, confirming that of all the polyamine scaffolds, the decyl chain length contributed most to the activity. Given the parity of activity, (MIC $3.9 \mu \mathrm{M}$ vs $3.3 \mu \mathrm{M}$ for 15) it would be tempting to conclude that in addition to the extended length of hydrophobicity between the two charged nitrogens, the important feature was the pendant steric bulk, were it not for the fact that none of the other 3-10-3 quinoline regioisomers exhibited any intrinsic activity at all. Further analysis leads to observe that the spatial positioning of the 8-substituted quinoline must also play a valid role in that it is oriented in such a fashion that insertion into the lipid bilayer is facilitated. Furthermore, the presence of the electron rich 6methoxy substituent on the quinoline ring also appears to be of significance. Thus, there are four motifs that all contribute to the activity: decyl chain length between the charged nitrogens, pendant hydrophobic steric bulk, an 8-substituted quinoline and a 6-methoxy quinoline substituent. Compound 49, (Series 2) with much more modest activity (MIC 17.6 $\mu \mathrm{M}$ ) and incorporating the shorter PA3-6-3 scaffold also retained the 8-quinoline substituted structure but lacked the 6-methoxy moiety and the 4-amino-pentyl substituent. Only compound $\mathbf{5 2}$ (PA3-10-3) in Series 2 exhibited some very weak haemolytic activity towards rat red blood cells with an $\mathrm{HC}_{50}$ (concentration at which $50 \%$ of red blood cells were lysed) of $30.5 \mu \mathrm{M}$. Otherwise no haemolytic or cytotoxic activity was observed (data not shown). Curiously none of these derivatives exhibited any activity against the yeast $C$. neoformans, unlike the original SPQ-PA analogues which all except SPQ-PA3-4-3 displayed potent activity.

Finally, the extended set of analogues were evaluated for their ability to act as adjuvants for doxycycline against P. aeruginosa, E. coli, K. pneumonia and A. baumannii. We were surprised to discover that unlike the SPQ-PA analogues, all of these compounds were completely ineffective at restoring the action of doxycycline not only against $P$. aeruginosa (Table 2) but also against the other Gram-negative pathogens (data not shown). Clearly, 
although the 4-amino-pentyl substituent was relatively inessential for intrinsic bioactivity, it was crucial for the mission of acting as an antibiotic adjuvant.

\section{Conclusions}

Our initial screening identified SPQ-PA3-10-3 (15) as a strongly active antimicrobial agent with excellent selectivity against the Gram-positive pathogen $S$. aureus and against the yeast $C$. neoformans which was also able to potently enhance the antibiotic susceptibility of $P$. aeruginosa to doxycycline. SPQ-PA3-4-3 (11), with the spermine scaffold, was even more interesting in that it was devoid of any intrinsic antibiotic activity in itself but was equipotent with $\mathbf{1 5}$ at enhancing the activity of doxycycline against $P$. aeruginosa. Given the fact that the ideal antibiotic adjuvant has no intrinsic activity that may activate resistance mechanisms in the pathogen, coupled with strong potentiating activity, $\mathbf{1 1}$ may have the potential to be a true antibiotic adjuvant.

Although SAR experiments failed to produce positive results in our attempts to simplify and enhance synergizing antibiotic activity, instead indeed, abrogating it altogether, they clearly showed that the 4-aminopentyl substituent on the quinoline ring of the SPQ-PA analogues 11-15 is critical for potentiating activity. Whether this is due to the lengthening of the alkyl chain, therefore increasing the lipophilicity outside of the positively charged nitrogen core or even the presence of a methyl group remains to be explored further. It may also allude to the possibility that these molecules are also interacting with other protein targets in the bacterial membranes, thereby augmenting the proposed cationic amphiphilic effect in their mode of action. In addition, the SAR experiments indicated that the decyl chain length between the positive charges, the 8-substituted quinoline ring and the electron rich 6-methoxy quinoline substituent all appear to be mandatory features for intrinsic antibiotic activity.

It has become evident through these investigations that there is more structural specificity and considerably less flexibility in structural constraints allowed in these molecules than has previously been considered. Following our previous investigations that demonstrated convincingly that this type of small cationic amphiphile disrupts lipid membranes, and a report that confirms that primaquine itself is also capable of intercalating and perturbing lipid bilayers, ${ }^{28}$ there is reasonable evidence to support the conclusion that the SPQ-PA analogues are also membrane disruptors. However, although this mode of action may be pivotal to the synergistic activity, it is clear that other factors are in play. Whether in addition, membrane proteins are actively involved remains interesting and unexplored territory for the focus of future investigations.

\section{Experimental}

\subsection{General remarks}

Infrared spectra were recorded on a Perkin-Elmer spectrometer 100 Fourier Transform infrared spectrometer equipped with a universal ATR accessory. Mass spectra were acquired on a Bruker micrOTOF Q II spectrometer. ${ }^{1} \mathrm{H}$ and ${ }^{13} \mathrm{C}$ NMR spectra were recorded at $298 \mathrm{~K}$ on a Bruker AVANCE 400 spectrometer at 400 and $100 \mathrm{MHz}$, respectively using standard pulse sequences. Proto-deutero solvent signals were used as internal 
references (DMSO- $d_{6}: \delta_{\mathrm{H}} 2.50, \delta_{\mathrm{C}} 39.52 ; \mathrm{CDCl}_{3}: \delta_{\mathrm{H}} 7.26, \delta_{\mathrm{C}} 77.16$ ). For ${ }^{1} \mathrm{H} \mathrm{NMR}$, the data are quoted as position $(\delta)$, relative integral, multiplicity $(\mathrm{s}=$ singlet, $\mathrm{d}=$ doublet, $\mathrm{t}=$ triplet, $\mathrm{q}=$ quartet, $\mathrm{m}=$ multiplet, $\mathrm{br}=$ broad), coupling constant $(\mathrm{J}, \mathrm{Hz})$, and assignment to the atom. The ${ }^{13} \mathrm{C}$ NMR data are quoted as position $(\delta)$, and assignment to the atom. Flash column chromatography was carried out using Davisil silica gel (40-60 $\mu \mathrm{m})$, Merck silica gel $(15-40 \mu \mathrm{m})$ or Merck Diol bonded silica $(40-63 \mu \mathrm{m})$ or Merck $\mathrm{C}_{8}$ reversed-phase $(40-63 \mu \mathrm{m})$ solid support. Thin layer chromatography was conducted on Merck DC-plastikfolien Kieselgel 60 F254 plates. Reverse-phase analytical thin layer chromatography (TLC) was carried out on $0.2 \mathrm{~mm}$ thick plates of DCKieselgel 60 RP-18 $\mathrm{F}_{254} \mathrm{~S}$ (Merck). Analytical reversed phase $\mathrm{C}_{18}$ HPLC was run on a Waters 600 HPLC photodiode array system using an Altech $3 \mu \mathrm{m}$ econosphere Rocket $^{\mathrm{TM}}$ column $(33 \mathrm{x} 7 \mathrm{~mm})$, eluting with a gradient from aqueous trifluoroacetic acid (0.05\%) through to $\mathrm{MeCN}$. All solvents used were of analytical grade or better and/or purified according to standard procedures. Chemical reagents used were purchased from standard chemical suppliers and used as purchased. All samples were determined to $>95 \%$ purity. Compounds 4a-e, di-tert-butyl butane-1,4-diylbis((3-aminopropyl)carbamate), di-tert-butyl hexane-1,6-diylbis((3aminopropyl)carbamate), di-tert-butyl heptane-1,7-diylbis((3-aminopropyl)carbamate), di-tert-butyl octane-1,8diylbis((3-aminopropyl)carbamate), and di-tert-butyl decane-1,10-diylbis((3-aminopropyl)carbamate) were synthesised by literature procedures. ${ }^{20,22-24}$

\subsection{Synthesis}

\subsubsection{Synthesis of $S P Q$ polyamines 5-15}

\subsubsection{General procedure A: synthesis of amido-acids}

To a stirred solution of succinic anhydride (1.1 equiv.) in anhydrous $\mathrm{CH}_{2} \mathrm{Cl}_{2}$ was added the amine (1 equiv.) at room temperature. The reaction mixture was stirred under $\mathrm{N}_{2}$ atmosphere for $20 \mathrm{~h}$ followed by solvent removal in vacuo. The product was purified either by silica gel column chromatography (4-15\% $\left.\mathrm{MeOH}: \mathrm{CH}_{2} \mathrm{Cl}_{2}\right)$ or by washing the solid with $\mathrm{EtOH}$ or $1 \% \mathrm{HCl}$.

\subsubsection{4-((6-methoxyquinolin-8-yl)amino)pentyl)amino)-4-oxobutanoic acid (5)}

Primaquine bisphosphate (700 mg, $1.54 \mathrm{mmol}$ ) was dissolved in $\mathrm{CH}_{2} \mathrm{Cl}_{2}(30 \mathrm{~mL})$ and washed with $1 \% \mathrm{~K}_{2} \mathrm{CO}_{3}$ $(30 \mathrm{~mL})$. The organic layer was separated, dried $\left(\mathrm{MgSO}_{4}\right)$ and removed in vacuo to afford the free-based product which was used without purification. Following general procedure A, succinic anhydride was added to the free-based primaquine $(320 \mathrm{mg}, 1.24 \mathrm{mmol})$ and was stirred under nitrogen at room temperature for $24 \mathrm{~h}$, followed by removal of the solvent in vacuo to afford 4-((6-methoxyquinolin-8-yl)amino)pentyl)amino)-4oxobutanoic acid (5) as a yellow solid (420 mg, $96 \%$ yield) which was used without purification. $\mathrm{R}_{f}(2 \%$ $\mathrm{MeOH} / \mathrm{CH}_{2} \mathrm{Cl}_{2}$ ) 0.32; m.p. 141-143 ${ }^{\circ} \mathrm{C}$ (Lit. 142-145 ${ }^{\circ} \mathrm{C}^{29}$ ); IR (ATR) v $v_{\max } 3455,3268,2928,1710,1671,1646$, $1615,1584,1563,1524,1452,1386,1227,826,786 \mathrm{~cm}^{-1} ;{ }^{1} \mathrm{H}$ NMR $\left(\mathrm{CD}_{3} \mathrm{OD}, 500 \mathrm{MHz}\right) \delta 8.48(1 \mathrm{H}, \mathrm{dd}, J=4.3$, $1.9 \mathrm{~Hz}, \mathrm{H}-2), 8.01(1 \mathrm{H}, \mathrm{dd}, J=8.4,1.8 \mathrm{~Hz}, \mathrm{H}-4), 7.35$ (1H, dd, $J=8.4,4.3 \mathrm{~Hz}, \mathrm{H}-3), 6.44(1 \mathrm{H}, \mathrm{d}, J=2.5 \mathrm{~Hz}, \mathrm{H}-$ 5), $6.31(1 \mathrm{H}, \mathrm{d}, J=2.5 \mathrm{~Hz}, \mathrm{H}-7), 3.86$ (3H, s, OMe), 3.67-3.61 (1H, m, H-10), 3.23-3.17 (2H, m, H $\left.{ }_{2}-13\right), 2.56$ $\left(2 \mathrm{H}, \mathrm{t}, J=7.2 \mathrm{~Hz}, \mathrm{H}_{2}-16\right.$ or $\left.\mathrm{H}_{2}-17\right), 2.43\left(2 \mathrm{H}, \mathrm{t}, J=7.2 \mathrm{~Hz}, \mathrm{H}_{2}-16\right.$ or $\left.\mathrm{H}_{2}-17\right), 1.73-1.59\left(4 \mathrm{H}, \mathrm{m}, \mathrm{H}_{2}-11, \mathrm{H}_{2}-12\right)$, 
$1.28(3 \mathrm{H}, \mathrm{d}, J=6.7 \mathrm{~Hz}, 10-\mathrm{Me}) ;{ }^{13} \mathrm{C}$ NMR $\left(\mathrm{CD}_{3} \mathrm{OD}, 125 \mathrm{MHz}\right) \delta 176.3(\mathrm{C}-18), 174.5$ (C-15), $161.0(\mathrm{C}-6)$, 146.2 (C-8), 145.3 (C-2), 136.3 (C-4), 131.6 (C-4a), 123.0 (C-3), 98.4 (C-7), 93.1(C-5), 55.6 (OMe), 48.9 (C10), 40.3(C-13), 34.9 (C-11), 31.7 (C-16 or C-17), 30.5 (C-16 or C-17), 27.1 (C-12), 20.7 (10-Me); HRESIMS $[\mathrm{M}+\mathrm{H}]^{+} \mathrm{m} / z 360.1926$ (calcd for $\mathrm{C}_{19} \mathrm{H}_{26} \mathrm{~N}_{3} \mathrm{O}_{4}, 360.1918$ ).

\subsubsection{General procedure B: diamide bond formation.}

To a solution of SPQ or the relevant acid (2.2 equiv.) and either CDI (2.4 equiv.), HBTU (2.2 equiv.), or EDC.HCl/HOBt (2.2 equiv.) with DIPEA (7 equiv.) stirred in dry DMF ( $3 \mathrm{~mL})$ at $0{ }^{\circ} \mathrm{C}$ for 15 min under $\mathrm{N}_{2}$ was added the appropriate Boc-protected polyamine (1 equiv.). The mixture was allowed to come to room temperature and stirred for a further $24 \mathrm{~h}$ under $\mathrm{N}_{2}$. The reaction mixture was poured into $\mathrm{CH}_{2} \mathrm{Cl}_{2}(20 \mathrm{~mL})$ and washed with saturated $\mathrm{NaHCO}_{3}(2 \times 30 \mathrm{~mL})$ followed by $\mathrm{H}_{2} \mathrm{O}(2 \times 30 \mathrm{~mL})$, then dried in vacuo and purified by silica gel flash column chromatography $\left(6-8 \% \mathrm{MeOH} / \mathrm{CH}_{2} \mathrm{Cl}_{2}\right)$ to afford the desired products.

5.2.3.1. Di-tert-butyl butane-1,4-diylbis((3-(4-((4-((6-methoxyquinolin-8-yl)amino)pentyl)amino)-4oxobutanamido)propyl)(carbamate) (6)

Following general procedure B, 4-((6-methoxyquinolin-8-yl)amino)pentyl)amino)-4-oxobutanoic acid (97 mg, $0.27 \mathrm{mmol})$ and di-tert-butyl butane 1,4-diylbis((3-aminopropyl)carbamate) $(50 \mathrm{mg}, 0.12 \mathrm{mmol})$ with CDI afforded di-tert-butyl butane-1,4-diylbis((3-(4-((4-((6-methoxyquinolin-8-yl)amino)pentyl)amino)-4oxobutanamido)propyl)carbamate) $(6),(114 \mathrm{mg}, 84 \%)$ as a green gum. $\mathrm{R}_{f}\left(5 \% \mathrm{MeOH} / \mathrm{CH}_{2} \mathrm{Cl}_{2}\right) 0.33$; IR (ATR) $v_{\max } 3299,2966,2931,1642,1616,1518,1454,1419,1387,1219,1155,822,790,728 \mathrm{~cm}^{-1} ;{ }^{1} \mathrm{H} \mathrm{NMR}\left(\mathrm{CDCl}_{3}\right.$, $500 \mathrm{MHz}) \delta 8.52(2 \mathrm{H}, \mathrm{dd}, J=4.3,1.3 \mathrm{~Hz}, \mathrm{H}-2), 7.91(2 \mathrm{H}, \mathrm{dd}, J=8.4,1.7 \mathrm{~Hz}, \mathrm{H}-4), 7.29,(2 \mathrm{H}, \mathrm{dd}, J=8.4,4.3$ Hz, H-3), 6.95 (2H, br s, NH-19), 6.54 (2H, br s, NH-14), 6.33 (2H, d, $J=2.4 \mathrm{~Hz}, \mathrm{H}-5), 6.26$ (2H, d, $J=2.4 \mathrm{~Hz}$, H-7), 5.99 (2H, br s, NH-9), 3.88 (6H, s, OMe), 3.60 (2H, br m, H-10), 3.28-3.07 (16H, m, $\mathrm{H}_{2}-13, \mathrm{H}_{2}-20, \mathrm{H}_{2}-$ 22, $\left.\mathrm{H}_{2}-24\right), 2.52-2.44$ ( $\left.8 \mathrm{H}, \mathrm{m}, \mathrm{H}_{2}-16, \mathrm{H}_{2}-17\right), 1.73-1.56\left(12 \mathrm{H}, \mathrm{m}, \mathrm{H}_{2}-11, \mathrm{H}_{2}-12, \mathrm{H}_{2}-21\right), 1.46-1.41\left(22 \mathrm{H}, \mathrm{m}, \mathrm{H}_{2}-\right.$ 25 , including 1.43, 9H, s, $t$-Bu), $1.27(6 \mathrm{H}, \mathrm{d}, J=6.6 \mathrm{~Hz}, 10-\mathrm{Me}) ;{ }^{13} \mathrm{C} \mathrm{NMR}\left(\mathrm{CDCl}_{3}, 125 \mathrm{MHz}\right) \delta 176.4(\mathrm{C}-15$, C-18), 159.5, (C-6), 156.3 (C-26), 145.0 (C-8), 144.4 (C-2), 135.4 (C-8a), 134.9 (C-4), 130.0 (C-4a), 122.0 (C3), 96.9 (C-7), 91.8 (C-5), 79.8 (C-27), 55.3 (OMe), 47.9 (C-10), 47.0 (C-24), 43.8 (C-22), 39.6 (C-13), 36.2 (C20), 34.1 (C-11), 32.0 (C-16, C-17), 28.5 ( $t$-Bu), 28.0 (C-21), 26.4 (C-12), 26.1 (C-25), 20.7 (C-10Me); HRESIMS $[\mathrm{M}+\mathrm{H}]^{+} m / z 1085.6800$ (calcd for $\mathrm{C}_{58} \mathrm{H}_{89} \mathrm{~N}_{10} \mathrm{O}_{10}, 1085.6758$ ).

5.2.3.2. Di-tert-butyl hexane-1,6-diylbis((3-(4-((4-((6-methoxyquinolin-8-yl)amino)pentyl)amino)-4oxobutanamido)propyl)carbamate) (7)

Following general procedure B, 4-((6-methoxyquinolin-8-yl)amino)pentyl)amino)-4-oxobutanoic acid (127 mg, $0.36 \mathrm{mmol})$ and di-tert-butyl hexane-1,6-diylbis((3-aminopropyl)carbamate) $(70 \mathrm{mg}, 0.16 \mathrm{mmol})$ with HBTU and DIPEA afforded di-tert-butyl hexane-1,6-diylbis((3-(4-((4-((6-methoxyquinolin-8-yl)amino)pentyl)amino)4-oxobutanamido)propyl)carbamate) (7), (147 $\mathrm{mg}, 81 \%)$ as a yellow gum. $\mathrm{R}_{f}\left(5 \% \mathrm{MeOH} / \mathrm{CH}_{2} \mathrm{Cl}_{2}\right)$ 0.27; IR( 
ATR) $v_{\max } 3305,2971,2932,1739,1650,1617,1510,1454,1421,1388,1366,1218,1161,823,792 \mathrm{~cm}^{-1} ;{ }^{1} \mathrm{H}$ NMR $\left(\mathrm{CDCl}_{3}, 500 \mathrm{MHz}\right) \delta 8.52(2 \mathrm{H}, \mathrm{dd}, J=4.4,1.5 \mathrm{~Hz}, \mathrm{H}-2), 7.91(2 \mathrm{H}, \mathrm{dd}, J=8.4,1.6 \mathrm{~Hz}, \mathrm{H}-4), 7.29,(2 \mathrm{H}$, dd, $J=8.4,4.4 \mathrm{~Hz}, \mathrm{H}-3), 6.98$ (2H, br s, NH-19), 6.49 (2H, br s, NH-14), 6.33 (2H, d, $J=2.4 \mathrm{~Hz}, \mathrm{H}-5), 6.26$ (2H, d, $J=2.4 \mathrm{~Hz}, \mathrm{H}-7), 5.98$ (2H, br s, NH-9), 3.88 (6H, s, OMe), 3.63-3.57 (2H, m, H-10), 3.30-3.01 (16H, $\left.\mathrm{m}, \mathrm{H}_{2}-13, \mathrm{H}_{2}-20, \mathrm{H}_{2}-22, \mathrm{H}_{2}-24\right), 2.53-2.44$ (8H, m, H $\left.\mathrm{H}_{2}-16, \mathrm{H}_{2}-17\right), 1.73-1.57$ (12H, m, $\mathrm{H}_{2}-11, \mathrm{H}_{2}-12, \mathrm{H}_{2}-21$ ), 1.51-1.40 (22H, m, $\mathrm{H}_{2}-25$, including 1.44, 9H, s, $\left.t-\mathrm{Bu}\right), 1.28(6 \mathrm{H}, \mathrm{d}, J=6.6 \mathrm{~Hz}, 10-\mathrm{Me}), 1.26-1.23\left(4 \mathrm{H}, \mathrm{m}, \mathrm{H}_{2^{-}}\right.$ 26); ${ }^{13} \mathrm{C}$ NMR $\left(\mathrm{CDCl}_{3}, 125 \mathrm{MHz}\right) \delta 172.4$ (C-15, C-18), 159.5, (C-6), 156.5 (C-27), 145.0 (C-8), 144.4 (C-2), 135.4 (C-8a), 134.9 (C-4), 130.0 (C-4a), 122.0 (C-3), 96.9 (C-7), 91.8 (C-5), 79.7 (C-28), 55.3 (OMe), 47.9 (C10), 47.1 (C-24), 43.6 (C-22), 39.6 (C-13), 36.1 (C-20), 34.1 (C-11), 32.1 (C-16, C-17), 28.5 ( $t$-Bu), 27.9 (C21), 26.7 (C-26), 26.4 (C-25, C-12), 20.6 (C-10Me); HRESIMS $[\mathrm{M}+\mathrm{H}]^{+} \mathrm{m} / \mathrm{z} 1113.7077$ (calcd for $\left.\mathrm{C}_{60} \mathrm{H}_{93} \mathrm{~N}_{10} \mathrm{O}_{10}, 1113.7071\right)$.

5.2.3.3. Di-tert-butyl heptane-1,7-diylbis((3-(4-((4-((6-methoxyquinolin-8-yl)amino)pentyl)amino)-4oxobutanamido)propyl)carbamate) (8)

Following general procedure B, 4-((6-methoxyquinolin-8-yl)amino)pentyl)amino)-4-oxobutanoic acid (100 mg, $0.28 \mathrm{mmol})$ and di-tert-butyl heptane-1,7-diylbis((3-aminopropyl)carbamate) $(63 \mathrm{mg}, 0.14 \mathrm{mmol})$ with CDI afforded di-tert-butyl heptane-1,7-diylbis((3-(4-((4-((6-methoxyquinolin-8-yl)amino)pentyl)amino)-4oxobutanamido)propyl)carbamate) (8), $(122 \mathrm{mg}, 76 \%)$ as a green gum. $\mathrm{R}_{f}\left(5 \% \mathrm{MeOH} / \mathrm{CH}_{2} \mathrm{Cl}_{2}\right) 0.30$; IR (ATR) $v_{\max } 3302,2929,1642,1618,1518,1454,1419,1387,1365,1219,1157,821,791,728 \mathrm{~cm}^{-1} ;{ }^{1} \mathrm{H} \mathrm{NMR}\left(\mathrm{CDCl}_{3}\right.$, $400 \mathrm{MHz}) \delta 8.52(2 \mathrm{H}, \mathrm{dd}, J=4.4,1.5 \mathrm{~Hz}, \mathrm{H}-2), 7.91(2 \mathrm{H}, \mathrm{dd}, J=8.3,1.5 \mathrm{~Hz}, \mathrm{H}-4), 7.29$, (2H, dd, $J=8.4,4.4$ Hz, H-3), 6.97 (2H, br s, NH-19), 6.49 (2H, br s, NH-14), 6.33 (2H, d, $J=2.5 \mathrm{~Hz}, \mathrm{H}-5$ ), 6.27 (2H, d, J = 2.5 Hz, H-7), 5.99 (2H, br d, NH-9), 3.88 (6H, s, OMe), 3.64-3.57 (2H, m, H-10), 3.30-3.02 (16H, m, H $\mathrm{H}_{2}-13, \mathrm{H}_{2}-20$, $\left.\mathrm{H}_{2}-22, \mathrm{H}_{2}-24\right)$, 2.53-2.44 (8H, m, $\left.\mathrm{H}_{2}-16, \mathrm{H}_{2}-17\right), 1.73-1.56\left(12 \mathrm{H}, \mathrm{m}, \mathrm{H}_{2}-11, \mathrm{H}_{2}-12, \mathrm{H}_{2}-21\right), 1.51-1.41(22 \mathrm{H}, \mathrm{m}$, $\mathrm{H}_{2}-25$, including 1.44, 9H, s, $t$-Bu), 1.31-1.19 (11H, m, $\mathrm{H}_{2}-26, \mathrm{H}-27$, including $\left.1.28,3 \mathrm{H}, \mathrm{d}, J=6.5 \mathrm{~Hz}, 10-\mathrm{Me}\right)$; ${ }^{13} \mathrm{C} \mathrm{NMR}\left(\mathrm{CDCl}_{3}, 100 \mathrm{MHz}\right) \delta 172.4$ (C-15, C-18), 159.5, (C-6), 156.5 (C-28), 145.0 (C-8), 144.4 (C-2), 135.4 (C-8a), 134.9 (C-4), 130.0 (C-4a), 122.0 (C-3), 96.9 (C-7), 91.8 (C-5), 79.7 (C-29), 55.3 (OMe), 47.9 (C-10), 47.1 (C-24), 43.6 (C-22), 39.6 (C-13), 36.0 (C-20), 34.1 (C-11), 32.0 (C-16, C-17), 29.2 (C-27), 28.5 ( $t$-Bu), 27.9 (C-21), 26.9 (C-25, C-26), 26.4 (C-12), 20.6 (C-10Me); HRESIMS [M + H] ${ }^{+} \mathrm{m} / z 1127.7271$ (calcd for $\left.\mathrm{C}_{61} \mathrm{H}_{95} \mathrm{~N}_{10} \mathrm{O}_{10}, 1127.7227\right)$.

5.2.3.4. Di-tert-butyl octane-1,8-diylbis((3-(4-((4-((6-methoxyquinolin-8-yl)amino)pentyl)amino)-4oxobutanamido)propyl)carbamate (9)

Following general procedure B, 4-((6-methoxyquinolin-8-yl)amino)pentyl)amino)-4-oxobutanoic acid (148 mg, $0.42 \mathrm{mmol})$ and di-tert-butyl octane-1,8-diylbis((3-aminopropyl)carbamate) $(87 \mathrm{mg}, 0.19 \mathrm{mmol})$ with HBTU and DIPEA afforded di-tert-butyl octane-1,8-diylbis((3-(4-((4-((6-methoxyquinolin-8-yl)amino)pentyl)amino)4-oxobutanamido)propyl)carbamate) (9), $(170 \mathrm{mg}, 78 \%)$ as a yellow gum. $\mathrm{R}_{f}\left(5 \% \mathrm{MeOH} / \mathrm{CH}_{2} \mathrm{Cl}_{2}\right)$ 0.24; IR (ATR) $v_{\max } 3306,2929,2858,1643,1616,1521,1454,1420,1387,1365,1219,1158,822,792,730 \mathrm{~cm}^{-1} ;{ }^{1} \mathrm{H}$ NMR $\left(\mathrm{CDCl}_{3}, 500 \mathrm{MHz}\right) \delta 8.52(2 \mathrm{H}, \mathrm{dd}, J=4.3,1.5 \mathrm{~Hz}, \mathrm{H}-2), 7.91(2 \mathrm{H}, \mathrm{dd}, J=8.5,1.5 \mathrm{~Hz}, \mathrm{H}-4), 7.29,(2 \mathrm{H}$, 
dd, $J=8.5,4.3 \mathrm{~Hz}, \mathrm{H}-3), 6.97$ (2H, br s, NH-19), 6.48 (2H, br s, NH-14), 6.33 (2H, d, $J=2.5 \mathrm{~Hz}, \mathrm{H}-5$ ), 6.27 $(2 \mathrm{H}, \mathrm{d}, J=2.5 \mathrm{~Hz}, \mathrm{H}-7), 5.99$ (2H, br s, NH-9), 3.88 (6H, s, OMe), 3.60 (2H, br m, H-10), 3.30-3.04 (16H, m, $\left.\mathrm{H}_{2}-13, \mathrm{H}_{2}-20, \mathrm{H}_{2}-22, \mathrm{H}_{2}-24\right), 2.52-2.43$ (8H, m, $\mathrm{H}_{2}-16, \mathrm{H}_{2}-17$ ), 1.72-1.56 126H, m, $\mathrm{H}_{2}-11, \mathrm{H}_{2}-12, \mathrm{H}_{2}-21$ ), $1.51-$ $1.42\left(22 \mathrm{H}, \mathrm{m}, \mathrm{H}_{2}-25\right.$, including $\left.1.44,9 \mathrm{H}, \mathrm{s}, t-\mathrm{Bu}\right), 1.30-1.20\left(14 \mathrm{H}, \mathrm{m}, \mathrm{H}_{2}-26, \mathrm{H}_{2}-27\right.$, including $1.28,3 \mathrm{H}, \mathrm{d}, J=$ $6.6 \mathrm{~Hz}, 10-\mathrm{Me}) ;{ }^{13} \mathrm{C}$ NMR (CDCl, $\left.125 \mathrm{MHz}\right) \delta 172.4$ (C-15, C-18), 159.5, (C-6), 156.5 (C-28), 145.0 (C-8), 144.4 (C-2), 135.4 (C-8a), 134.9 (C-4), 130.0 (C-4a), 122.0 (C-3), 96.9 (C-7), 91.8 (C-5), 80.0 (C-29), 55.3 (OMe), 47.9 (C-10), 47.1 (C-24), 43.5 (C-22), 39.6 (C-13), 36.0 (C-20), 34.1 (C-11), 32.0 (C-16, C-17), 29.4 (C-27), 28.5 ( $t$-Bu), 27.9 (C-21), 26.9 (C-25, C-26), 26.4 (C-12), 20.6 (C-10Me); HRESIMS [M + Na] ${ }^{+} \mathrm{m} / \mathrm{z}$ 1163.7193 (calcd for $\mathrm{C}_{62} \mathrm{H}_{96} \mathrm{~N}_{10} \mathrm{NaO}_{10}, 1163.7203$ ).

5.2.3.5. Di-tert-butyl decane-1,10-diylbis((3-(4-((4-((6-methoxyquinolin-8-yl)amino)pentyl)amino)-4oxobutanamido)propyl)carbamate) (10)

Following general procedure B, 4-((6-methoxyquinolin-8-yl)amino)pentyl)amino)-4-oxobutanoic acid (114 mg, $0.32 \mathrm{mmol})$ and di-tert-butyl decane-1,10-diylbis((3-aminopropyl)carbamate) $(71 \mathrm{mg}, 0.15 \mathrm{mmol})$ with HBTU and DIPEA afforded di-tert-butyl decane-1,10-diylbis((3-(4-((4-((6-methoxyquinolin-8yl)amino)pentyl)amino)-4-oxobutanamido)propyl)carbamate) (10), (120 $\mathrm{mg}, 70 \%)$ as a yellow gum. $\mathrm{R}_{f}(5 \%$ $\mathrm{MeOH} / \mathrm{CH}_{2} \mathrm{Cl}_{2}$ ) 0.28; IR (ATR) $v_{\max } 3306,2928,2856,1645,1616,1524,1455,1420,1388,1365,1219,1159$, $822,792 \mathrm{~cm}^{-1} ;{ }^{1} \mathrm{H} \mathrm{NMR}\left(\mathrm{CDCl}_{3}, 400 \mathrm{MHz}\right) \delta 8.52(2 \mathrm{H}, \mathrm{dd}, J=4.4,1.5 \mathrm{~Hz}, \mathrm{H}-2), 7.91(2 \mathrm{H}, \mathrm{dd}, J=8.4,1.5 \mathrm{~Hz}$, H-4), 7.29, (2H, dd, $J=8.4,4.4 \mathrm{~Hz}, \mathrm{H}-3$ ), 7.00 (2H, br s, NH-19), 6.54 (2H, br s, NH-14), 6.33 (2H, d, $J=2.4$ Hz, H-5), 6.27 (2H, d, J = 2.4 Hz, H-7), 6.00 (2H, br s, NH-9), 3.88 (6H, s, OMe), 3.63-3.57 (2H, m, H-10), 3.29-3.04 (16H, m, H $\left.\mathrm{H}_{2}-13, \mathrm{H}_{2}-20, \mathrm{H}_{2}-22, \mathrm{H}_{2}-24\right)$, 2.54-2.44 (8H, m, $\left.\mathrm{H}_{2}-16, \mathrm{H}_{2}-17\right), 1.74-1.57$ (12H, m, $\mathrm{H}_{2}-11$, $\left.\mathrm{H}_{2}-12, \mathrm{H}_{2}-21\right), 1.51-1.41\left(22 \mathrm{H}, \mathrm{m}, \mathrm{H}_{2}-25\right.$, including $\left.1.44,9 \mathrm{H}, \mathrm{s}, t-\mathrm{Bu}\right), 1.32-1.19\left(18 \mathrm{H}, \mathrm{m}, \mathrm{H}_{2}-26, \mathrm{H}_{2}-27, \mathrm{H}_{2}-28\right.$ including 1.28, 3H, d, $J=6.5 \mathrm{~Hz}, 10-\mathrm{Me}) ;{ }^{13} \mathrm{C} \mathrm{NMR}\left(\mathrm{CDCl}_{3}, 100 \mathrm{MHz}\right) \delta 172.4(\mathrm{C}-15, \mathrm{C}-18), 159.5,(\mathrm{C}-6)$, 156.6 (C-29), 145.0 (C-8), 144.4 (C-2), 135.4 (C-8a), 134.9 (C-4), 130.0 (C-4a), 122.0 (C-3), 96.9 (C-7), 91.8 (C-5), 79.6 (C-30), 55.3 (OMe), 47.9 (C-10), 47.1 (C-24), 43.5 (C-22), 39.6 (C-13), 36.0 (C-20), 34.1 (C-11), 32.0 (C-16, C-17), 29.6 (C-28), 29.4 (C-27), 28.5 ( $t$-Bu), 27.8 (C-21), 26.9 (C-25, C-26), 26.3 (C-12), 20.6 (C10Me); HRESIMS $[\mathrm{M}+\mathrm{Na}]^{+} m / z 1191.7559$ (calcd for $\mathrm{C}_{64} \mathrm{H}_{100} \mathrm{~N}_{10} \mathrm{NaO}_{10}, 1191.7516$ ).

\subsubsection{General procedure C: Boc deprotection.}

A solution of the tert-butyl-carbamate derivative was stirred either in $\mathrm{CH}_{2} \mathrm{Cl}_{2}(2 \mathrm{~mL})$ with TFA $(0.2 \mathrm{~mL})$ at room temperature under $\mathrm{N}_{2}$ for $2 \mathrm{~h}$, or alternatively in dioxane $(2 \mathrm{~mL})$ with $4 \mathrm{M} \mathrm{HCl}$ in dioxane $(2 \mathrm{~mL})$ for $4 \mathrm{~h}$ followed by solvent removal in vacuo. The crude product was purified using $\mathrm{C}_{8}$ reversed-phase flash column chromatography eluting with $50 \%-75 \% \mathrm{MeOH} / \mathrm{H}_{2} \mathrm{O}(0.05 \%$ TFA or $\mathrm{HCl})$ to afford the corresponding polyamine as the acid salt. 
5.2.4.1. $\quad N^{l}-N^{I^{\prime}}-\left((\right.$ Butane-1,4-diylbis(azanediyl))bis(propane-3,1-diyl) $)$ bis $\left(N^{4}-(4-((6-m e t h o x y q u i n o l i n e-8-\right.$ yl)amino)pentyl)succinamide)bis(2,2,2-trifluoracetate) (11)

Following general procedure $\mathrm{C}$, di-tert-butyl butane-1,4-diylbis((3-(4-((4-((6-methoxyquinolin-8yl)amino)pentyl)amino)-4-oxobutanamido)propyl)carbamate) $(12 \mathrm{mg}, 0.01 \mathrm{mmol})$ was treated with TFA in $\mathrm{CH}_{2} \mathrm{Cl}_{2}$ to afford the title compound $(9 \mathrm{mg}, 93 \%)$ as an orange oil. $\mathrm{R}_{f}\left(75 \% \mathrm{MeOH} / \mathrm{H}_{2} \mathrm{O} / 0.05 \% \mathrm{TFA}, \mathrm{C}_{18}\right)$ 0.52; IR (ATR) $v_{\max } 3322,2962,1594,1453,1385,1294,1201,1172,1015,760 \mathrm{~cm}^{-1} ;{ }^{1} \mathrm{H}$ NMR $\left(\mathrm{CD}_{3} \mathrm{OD}, 500 \mathrm{MHz}\right.$, $*=$ reduced in intensity due to deuterium exchange $\left.{ }^{30}\right) \delta 8.62(2 \mathrm{H}, \mathrm{d}, J=4.5 \mathrm{~Hz}, \mathrm{H}-2), 8.35(2 \mathrm{H}, \mathrm{d}, J=8.7 \mathrm{~Hz}$, H-4), 7.57, (2H, dd, $J=87,4.5 \mathrm{~Hz}, \mathrm{H}-3), 6.70\left(0.04 \mathrm{H}^{*}\right.$, br s, H-5), 6.56 (1H*, br s, H-7), 3.91 (6H, s, OMe), 3.71-3.68 (2H, m, H-10), 3.28 (4H, t, $\left.J=6.3 \mathrm{~Hz}, \mathrm{H}_{2}-20\right), 3.19\left(4 \mathrm{H}, \mathrm{t}, J=6.3 \mathrm{~Hz}, \mathrm{H}_{2}-13\right), 3.01-2.98\left(8 \mathrm{H}, \mathrm{m}, \mathrm{H}_{2}-\right.$ $\left.22, \mathrm{H}_{2}-24\right), 2.52-2.44\left(8 \mathrm{H}, \mathrm{m}, \mathrm{H}_{2}-16, \mathrm{H}_{2}-17\right), 1.87-1.81\left(4 \mathrm{H}, \mathrm{m}, \mathrm{H}_{2}-21\right), 1.78-1.61\left(12 \mathrm{H}, \mathrm{m}, \mathrm{H}_{2}-11, \mathrm{H}_{2}-12, \mathrm{H}_{2}-\right.$ 25), $1.30(6 \mathrm{H}, \mathrm{d}, J=6.4 \mathrm{~Hz}, 10-\mathrm{Me}) ;{ }^{13} \mathrm{C} \mathrm{NMR}\left(\mathrm{CD}_{3} \mathrm{OD}, 125 \mathrm{MHz}\right.$, * = reduced in intensity due to deuterium exchange $^{30}$ ) $\delta 176.2$ (C-18), 174.5 (C-15), 161.5 (C-6), 143.8 (C-2), 143.4 (C-8), 140.0 (C-4), 133.1 (C-8a), 132.4 (C-4a), 123.1 (C-3), 102.4 (C-7), 95.0* (C-5), 56.0 (OMe), 50.1 (C-10), 48.1 (C-24), 46.1 (C-22), 40.3 (C-13), 36.6 (C-20), 34.5 (C-11), 31.9 (C-16 or C-17), 31.8 (C-16 or C-17), 27.7 (C-21), 27.1 (C-12), 24.3 (C25), 20.2 (C-10Me); HRESIMS $[\mathrm{M}+2 \mathrm{H}]^{2+} \mathrm{m} / z 443.2902$ (calcd for $\mathrm{C}_{48} \mathrm{H}_{74} \mathrm{~N}_{10} \mathrm{O}_{6}, 443.2891$ ).

5.2.4.2. $\quad N^{l}-N^{l^{\prime}}-\left(\left(\right.\right.$ Hexane-1,6-diylbis(azanediyl))bis(propane-3,1-diyl))bis $\left(N^{4}-(4-((6-m e t h o x y q u i n o l i n e-8-\right.$ yl)amino)pentyl)succinamide)bis(2,2,2-trifluoroacetate) (12)

Following general procedure C, di-tert-butyl hexane-1,6-diylbis((3-(4-((4-((6-methoxyquinolin-8yl)amino)pentyl)amino)-4-oxobutanamido)propyl)carbamate) (140 mg, $0.13 \mathrm{mmol})$ was treated with TFA in $\mathrm{CH}_{2} \mathrm{Cl}_{2}$ to afford the title compound (138 mg, $97 \%$ ) as a yellow oil. $\mathrm{R}_{f}\left(75 \% \mathrm{MeOH} / \mathrm{H}_{2} \mathrm{O} / 0.05 \% \mathrm{TFA}, \mathrm{C}_{18}\right) 0.28$; IR (ATR) $v_{\max } 3383,2940$ 2866, 1598, 1428, 1389, 1151, 1038, 812, 796, 782, $701 \mathrm{~cm}^{-1}$; ${ }^{1} \mathrm{H} \mathrm{NMR}\left(\mathrm{CD}_{3} \mathrm{OD}, 500\right.$ $\mathrm{MHz}, *=$ reduced in intensity due to deuterium exchange $\left.{ }^{30}\right) \delta 8.52(2 \mathrm{H}, \mathrm{dd}, J=4.4,1.5 \mathrm{~Hz}, \mathrm{H}-2), 8.11(2 \mathrm{H}, \mathrm{dd}$, $J=8.4,1.5 \mathrm{~Hz}, \mathrm{H}-4), 7.41,(2 \mathrm{H}, \mathrm{dd}, J=8.4,4.4 \mathrm{~Hz}, \mathrm{H}-3), 6.51$ (0.10H*, br d, H-5), 6.37 (2H, s, H-7), 3.87 (6H, s, OMe), 3.67-3.61 (2H, m, H-10), 3.27 (4H, t, $\left.J=6.3 \mathrm{~Hz}, \mathrm{H}_{2}-20\right), 3.18$ (4H, t, $\left.J=6.2 \mathrm{~Hz}, \mathrm{H}_{2}-13\right), 2.96$ (4H, t, $J$ $\left.=6.4 \mathrm{~Hz}, \mathrm{H}_{2}-22\right), 2.89\left(4 \mathrm{H}, \mathrm{t}, J=7.6 \mathrm{~Hz}, \mathrm{H}_{2}-24\right), 2.51-2.43\left(8 \mathrm{H}, \mathrm{m}, \mathrm{H}_{2}-16, \mathrm{H}_{2}-17\right), 1.85-1.80\left(4 \mathrm{H}, \mathrm{m}, \mathrm{H}_{2}-21\right)$, 1.72-1.57 (12H, m, $\left.\mathrm{H}_{2}-11, \mathrm{H}_{2}-12, \mathrm{H}_{2}-25\right), 1.37-1.34\left(4 \mathrm{H}, \mathrm{m}, \mathrm{H}_{2}-26\right), 1.27(6 \mathrm{H}, \mathrm{d}, J=6.2 \mathrm{~Hz}, 10-\mathrm{Me}) ;{ }^{13} \mathrm{C} \mathrm{NMR}$ $\left(\mathrm{CD}_{3} \mathrm{OD}, 125 \mathrm{MHz}, *\right.$ reduced in intensity due to deuterium exchange $\left.{ }^{30}\right) \delta 176.1(\mathrm{C}-18), 174.4(\mathrm{C}-15), 161.1$ (C-6), 145.2 (C-8), 144.8 (C-2), 137.5 (C-4), 135.2 (C-8a), 131.8 (C-4a), 123.0 (C-3), 99.6 (C-7), 93.7* (C-5), 56.8 (OMe), 49.3 (C-10), 48.8 (C-24), 46.0 (C-22), 40.3 (C-13), 36.6 (C-20), 34.8 (C-11), 31.9 (C-16 or C-17), 31.7 (C-16 or C-17), 27.7 (C-21), 27.1, 27.0, 26.9 (C-12, C-25, C-26), 20.6 (C-10Me); HRESIMS [M + H] $]^{+} \mathrm{m} / \mathrm{z}$ 913.6029 (calcd for $\mathrm{C}_{50} \mathrm{H}_{77} \mathrm{~N}_{10} \mathrm{O}_{6}, 913.6022$ ).

5.2.4.3. $\quad N^{l}-N^{I^{\prime}}-\left(\left(\right.\right.$ Heptane-1,7-diylbis(azanediyl))bis(propane-3,1-diyl))bis $\left(N^{4}-(4-((6-m e t h o x y q u i n o l i n e-8-\right.$ yl)amino)pentyl)succinamide)dihydrochoride (13)

Following general procedure C, di-tert-butyl heptane-1,7-diylbis((3-(4-((4-((6-methoxyquinolin-8yl)amino)pentyl)amino)-4-oxobutanamido)propyl)carbamate) (100 $\mathrm{mg}, 0.09 \mathrm{mmol})$ was treated in dioxane with 
$4 \mathrm{M} \mathrm{HCl}$ in dioxane to afford the title compound $(77 \mathrm{mg}, 87 \%)$ as a yellow oil. $\mathrm{R}_{f}\left(75 \% \mathrm{MeOH} / \mathrm{H}_{2} \mathrm{O} / 0.05 \%\right.$ TFA, $C_{18}$ ) 0.42; IR (ATR) $v_{\max } 3317,2944,1629,1595,1473,1454,1425,1387,1202,1173,1021,833,795$, $710 \mathrm{~cm}^{-1} ;{ }^{1} \mathrm{H} \mathrm{NMR}\left(\mathrm{CD}_{3} \mathrm{OD}, 400 \mathrm{MHz}, *\right.$ reduced in intensity due to deuterium exchange $\left.{ }^{30}\right) \delta 8.85(2 \mathrm{H}, \mathrm{dd}, J$ $=8.3,1.2 \mathrm{~Hz}, \mathrm{H}-4), 8.79(2 \mathrm{H}, \mathrm{dd}, J=5.2,1.2 \mathrm{~Hz}, \mathrm{H}-2), 7.91,(2 \mathrm{H}, \mathrm{dd}, J=8.3,5.2 \mathrm{~Hz}, \mathrm{H}-3), 7.03\left(0.14 \mathrm{H}^{*}\right.$, br d, H-5), 6.88 (1.3H*, br s, H-7), 3.98 (6H, s, OMe), 3.82-3.78 (2H, m, H-10), 3.37 (4H, t, $J=6.4$ Hz, $\left.\mathrm{H}_{2}-20\right), 3.33$ (4H, $\mathrm{H}_{2}-13$, obsc. $\left.\mathrm{MeOH}\right), 3.06\left(4 \mathrm{H}, \mathrm{t}, J=7.5 \mathrm{~Hz}, \mathrm{H}_{2}-22\right), 3.00\left(4 \mathrm{H}, \mathrm{t}, J=7.7 \mathrm{~Hz}, \mathrm{H}_{2}-24\right), 2.76-2.68(8 \mathrm{H}, \mathrm{m}$, $\left.\mathrm{H}_{2}-16, \mathrm{H}_{2}-17\right), 2.00-1.68$ (16H, m, $\left.\mathrm{H}_{2}-11, \mathrm{H}_{2}-12, \mathrm{H}_{2}-21, \mathrm{H}_{2}-25\right), 1.45-1.39$ (6H, m, $\left.\mathrm{H}_{2}-26, \mathrm{H}_{2}-27\right), 1.35$ (6H, d, $J=6.4 \mathrm{~Hz}, 10-\mathrm{Me}) ;{ }^{13} \mathrm{C}$ NMR $\left(\mathrm{CD}_{3} \mathrm{OD}, 100 \mathrm{MHz}, *\right.$ = reduced in intensity due to deuterium exchange $\left.{ }^{30}\right) \delta$ 176.7 (C-18), 176.2 (C-15), 162.6 (C-6), 145.7 (C-4), 140.8 (C-2), 140.1 (C-8), 133.7 (C-4a), 127.5 (C-8a), 123.1 (C-3), 106.8 (C-7), 97.1* (C-5), 56.6 (OMe), 51.3 (C-10), 49.1 (C-24), 46.4 (C-22), 41.3 (C-13), 37.8 (C20), 34.0 (C-11), 31.3 (C-16 or C-17), 31.0 (C-16 or C-17), 29.4 (C-27), 27.2, 27.1, 27.1 (C-21, C-25, C-26), 26.5 (C-12), 19.7 (C-10Me); HRESIMS $[\mathrm{M}+2 \mathrm{H}]^{2+} \mathrm{m} / \mathrm{z} 464.3127$ (calcd for $\mathrm{C}_{51} \mathrm{H}_{80} \mathrm{~N}_{10} \mathrm{O}_{6}, 464.3126$ ).

5.2.4.4. $\quad N^{l}-N^{I^{\prime}}-\left(\left(\right.\right.$ Octane-1,8-diylbis(azanediyl))bis(propane-3,1-diyl))bis $\left(N^{4}-(4-((6-m e t h o x y q u i n o l i n e-8-\right.$ yl)amino)pentyl)succinamide)bis(2,2,2-trifluoroacetate) (14)

Following general procedure $\mathrm{C}$, di-tert-butyl octane-1,8-diylbis((3-(4-((4-((6-methoxyquinolin-8yl)amino)pentyl)amino)-4-oxobutanamido)propyl)carbamate) $(160 \mathrm{mg}, 0.14 \mathrm{mmol})$ was treated with TFA in $\mathrm{CH}_{2} \mathrm{Cl}_{2}$ to afford the title compound $(83 \mathrm{mg}, 97 \%)$ as a yellow oil. $\mathrm{R}_{f}\left(75 \% \mathrm{MeOH} / \mathrm{H}_{2} \mathrm{O} / 0.05 \% \mathrm{TFA}, \mathrm{C}_{18}\right)$ 0.44; IR (ATR) $v_{\max } 3302,2936,2862,1643,1597,1455,1426,1387,1172,1051,831,798,719 \mathrm{~cm}^{-1}$; ${ }^{1} \mathrm{H}$ NMR $\left(\mathrm{CD}_{3} \mathrm{OD}, 500 \mathrm{MHz}, *\right.$ reduced in intensity due to deuterium exchange $\left.{ }^{30}\right) \delta 8.52(2 \mathrm{H}, \mathrm{dd}, J=4.3,1.2 \mathrm{~Hz}, \mathrm{H}-2)$, $8.11(2 \mathrm{H}, \mathrm{dd}, J=8.4,1.8 \mathrm{~Hz}, \mathrm{H}-4), 7.41,(2 \mathrm{H}, \mathrm{dd}, J=8.4,4.3 \mathrm{~Hz}, \mathrm{H}-3), 6.51\left(0.08 \mathrm{H}^{*}\right.$, br d, H-5), 6.37 (1.7H*, br s, H-7), 3.87 (6H, s, OMe), 3.67-3.60 (2H, m, H-10), 3.27 (4H, t, $\left.J=6.1 \mathrm{~Hz}, \mathrm{H}_{2}-20\right), 3.18(4 \mathrm{H}, \mathrm{t}, J=6.9 \mathrm{~Hz}$, $\mathrm{H}_{2}-13$ ), 2.97 (4H, t, $\left.J=7.1 \mathrm{~Hz}, \mathrm{H}_{2}-22\right), 2.87$ (4H, t, $\left.J=7.8 \mathrm{~Hz}, \mathrm{H}_{2}-24\right), 2.50$ (4H, t, $J=6.7 \mathrm{~Hz}, \mathrm{H}_{2}-16$ or H$_{2}-17$ ), $2.45\left(4 \mathrm{H}, \mathrm{t}, J=6.7 \mathrm{~Hz}, \mathrm{H}_{2}-16\right.$ or $\left.\mathrm{H}_{2}-17\right), 1.85-1.80\left(4 \mathrm{H}, \mathrm{m}, \mathrm{H}_{2}-21\right), 1.74-1.58\left(12 \mathrm{H}, \mathrm{m}, \mathrm{H}_{2}-11, \mathrm{H}_{2}-12, \mathrm{H}_{2}-25\right)$, 1.36-1.25 (14H, m, $\mathrm{H}_{2}-26, \mathrm{H}_{2}-27$, including 1.27, 6H, d, $\left.J=6.7 \mathrm{~Hz}, 10-\mathrm{Me}\right) ;{ }^{13} \mathrm{C} \mathrm{NMR}\left(\mathrm{CD}_{3} \mathrm{OD}, 125 \mathrm{MHz}\right.$, * = reduced in intensity due to deuterium exchange ${ }^{30}$ ) $\delta 176.2$ (C-18), 174.4 (C-15), 161.1 (C-6), 145.3 (C-8), 144.8 (C-2), 137.5 (C-4), 135.3 (C-8a), 131.8 (C-4a), 123.0 (C-3), 99.5 (C-7), 93.4* (C-5), 55.8 (OMe), 49.3 (C-10), 49.0 (C-24), 46.0 (C-22), 40.3 (C-13), 36.6 (C-20), 34.8 (C-11), 31.9 (C-16 or C-17), 31.7 (C-16 or C-17), 29.9 (C-27), 27.7 (C-21), 27.4, 27.2, 27.1 (C-12, C-25, C-26, C-27), $20.6(\mathrm{C}-10 \mathrm{Me})$; HRESIMS $[\mathrm{M}+\mathrm{Na}]^{+} \mathrm{m} / \mathrm{z}$ 963.6141 (calcd for $\mathrm{C}_{52} \mathrm{H}_{80} \mathrm{~N}_{10} \mathrm{NaO}_{6}, 963.6155$ ).

5.2.4.5. $\quad N^{l}-N^{l^{\prime}}-(($ Decane-1,10-diylbis(azanediyl))bis(propane-3,1-diyl $))$ bis $\left(N^{4}-(4-((6-m e t h o x y q u i n o l i n e-8-\right.$ yl)amino)pentyl)succinamide)bis(2,2,2-trifluoroacetate) (15)

Following general procedure C, di-tert-butyl decane-1,10-diylbis((3-(4-((4-((6-methoxyquinolin-8yl)amino)pentyl)amino)-4-oxobutanamido)propyl)carbamate) $(80 \mathrm{mg}, 0.07 \mathrm{mmol})$ was treated with TFA in $\mathrm{CH}_{2} \mathrm{Cl}_{2}$ to afford the title compound $(75 \mathrm{mg}, 92 \%)$ as a yellow oil. $\mathrm{R}_{f}\left(75 \% \mathrm{MeOH} / \mathrm{H}_{2} \mathrm{O} / 0.05 \% \mathrm{TFA}, \mathrm{C}_{18}\right)$ 0.29; IR (ATR) $v_{\max } 3370,2935,2860,1775,1644,1597,1549,1455,1427,1387,1171,1060,831,797,720 \mathrm{~cm}^{-1} ;{ }^{1} \mathrm{H}$ $\operatorname{NMR}\left(\mathrm{CD}_{3} \mathrm{OD}, 500 \mathrm{MHz}, *\right.$ reduced in intensity due to deuterium exchange $\left.{ }^{30}\right) \delta 8.52(2 \mathrm{H}, \mathrm{dd}, J=4.3,1.8 \mathrm{~Hz}$, 
H-2), 8.10 (2H, dd, $J=8.2,1.8 \mathrm{~Hz}, \mathrm{H}-4), 7.40,(2 \mathrm{H}, \mathrm{dd}, J=8.2,4.3 \mathrm{~Hz}, \mathrm{H}-3), 6.50\left(0.10 \mathrm{H}^{*}\right.$, br d, H-5), 6.36 (2H, br s, H-7), 3.87 (6H, s, OMe), 3.66-3.61 (2H, m, H-10), $3.28\left(4 \mathrm{H}, \mathrm{t}, J=5.8 \mathrm{~Hz}, \mathrm{H}_{2}-20\right), 3.18(4 \mathrm{H}, \mathrm{t}, J=6.2$ $\left.\mathrm{Hz}, \mathrm{H}_{2}-13\right), 2.97$ (4H, t, $J=7.2 \mathrm{~Hz}, \mathrm{H}_{2}-22$ ), 2.87 (4H, t, $\left.J=7.7 \mathrm{~Hz}, \mathrm{H}_{2}-24\right), 2.50$ (4H, m, $\mathrm{H}_{2}-16$ or $_{2}-17$ ), 2.45 (4H, m, $\mathrm{H}_{2}-16$ or $\left.\mathrm{H}_{2}-17\right)$, $1.85-1.80\left(4 \mathrm{H}, \mathrm{m}, \mathrm{H}_{2}-21\right), 1.74-1.58\left(12 \mathrm{H}, \mathrm{m}, \mathrm{H}_{2}-11, \mathrm{H}_{2}-12, \mathrm{H}_{2}-25\right), 1.33-1.23(18 \mathrm{H}$, $\mathrm{m}, \mathrm{H}_{2}-26, \mathrm{H}_{2}-27, \mathrm{H}_{2}-28$ including $\left.1.28,6 \mathrm{H}, \mathrm{d}, J=6.2 \mathrm{~Hz}, 10-\mathrm{Me}\right) ;{ }^{13} \mathrm{C} \mathrm{NMR}\left(\mathrm{CD}_{3} \mathrm{OD}, 125 \mathrm{MHz}, *=\right.$ reduced in intensity due to deuterium exchange $\left.{ }^{30}\right) \delta 176.2$ (C-18), 174.4 (C-15), 161.1 (C-6), 145.4 (C-8), 144.9 (C-2), 137.3 (C-4), 135.6 (C-8a), 131.7 (C-4a), 123.0 (C-3), 99.3 (C-7), 93.5* (C-5), 55.8 (OMe), 49.2 (C-10), 49.1 (C24), 46.0 (C-22), 40.4 (C-13), 36.6 (C-20), 34.9 (C-11), 31.8 (C-16 or C-17), 31.6 (C-16 or C-17), 27.7 (C-21), 30.4, 30.2, 27.5, 27.3, 27.2 (C-12, C-25, C-26, C-27, C-28), 20.6 (C-10Me); HRESIMS $[\mathrm{M}+\mathrm{Na}]^{+} \mathrm{m} / \mathrm{z}$ 991.6462 (calcd for $\mathrm{C}_{54} \mathrm{H}_{84} \mathrm{~N}_{10} \mathrm{NaO}_{6}, 991.6468$ ).

\subsubsection{Synthesis of SAR analogues 16-62}

\subsubsection{4-((6-Methoxyquinolin-8-yl)amino)-4-oxobutanoic acid (16)}

Following general procedure A, succinic anhydride was added to 8-amino-6-methoxyquinoline (300 mg, 1.72 mmol) under $\mathrm{N}_{2}$ atmosphere at room temperature. The mixture was stirred for $18 \mathrm{~h}$, the solvent removed in vacuo and the solid washed with cold ethanol $(50 \mathrm{~mL})$ to afford 4-((6-methoxyquinolin-8-yl)amino)-4oxobutanoic acid as a brown solid (120 mg, 25\%). $\mathrm{R}_{f}\left(\mathrm{CH}_{2} \mathrm{Cl}_{2}: \mathrm{MeOH}, 9: 1\right)$ 0.37; m.p. 148-150 ${ }^{\circ} \mathrm{C}$; IR (ATR) ) $v_{\max } 3568,3482,3340,3062,2969,2932,1981,1681,1525,1167,850,830 \mathrm{~cm}^{-1}$; ${ }^{1} \mathrm{H}$ NMR (400 MHz, DMSO$\left.d_{6}\right) \delta 12.15(1 \mathrm{H}, \mathrm{br} \mathrm{s}, \mathrm{OH}), 10.10(1 \mathrm{H}, \mathrm{br} \mathrm{s}, \mathrm{NH}-9), 8.74(1 \mathrm{H}, \mathrm{dd}, J=4.2,1.6 \mathrm{~Hz}, \mathrm{H}-2), 8.30(1 \mathrm{H}, \mathrm{d}, J=2.9 \mathrm{~Hz}$, H-7), 8.27 (1H, dd, $J=8.5,1.6 \mathrm{~Hz}, \mathrm{H}-4), 7.57$ (1H, dd, $J=8.5,4.2 \mathrm{~Hz}, \mathrm{H}-3), 7.06$ (1H, d, $J=2.5 \mathrm{~Hz}, \mathrm{H}-5), 3.88$ (3H, br s, OMe), $2.82\left(2 \mathrm{H}, \mathrm{t}, J=6.6 \mathrm{~Hz}, \mathrm{H}_{2}-12\right), 2.57\left(2 \mathrm{H}, \mathrm{t}, J=6.6 \mathrm{~Hz}, \mathrm{H}_{2}-11\right) ;{ }^{13} \mathrm{C}$ NMR (100 MHz, DMSO$\left.d_{6}\right) \delta 173.8$ (C-13), 170.9 (C-10), 157.5 (C-16), 146.1 (C-2), 135.5 (C-8a), 135.3 (C-4), 134.5 (C-8), 128.9 (C4a), 122.5 (C-3), 108.8 (C-7), 99.6 (C-5), 55.5 (OMe), 31.5 (C-12), 28.8 (C-11); (+)-HRESIMS m/z 297.0854 $[\mathrm{M}+\mathrm{Na}]^{+}$(calcd for $\mathrm{C}_{14} \mathrm{H}_{14} \mathrm{~N}_{2} \mathrm{NaO}_{4}, 297.0846$ ).

\subsubsection{4-Oxo-4-(quinolin-8-ylamino)butanoic acid (17)}

Using general procedure A, quinolin-8-amine $(200 \mathrm{mg}, 1.39 \mathrm{mmol})$ and succinic anhydride were reacted in dry $\mathrm{CH}_{2} \mathrm{Cl}_{2}(10 \mathrm{~mL})$. The solid was washed with cold $\mathrm{CH}_{2} \mathrm{Cl}_{2}(25 \mathrm{~mL})$ and cold EtOH $(50 \mathrm{~mL})$ to afford 4-oxo-4(quinoline-8-ylamino) butanoic acid as a brown-purple solid (272 mg, 80\%). $\mathrm{R}_{f}(10 \% \mathrm{MeOH})$ 0.58; m.p. 143$145{ }^{\circ} \mathrm{C}$; IR (ATR) $v_{\max } 3439,3072,2931,2436,1962,1710,1684,1527,1490,1262,825,710 \mathrm{~cm}^{-1} ;{ }^{1} \mathrm{H}$ NMR $\left(400 \mathrm{MHz}, \mathrm{DMSO}-d_{6}\right) \delta 12.15(1 \mathrm{H}, \mathrm{br} \mathrm{s}, \mathrm{OH}), 10.13(1 \mathrm{H}, \mathrm{br} \mathrm{s}, \mathrm{NH}-9), 8.93(1 \mathrm{H}, \mathrm{dd}, J=4.0,1.5 \mathrm{~Hz}, \mathrm{H}-2), 8.61$ $(1 \mathrm{H}, \mathrm{dd}, J=7.5,1.0 \mathrm{~Hz}, \mathrm{H}-7), 8.40(1 \mathrm{H}, \mathrm{dd}, J=7.5,1.0 \mathrm{~Hz}, \mathrm{H}-4), 7.67-7.62(2 \mathrm{H}, \mathrm{m}, \mathrm{H}-3, \mathrm{H}-6), 7.56(1 \mathrm{H}, \mathrm{t}, J=$ $8.0 \mathrm{~Hz}, \mathrm{H}-5), 2.83\left(2 \mathrm{H}, \mathrm{t}, J=6.5 \mathrm{~Hz}, \mathrm{H}_{2}-12\right), 2.58\left(2 \mathrm{H}, \mathrm{t}, J=6.8 \mathrm{~Hz}, \mathrm{H}_{2}-11\right) ;{ }^{13} \mathrm{C}$ NMR (100 MHz, DMSO- $\left.d_{6}\right) \delta$ 173.8 (C-13), 170.6 (C-10), 148.9 (C-2), 138.0 (C-8a), 136.5 (C-4), 134.6 (C-8), 127.8 (C-4a), 126.9 (C-5), 122.1 (C-3), 121.7 (C-6), 116.5 (C-7), 31.5 (C-12), 28.9 (C-11); (+)-HRESIMS m/z 267.0737 [M + Na] ${ }^{+}$(calcd for $\left.\mathrm{C}_{13} \mathrm{H}_{12} \mathrm{~N}_{2} \mathrm{NaO}_{3}, 267.0740\right)$. 


\subsubsection{4-Oxo-4-(quinolin-2-ylamino)butanoic acid (18)}

Using general procedure A, quinolin-2-amine $(200 \mathrm{mg}, 1.39 \mathrm{mmol})$ and succinic anhydride were reacted in dry $\mathrm{CH}_{2} \mathrm{Cl}_{2}(10 \mathrm{~mL})$. The impure solid was washed with cold $\mathrm{CH}_{2} \mathrm{Cl}_{2}(25 \mathrm{~mL})$ and cold EtOH $(50 \mathrm{~mL})$ to afford 4oxo-4-(quinoline-2-ylamino) butanoic acid as a white solid (266 mg, 78\%). $\mathrm{R}_{f}\left(10 \% \mathrm{MeOH} / \mathrm{CH}_{2} \mathrm{Cl}_{2}\right.$ ) 0.39; m.p 190.5-192 ${ }^{\circ} \mathrm{C}$; IR (ATR) $v_{\max } 3227,3027,2927,2429,1902,1700,1599,1505,1120,847,755 \mathrm{~cm}^{-1} ;{ }^{1} \mathrm{H}$ NMR $\left(400 \mathrm{MHz}, \mathrm{DMSO}-d_{6}\right) \delta 12.12(1 \mathrm{H}, \mathrm{br} \mathrm{s}, \mathrm{OH}), 10.84(1 \mathrm{H}, \mathrm{br} \mathrm{s}, \mathrm{NH}-9), 8.34-8.26(2 \mathrm{H}, \mathrm{m}, \mathrm{H}-3, \mathrm{H}-4), 7.90(1 \mathrm{H}$, dd, $J=8.5,1.0 \mathrm{~Hz}, \mathrm{H}-5), 7.80$ (1H, d, $J=8.30 \mathrm{~Hz}, \mathrm{H}-8), 7.72-7.69(1 \mathrm{H}, \mathrm{m}, \mathrm{H}-7), 7.50-7.45$ (1H, m, H-6), 2.70 $\left(2 \mathrm{H}, \mathrm{t}, J=6.65 \mathrm{~Hz}, \mathrm{H}_{2}-12\right), 2.54\left(2 \mathrm{H}, \mathrm{t}, J=6.65 \mathrm{~Hz}, \mathrm{H}_{2}-11\right) ;{ }^{13} \mathrm{C}$ NMR (100 MHz, DMSO- $\left.d_{6}\right) \delta 173.7$ (C-13), 171.6 (C-10), 151.6 (C-2), 146.3 (C-8a), 138.2 (C-4), 129.9 (C-7), 127.7 (C-5), 126.8 (C-8), 125.5 (C-4a), 124.8 (C-6), 114.2 (C-3), $31.0(\mathrm{C}-12), 28.5(\mathrm{C}-11)$; (+)-HRESIMS $\mathrm{m} / z 267.0733[\mathrm{M}+\mathrm{Na}]^{+}\left(\right.$calcd for $\mathrm{C}_{13} \mathrm{H}_{12} \mathrm{~N}_{2} \mathrm{NaO}_{3}$, 267.0740).

\subsubsection{4-Oxo-4-(quinolin-5-ylamino)butanoic acid (19)}

Using general procedure A, quinolin-5-amine $(200 \mathrm{mg}, 1.39 \mathrm{mmol})$ and succinic anhydride were reacted in dry $\mathrm{CH}_{2} \mathrm{Cl}_{2}(10 \mathrm{~mL})$. The solid was washed with cold $\mathrm{CH}_{2} \mathrm{Cl}_{2}(25 \mathrm{~mL})$ and cold EtOH $(50 \mathrm{~mL})$ to afford 4-oxo-4(quinoline-5-ylamino) butanoic acid as a white solid (212 mg, 62\%). $\mathrm{R}_{f}\left(10 \% \mathrm{MeOH} / \mathrm{CH}_{2} \mathrm{Cl}_{2}\right)$ 0.13; m.p $143-$ $145^{\circ} \mathrm{C}$; IR (ATR) $v_{\max } 3273,2450,1890,1655,1538,1335,1187,813 \mathrm{~cm}^{-1} ;{ }^{1} \mathrm{H}$ NMR $\left(400 \mathrm{MHz}\right.$, DMSO- $\left.d_{6}\right) \delta$ $12.18(1 \mathrm{H}$, br s, OH), $10.08(1 \mathrm{H}$, br s, NH-9), $8.91(1 \mathrm{H}, \mathrm{dd}, J=4.0,1.5 \mathrm{~Hz}, \mathrm{H}-122), 8.50(1 \mathrm{H}$, br d, $J=8.35 \mathrm{~Hz}$, H-4), 7.86-7.84 (1H, m, H-8), 7.73-7.72 (2H, m, H-6, H-7), 7.56-7.53 (1H, m, H-3), 2.73 (2H, t, $J=6.50 \mathrm{~Hz}$, $\left.\mathrm{H}_{2}-12\right), 2.59\left(2 \mathrm{H}, \mathrm{t}, J=6.7 \mathrm{~Hz}, \mathrm{H}_{2}-11\right) ;{ }^{13} \mathrm{C}$ NMR $\left(100 \mathrm{MHz}\right.$, DMSO- $\left.d_{6}\right) \delta 173.9$ (C-13), $171.0(\mathrm{C}-10), 150.4$ (C-2), 148.1 (C-8a), 134.1 (C-5), 131.6 (C-4), 129.0 (C-7), 126.0 (C-8), 122.9 (C-4a) 121.5 (C-6), 120.8 (C-3), 30.7 (C-12), 29.0 (C-11); (+)-HRESIMS m/z $245.0917[\mathrm{M}+\mathrm{H}]^{+}$(calcd for $\mathrm{C}_{13} \mathrm{H}_{13} \mathrm{~N}_{2} \mathrm{O}_{3}, 245.0921$ ).

\subsubsection{4-Oxo-4-(quinolin-6-ylamino)butanoic acid (20)}

Using general procedure A, quinolin-6-amine $(200 \mathrm{mg}, 1.39 \mathrm{mmol})$ and succinic anhydride were reacted in dry $\mathrm{CH}_{2} \mathrm{Cl}_{2}(10 \mathrm{~mL})$. The impure solid was washed with cold $\mathrm{CH}_{2} \mathrm{Cl}_{2}(25 \mathrm{~mL})$ and cold EtOH (50 mL) to afford 4oxo-4-(quinoline-6-ylamino) butanoic acid) as a white solid (272 mg, 80\%). $\mathrm{R}_{f}\left(10 \% \mathrm{MeOH} / \mathrm{CH}_{2} \mathrm{Cl}_{2}\right)$ 0.13; m.p. 209-211 ${ }^{\circ} \mathrm{C}$; IR (ATR) $v_{\max } 3289,3218,3181,3098,2955,2928,2369,1881,1722,1680,1565,1390,875,755$ $\mathrm{cm}^{-1}$; ${ }^{1} \mathrm{H}$ NMR $\left(400 \mathrm{MHz}\right.$, DMSO- $\left.d_{6}\right) \delta 10.30(1 \mathrm{H}, \mathrm{br} \mathrm{s}, \mathrm{NH}-9), 8.76(1 \mathrm{H}, \mathrm{dd}, J=4.0,1.5 \mathrm{~Hz}, \mathrm{H}-2), 8.37(1 \mathrm{H}$, d, $J=2.5 \mathrm{~Hz}, \mathrm{H}-5), 8.26(1 \mathrm{H}, \mathrm{dd}, J=8.5,1.1 \mathrm{~Hz}, \mathrm{H}-4), 7.95(1 \mathrm{H}, \mathrm{d}, J=9.0 \mathrm{~Hz}, \mathrm{H}-8), 7.78(1 \mathrm{H}, \mathrm{dd}, J=9.0,2.5$ $\mathrm{Hz}, \mathrm{H}-7), 7.48-7.45(1 \mathrm{H}, \mathrm{m}, \mathrm{H}-3), 2.64\left(2 \mathrm{H}, \mathrm{t}, J=6.3 \mathrm{~Hz}, \mathrm{H}_{2}-12\right), 2.56\left(2 \mathrm{H}, \mathrm{t}, J=6.25 \mathrm{~Hz}, \mathrm{H}_{2}-11\right) ;{ }^{13} \mathrm{C} \mathrm{NMR}$ (100 MHz, DMSO- $d_{6}$ ) $\delta 174.0$ (C-13), 170.8 (C-10), 148.8 (C-2), 144.5 (C-8a), 137.2 (C-6), 135.4 (C-4), 129.4 (C-8), 128.3 (C-4a), 123.2 (C-7), 121.7 (C-3), 114.6 (C-5), 31.4 (C-12), 29.2 (C-11); (+)-HRESIMS m/z $245.0925[\mathrm{M}+\mathrm{H}]^{+}$(calcd for $\mathrm{C}_{13} \mathrm{H}_{13} \mathrm{~N}_{2} \mathrm{O}_{3}, 245.0921$ ). 
Following general procedure $\mathrm{A}$, succinic anhydride in anhydrous $\mathrm{CH}_{2} \mathrm{Cl}_{2}(5 \mathrm{~mL})$ was reacted with 2aminomethylpyridine $(300 \mathrm{mg}, 2.77 \mathrm{mmol})$. The solid was washed with EtOH $(50 \mathrm{~mL})$ affording 4-oxo-4(pyridine-2-ylamino)butanoic acid as a white solid (289 mg, 54\%). $\mathrm{R}_{f}(10 \% \mathrm{MeOH}) 0.08$; m.p 157-158.5 ${ }^{\circ} \mathrm{C}$; IR (ATR) $v_{\max } 3724,3580,3343,3105,2925,2085,1715,1651,1533,1164,823,793,757 \mathrm{~cm}^{-1} ;{ }^{1} \mathrm{H}$ NMR (400 MHz, DMSO- $\left.d_{6}\right) \delta 12.09(1 \mathrm{H}, \mathrm{br} \mathrm{s}, \mathrm{OH}), 8.49-8.47(1 \mathrm{H}, \mathrm{m}, \mathrm{H}-6), 8.45(1 \mathrm{H}, \mathrm{t}, J=5.85 \mathrm{~Hz}, \mathrm{NH}-8), 7.73(1 \mathrm{H}$, ddd, $J=7.6,7.6,1.8 \mathrm{~Hz}, \mathrm{H}-4), 7.28(1 \mathrm{H}, \mathrm{d}, J=7.6 \mathrm{~Hz}, \mathrm{H}-3), 7.24(1 \mathrm{H}, \mathrm{dd}, J=7.6,4.8 \mathrm{~Hz}, \mathrm{H}-5), 4.34(2 \mathrm{H}, \mathrm{d}, J$ $\left.=6.04 \mathrm{~Hz}, \mathrm{H}_{2}-7\right), 2.49-2.46\left(2 \mathrm{H}, \mathrm{m}, \mathrm{H}_{2}-10\right), 2.44-2.40\left(2 \mathrm{H}, \mathrm{m}, \mathrm{H}_{2}-11\right) ;{ }^{13} \mathrm{C}$ NMR $\left(100 \mathrm{MHz}\right.$, DMSO- $\left.d_{6}\right) \delta$ 173.9 (C-12), 171.2 (C-9), 158.8 (C-2), 148.7 (C-6), 136.6 (C-4), 122.0 (C-5), 120.8 (C-3), 44.2 (C-7), 30.0 (C11), $29.1(\mathrm{C}-10)$; (+)-HRESIMS $m / z 231.0748[\mathrm{M}+\mathrm{Na}]^{+}$(calcd for $\mathrm{C}_{10} \mathrm{H}_{12} \mathrm{~N}_{2} \mathrm{NaO}_{3}, 231.0740$ ).

\subsubsection{4-Oxo-4-(pyridin-3-ylamino)butanoic acid (22)}

Following general procedure A, succinic anhydride in anhydrous $\mathrm{CH}_{2} \mathrm{Cl}_{2}(7 \mathrm{~mL})$ was reacted with 3aminomethylpyridine (300 mg, $2.77 \mathrm{mmol})$. Purification was achieved by washing with EtOH $(50 \mathrm{~mL})$ affording 4-oxo-4-(pyridine-3-ylamino)butanoic acid as a white solid (400 mg, 74\%). $\mathrm{R}_{f}(10 \% \mathrm{MeOH}) 0.07$; m.p 180-182 ${ }^{\circ}$ C; IR (ATR) $v_{\max } 3649,3344,3063,2926,2498,1969,1714,1648,1532,1489,1164,823,793$ $\mathrm{cm}^{-1}$; ${ }^{1} \mathrm{H}$ NMR (400 MHz, DMSO- $\left.d_{6}\right) \delta 12.07(1 \mathrm{H}, \mathrm{br} \mathrm{s}, \mathrm{OH}), 8.47(1 \mathrm{H}, \mathrm{d}, J=1.9 \mathrm{~Hz}, \mathrm{H}-2), 8.45-8.40(2 \mathrm{H}, \mathrm{m}$, NH-8, H-6), $7.64(1 \mathrm{H}, \mathrm{dt}, J=7.80,1.90 \mathrm{~Hz}, \mathrm{H}-4), 7.33(1 \mathrm{H}, \mathrm{dd}, J=7.80,4.80 \mathrm{~Hz}, \mathrm{H}-5), 4.39$ (2H, d, $J=5.95$ $\left.\mathrm{Hz}, \mathrm{H}_{2}-7\right), 2.48-2.45\left(2 \mathrm{H}, \mathrm{m}, \mathrm{H}_{2}-10\right), 2.40-2.36\left(2 \mathrm{H}, \mathrm{m}, \mathrm{H}_{2}-11\right) ;{ }^{13} \mathrm{C}$ NMR (100 MHz, DMSO- $\left.d_{6}\right) \delta 173.8(\mathrm{C}-$ 12), 171.2 (C-9), 148.6 (C-2), 148.0 (C-6), 135.0 (C-3), 134.9 (C-4), 123.4 (C-5), 39.7 (C-7), 29.9 (C-11), 29.0 (C-10); (+)-HRESIMS m/z $231.0747[\mathrm{M}+\mathrm{Na}]^{+}$(calcd for $\mathrm{C}_{10} \mathrm{H}_{12} \mathrm{~N}_{2} \mathrm{NaO}_{3}, 231.0740$ ).

5.2.5.8.

Di-tert-butyl

butane-1,4-diylbis((3-(4-((6-methoxyquinolin-8-yl)amino)-4-

oxobutanamido)propyl)(arbamate) (23)

Following general procedure B, reaction of 4-((6-methoxyquinolin-8-yl)amino)-4-oxobutanoic acid (75 mg, $0.27 \mathrm{mmol})$ with di-tert-butyl butane 1,4-diylbis((3-aminopropyl)carbamate) (50 mg, $0.12 \mathrm{mmol})$, EDC.HCl, HOBt and DIPEA afforded the title compound as a pale brown oil (36 mg, 32\%). $\mathrm{R}_{f}\left(\mathrm{CH}_{2} \mathrm{Cl}_{2}: \mathrm{MeOH}, 9: 1\right) 0.57$; IR (ATR) $v_{\max } 3334,3085,2968,2927,2856,1664,1628,1523,1418,1156,792 \mathrm{~cm}^{-1} ;{ }^{1} \mathrm{H}$ NMR $(400 \mathrm{MHz}$, $\mathrm{CDCl}_{3}$ ) $\delta 9.87$ (2H, br s, NH-9), $8.62(2 \mathrm{H}, \mathrm{dd}, J=4.4,1.5 \mathrm{~Hz}, \mathrm{H}-2), 8.49-8.43(2 \mathrm{H}, \mathrm{m}, \mathrm{H}-7), 8.00$ (2H, dd, $J=$ 8.4, 1.5 Hz, H-4), 7.37 (2H, dd, $J=8.4,4.4 \mathrm{~Hz}, \mathrm{H}-3), 7.02-6.88$ (2H, m, NH-14), 6.76 (2H, d, $J=2.5 \mathrm{~Hz}, \mathrm{H}-5$ ), 3.90 (6H, br s, OMe), 3.30-3.16 (8H, m, $\left.\mathrm{H}_{2}-15, \mathrm{H}_{2}-17\right), 3.16-3.05$ (4H, m, $\left.\mathrm{H}_{2}-19\right), 2.92\left(4 \mathrm{H}, \mathrm{t}, J=6.9 \mathrm{~Hz}, \mathrm{H}_{2^{-}}\right.$ 11 or $\left.\mathrm{H}_{2}-12\right), 2.67$ (4H, t, $J=6.9 \mathrm{~Hz}, \mathrm{H}_{2}-11$ or $\left.\mathrm{H}_{2}-12\right), 1.71-1.59$ (4H, m, $\left.\mathrm{H}_{2}-16\right), 1.49-1.42$ (4H, m, $\mathrm{H}_{2}-20$ ), $1.44\left(18 \mathrm{H}\right.$, br s, $t$-Bu); ${ }^{13} \mathrm{C}$ NMR (100 MHz, $\mathrm{CDCl}_{3}$ ) $\delta 171.9$ (C-13), 170.9 (C-10), 158.5 (C-6), 156.3 (C-21), 145.7 (C-2), 135.4 (C-4), 135.0 (C-8, C-8a), 129.0 (C-4a), 122.2 (C-3), 109.1 (C-7), 99.8 (C-5), 79.8 (C-22), 55.6 (OMe), 46.9 (C-21), 43.6 (C-17), 36.1 (C-15), 33.2, 31.6 (C-11, C-12), 28.5 (C-20, t-Bu), 27.9 (C-16); (+)HRESIMS $m / z 937.4785[\mathrm{M}+\mathrm{Na}]^{+}$(calcd for $\left.\mathrm{C}_{48} \mathrm{H}_{66} \mathrm{~N}_{8} \mathrm{NaO}_{10}, 937.4794\right)$. 
oxobutanamido)propyl)(arbamate) (24)

Following general procedure B, reaction of 4-((6-methoxyquinolin-8-yl)amino)-4-oxobutanoic acid (70 mg, $0.26 \mathrm{mmol})$ with di-tert-butyl hexane-1,6-diylbis((3-aminopropyl)carbamate) $(50 \mathrm{mg}, 0.12 \mathrm{mmol})$, EDC.HCl, HOBt and DIPEA afforded the title compound as a pale brown oil (61 mg, 56\%). $\mathrm{R}_{f}\left(\mathrm{CH}_{2} \mathrm{Cl}_{2}: \mathrm{MeOH}, 9: 1\right) 0.67$; IR (ATR) $v_{\max } 3334,3073,2978,2928,2857,1662,1628,1523,1418,1155 \mathrm{~cm}^{-1} ;{ }^{1} \mathrm{H}$ NMR $\left(400 \mathrm{MHz}, \mathrm{CDCl}_{3}\right)$ $\delta 9.87$ (2H, br s, NH-9), 8.61 (2H, dd, $J=4.4,1.5 \mathrm{~Hz}, \mathrm{H}-2), 8.48-8.43(2 \mathrm{H}, \mathrm{m}, \mathrm{H}-7), 7.99$ (2H, dd, $J=8.5,1.5$ $\mathrm{Hz}, \mathrm{H}-4), 7.37$ (2H, dd, $J=8.5,4.4 \mathrm{~Hz}, \mathrm{H}-3), 7.08-7.00$ (2H, m, NH-14), 6.75 (2H, d, $J=2.5 \mathrm{~Hz}, \mathrm{H}-5), 3.89$ (6H, br s, OMe), 3.29-3.19 (8H, m, H $\left.\mathrm{H}_{2}-15, \mathrm{H}_{2}-17\right), 3.13-3.03\left(4 \mathrm{H}, \mathrm{m}, \mathrm{H}_{2}-19\right), 2.92$ (4H, t, $J=6.8 \mathrm{~Hz}, \mathrm{H}_{2}-11$ or $\left.\mathrm{H}_{2}-12\right), 2.68\left(4 \mathrm{H}, \mathrm{t}, J=6.8 \mathrm{~Hz}, \mathrm{H}_{2}-11\right.$ or $\left.\mathrm{H}_{2}-12\right), 1.71-1.60\left(4 \mathrm{H}, \mathrm{m}, \mathrm{H}_{2}-16\right), 1.51-1.42\left(4 \mathrm{H}, \mathrm{m}_{1} \mathrm{H}_{2}-20\right), 1.44$ (18H, br s, $t$-Bu), 1.28-1.19 (4H, m, H $\left.{ }_{2}-21\right) ;{ }^{13} \mathrm{C}$ NMR (100 MHz, CDCl 3 ) $\delta 171.9$ (C-13), 170.9 (C-10), 158.4 (C-6), 156.4 (C-22), 145.7 (C-2), 135.4, 135.0 (C-8, C-8a, C-4), 128.9 (C-4a), 122.1 (C-3), 109.1 (C-7), 99.7 (C-5), 79.6 (C-23), 55.6 (OMe), 47.0 (C-19), 43.6 (C-17), 36.1 (C-15), 33.2, 31.5 (C-11, C-12), 28.5 (C-20, $t$ $\mathrm{Bu}), 27.8(\mathrm{C}-16), 26.7$ (C-21); (+)-HRESIMS $m / z$ 965.5107 [M + Na] ${ }^{+}$(calcd for $\mathrm{C}_{50} \mathrm{H}_{70} \mathrm{~N}_{8} \mathrm{NaO}_{10}, 965.5107$ ).

5.2.5.10.

Di-tert-butyl

heptane-1,7-diylbis((3-(4-((6-methoxyquinolin-8-yl)amino)-4oxobutanamido)propyl)(arbamate) (25)

Following general procedure B, reaction of 4-((6-methoxyquinolin-8-yl)amino)-4-oxobutanoic acid (68 mg, $0.25 \mathrm{mmol})$ with di-tert-butyl heptane-1,7-diylbis((3-aminopropyl)carbamate) $(50 \mathrm{mg}, 0.11 \mathrm{mmol}), \mathrm{EDC} . \mathrm{HCl}$, HOBt and DIPEA, afforded the title compound as a pale brown oil (45 mg, 42\%). $\mathrm{R}_{f}\left(\mathrm{CH}_{2} \mathrm{Cl}_{2}: \mathrm{MeOH}, 9: 1\right)$ 0.67; IR (ATR) $v_{\max } 3334,3078,2970,2927,2855,1667,1627,1523,1418,1155 \mathrm{~cm}^{-1} ;{ }^{1} \mathrm{H}$ NMR (400 MHz, $\mathrm{CDCl}_{3}$ ) $\delta 9.87(2 \mathrm{H}, \mathrm{br} \mathrm{s}, \mathrm{NH}-9), 8.62$ (2H, dd, $J=4.4,1.5 \mathrm{~Hz}, \mathrm{H}-2), 8.50-8.45(2 \mathrm{H}, \mathrm{m}, \mathrm{H}-7), 8.01(2 \mathrm{H}, \mathrm{dd}, J=8.5,1.5$ Hz, H-4), 7.38 (2H, dd, $J=8.5,1.5 \mathrm{~Hz}, \mathrm{H}-3), 7.00-6.88(2 \mathrm{H}, \mathrm{m}, \mathrm{NH}-14), 6.77(2 \mathrm{H}, \mathrm{d}, J=2.5 \mathrm{~Hz}, \mathrm{H}-5), 3.91$ (6H, br s, OMe), 3.29-3.19 (8H, m, $\left.\mathrm{H}_{2}-15, \mathrm{H}_{2}-17\right), 3.13-3.04\left(4 \mathrm{H}, \mathrm{m}, \mathrm{H}_{2}-19\right), 2.92$ (4H, t, $J=6.8 \mathrm{~Hz}, \mathrm{H}_{2}-11$ or $\left.\mathrm{H}_{2}-12\right), 2.67\left(4 \mathrm{H}, \mathrm{t}, J=6.8 \mathrm{~Hz}, \mathrm{H}_{2}-11\right.$ or $\left.\mathrm{H}_{2}-12\right), 1.70-1.60\left(4 \mathrm{H}, \mathrm{m}, \mathrm{H}_{2}-16\right), 1.51-1.43$ (4H, m, $\left.\mathrm{H}_{2}-20\right), 1.44$ (18H, br s, $t$-Bu), 1.32-1.15 (5H, m, H $\left.\mathrm{H}_{2}-21, \mathrm{H}-22\right) ;{ }^{13} \mathrm{C}$ NMR (100 MHz, $\mathrm{CDCl}_{3}$ ) $\delta 171.7$ (C-13), 170.8 (C-10), 158.4 (C-6), 156.4 (C-23), 145.6 (C-2), 135.4, 135.0, 134.9 (C-8, C-8a, C-4), 128.9 (C-4a), 122.1 (C-3), 109.0 (C-7), 99.7 (C-5), 79.5 (C-24), 55.6 (OMe), 47.0 (C-19), 43.4 (C-17), 35.9 (C-15), 33.1, 31.5 (C-11, C-12), 29.1 (C-21 or C-22), 28.5 (C-20, $t$-Bu), 27.7 (C-16), 26.8 (C-21 or C-22); (+)-HRESIMS $m / z$ 979.5262 [M + Na $]^{+}$ (calcd for $\mathrm{C}_{51} \mathrm{H}_{72} \mathrm{~N}_{8} \mathrm{NaO}_{10}, 979.5264$ ).

5.2.5.11. Di-tert-butyl octane-1,8-diylbis((3-(4-((6-methoxyquinolin-8-yl)amino)-4-oxobutanamido) propyl)carbamate) (26)

Following general procedure B, reaction of 4-((6-methoxyquinolin-8-yl)amino)-4-oxobutanoic acid (66 mg, $0.24 \mathrm{mmol})$ with di-tert-butyl octane-1,8-diylbis((3-aminopropyl)carbamate) (50 mg, $0.11 \mathrm{mmol})$, EDC.HCl, $\mathrm{HOBt}$ and DIPEA afforded the title compound as a pale brown oil (41 mg, 39\%). $\mathrm{R}_{f}\left(\mathrm{CH}_{2} \mathrm{Cl}_{2}: \mathrm{MeOH}, 9: 1\right) 0.57$; IR (ATR) ) $v_{\max } 3334,3085,2968,2927,2855,1667,1652,1523,1417,1155,792 \mathrm{~cm}^{-1} ;{ }^{1} \mathrm{H}$ NMR $(400 \mathrm{MHz}$, 
$\left.\mathrm{CDCl}_{3}\right) \delta 9.87$ (2H, br s, NH-9), $8.62(2 \mathrm{H}, \mathrm{dd}, J=4.4,1.5 \mathrm{~Hz}, \mathrm{H}-2), 8.49-8.45$ (2H, m, H-7), 8.00 (2H, dd, $J=$ 8.5, 1.5 Hz, H-4), 7.37 (2H, dd, $J=8.5,4.4 \mathrm{~Hz}, \mathrm{H}-3), 6.99-6.90$ (2H, m, NH-14), 6.77 (2H, d, J=2.5 Hz, H-5),

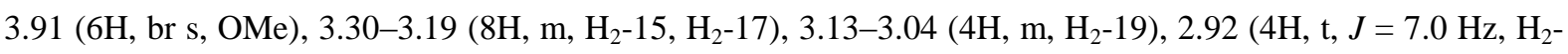
11 or $\left.\mathrm{H}_{2}-12\right), 2.68\left(4 \mathrm{H}, \mathrm{t}, J=7.0 \mathrm{~Hz}, \mathrm{H}_{2}-11\right.$ or $\left.\mathrm{H}_{2}-12\right), 1.71-1.60$ (4H, m, H $\left.\mathrm{H}_{2}-16\right), 1.51-1.43\left(4 \mathrm{H}, \mathrm{m}, \mathrm{H}_{2}-20\right)$, $1.46\left(18 \mathrm{H}\right.$, br s, $t$-Bu), $1.31-1.16\left(8 \mathrm{H}, \mathrm{m}, \mathrm{H}_{2}-21, \mathrm{H}_{2}-22\right) ;{ }^{13} \mathrm{C} \mathrm{NMR}\left(100 \mathrm{MHz}, \mathrm{CDCl}_{3}\right) \delta 171.1(\mathrm{C}-13), 170.8(\mathrm{C}-$ 10), 158.4 (C-6), 156.4 (C-23), 145.6 (C-2), 135.4, 135.0 (C-8, C-8a), 134.9 (C-4), 128.9 (C-4a), 122.1 (C-3), 109.0 (C-7), 99.7 (C-5), 79.5 (C-24), 55.6 (OMe), 47.0 (C-19), 43.4 (C-17), 36.0 (C-15), 33.1, 31.5 (C-11, C12), 29.3 (C-21 or C-22), 28.5 (C-20, $t$-Bu), 27.8 (C-16), 26.8 (C-21 or C-22); (+)-HRESIMS m/z 993.5419 [M $+\mathrm{Na}^{+}$(calcd for $\left.\mathrm{C}_{52} \mathrm{H}_{74} \mathrm{~N}_{8} \mathrm{NaO}_{10}, 993.5420\right)$.

5.2.5.12. Di-tert-butyl decane-1,10-diylbis((3-(4-((6-methoxyquinolin-8-yl)amino)-4oxobutanamido)propyl)carbamate) (27)

Following general procedure $\mathrm{B}$, reaction of 4-((6-methoxyquinolin-8-yl)amino)-4-oxobutanoic acid (62 mg, $0.23 \mathrm{mmol})$ with di-tert-butyl decane-1,10-diylbis((3-aminopropyl)carbamate) (50 $\mathrm{mg}, 0.10 \mathrm{mmol}), \mathrm{EDC} . \mathrm{HCl}$, $\mathrm{HOBt}$, and DIPEA, afforded the title compound as a pale brown oil (52 mg, 51\%). $\mathrm{R}_{f}\left(\mathrm{CH}_{2} \mathrm{Cl}_{2}: \mathrm{MeOH}, 9: 1\right)$ 0.47; IR (ATR) ) $v_{\max } 3334,3073,2975,2926,2854,1667,1628,1524,1418,1155 \mathrm{~cm}^{-1} ;{ }^{1} \mathrm{H}$ NMR $\left(400 \mathrm{MHz}, \mathrm{CDCl}_{3}\right)$ $\delta 9.87$ (2H, br s, NH-9), 8.62 (2H, dd, $J=4.4,1.4$ Hz, H-2), 8.50-8.45 (2H, m, H-7), 8.01 (2H, dd, $J=8.5,1.5$ Hz, H-4), 7.38 (2H, dd, $J=8.5,4.4$ Hz, H-3), 6.98-6.90 (2H, m, NH-14), 6.78 (2H, d, $J=2.8$ Hz, H-5), 3.91 (6H, s, OMe), 3.30-3.19 (8H, m, H2-15, H2-17), 3.08 (4H, t, $\left.J=6.6 \mathrm{~Hz}, \mathrm{H}_{2}-19\right), 2.92\left(4 \mathrm{H}, \mathrm{t}, J=6.6 \mathrm{~Hz}, \mathrm{H}_{2}-11\right.$ or $\left.\mathrm{H}_{2}-12\right), 2.68$ (4H, t, $J=6.6 \mathrm{~Hz}, \mathrm{H}_{2}-11$ or $\left.\mathrm{H}_{2}-12\right), 1.70-1.60$ (4H, m, $\left.\mathrm{H}_{2}-16\right), 1.51-1.45$ (4H, m, $\left.\mathrm{H}_{2}-20\right), 1.45$ (18H, br s, $t$-Bu), 1.30-1.17 (12H, m, H2-21, H $\left.2-22, \mathrm{H}_{2}-23\right) ;{ }^{13} \mathrm{C}$ NMR (100 MHz, CDCl 3 ) $\delta 171.7(\mathrm{C}-13), 170.8$ (C-10), 158.4 (C-6), 156.5 (C-24), 145.6 (C-2), 135.0, 135.4, 134.9 (C-8, C-8a, C-4), 128.9 (C-4a), 122.1 (C-3), 109.0 (C-7), 99.7 (C-5), 79.5 (C-25), 55.6 (OMe), 47.0 (C-19), 43.4 (C-17), 35.9 (C-15), 33.2, 31.6 (C-11, C12), 29.5, 29.3, 26.9 (C-21, C-22, C-23), 28.5 (C-20, $t$-Bu), 27.7 (C-16); (+)-HRESIMS m/z 1021.5727 [M + $\mathrm{Na}]^{+}$(calcd for $\mathrm{C}_{54} \mathrm{H}_{78} \mathrm{~N}_{8} \mathrm{NaO}_{10}, 1021.5733$ ).

5.2.5.13. Di-tert-butyl butane-1,4-diylbis((3-(4-oxo-4-(quinolin-8-ylamino)butanamido)propyl)carbamate) (28)

To a solution of 4-oxo-4-(quinolin-8-ylamino)butanoic acid $(76 \mathrm{mg}, 0.3125 \mathrm{mmol}$ ) dissolved in anhydrous $\mathrm{CH}_{2} \mathrm{Cl}_{2}(1.5 \mathrm{~mL})$ was added $\mathrm{EDC} \cdot \mathrm{HCl}(67 \mathrm{mg}, 0.35 \mathrm{mmol})$ and DMAP $(76 \mathrm{mg}, 0.625 \mathrm{mmol})$ and the reaction was left to stir for $10 \mathrm{~min}$ under nitrogen atmosphere at $0{ }^{\circ} \mathrm{C}$. Then di-tert-butyl butane 1,4-diylbis((3aminopropyl)carbamate) $(50 \mathrm{mg}, 0.125 \mathrm{mmol})$ dissolved in anhydrous $\mathrm{CH}_{2} \mathrm{Cl}_{2}(1.5 \mathrm{~mL})$ was added and the reaction was left to stir under nitrogen atmosphere at room temperature for $12 \mathrm{~h} . \mathrm{CH}_{2} \mathrm{Cl}_{2}(30 \mathrm{~mL})$ was added and the mixture was washed with $\mathrm{NaHCO}_{3}(2 \times 20 \mathrm{~mL})$ and deionised water $(2 \times 30 \mathrm{~mL})$. The organic layer was collected and dried with $\mathrm{MgSO}_{4}$ salts, then in vacuo. The crude oil was purified with silica gel flash column chromatography $\left(10 \% \mathrm{MeOH} / \mathrm{CH}_{2} \mathrm{Cl}_{2}\right)$ to afford the product as a brown oil $(67 \mathrm{mg}, 63 \%) . \quad \mathrm{R}_{f}(5 \%$ $\mathrm{MeOH} / \mathrm{CH}_{2} \mathrm{Cl}_{2}$ ) 0.42; IR (ATR) $v_{\max } 3345,2929,1684,1527,1487,1163,827,793 \mathrm{~cm}^{-1}$; ${ }^{1} \mathrm{H}$ NMR $(400 \mathrm{MHz}$, $\left.\mathrm{CDCl}_{3}\right) \delta 9.92(2 \mathrm{H}$, br s, NH-9), $8.80(2 \mathrm{H}, \mathrm{dd}, J=4.5,2.0 \mathrm{~Hz}, \mathrm{H}-2), 8.73(2 \mathrm{H}, \mathrm{d}, J=6.5 \mathrm{~Hz}, \mathrm{H}-7), 8.14(2 \mathrm{H}, \mathrm{dd}$, $J=8.0,1.5 \mathrm{~Hz}, \mathrm{H}-4), 7.51-7.47$ (4H, m, H-5, H-6), 7.47-7.43 (2H, m, H-3), 6.89 (2H, br s, NH-14), 3.24-3.10 
(12H, m, $\left.\mathrm{H}_{2}-15, \mathrm{H}_{2}-17, \mathrm{H}_{2}-19\right), 2.93$ (4H, t, $\left.J=7.0 \mathrm{~Hz}, \mathrm{H}_{2}-12\right), 2.68$ (4H, s, $\left.\mathrm{H}_{2}-11\right), 1.64$ (4H, br s, $\left.\mathrm{H}_{2}-16\right), 1.43$ $\left(18 \mathrm{H}\right.$, br s, $t$-Bu), $1.42\left(4 \mathrm{H}\right.$, br s, $\left.\mathrm{H}_{2}-20\right) ;{ }^{13} \mathrm{C} \mathrm{NMR}\left(100 \mathrm{MHz}, \mathrm{CDCl}_{3}\right) \delta 171.9(\mathrm{C}-13), 170.9(\mathrm{C}-10), 156.4(\mathrm{C}-$ 21), 148.3 (C-2), 138.5 (C-8a), 136.4 (C-4), 134.6 (C-8), 128.1 (C-4a), 127.4 (C-5), 121.7 (C-3, C-6), 116.6, (C7), 80.0 (C-23), 47.0 (C-19), 43.8 (C-17), 36.3 (C-15), 33.1 (C-12), 31.7 (C-11), 28.5 (t-Bu), 27.9 (C-16), 26.1 (C-20); (+)-HRESIMS $m / z$ 877.4608 [M+ Na $]^{+}$(calcd for $\mathrm{C}_{46} \mathrm{H}_{62} \mathrm{~N}_{8} \mathrm{NaO}_{8}, 877.4583$ ).

5.2.5.14. Di-tert-butyl hexane-1,6-diylbis((3-(4-oxo-4-(quinolin-8-ylamino)butanamido)propyl) carbamate) (29)

Following general procedure B, reaction of 4-oxo-4-(quinolin-8-ylamino)butanoic acid (62 mg, $0.26 \mathrm{mmol}$ ) with di-tert-butyl hexane-1,6-diylbis((3-aminopropyl)carbamate) (50 mg, $0.12 \mathrm{mmol})$, EDC.HCl, HOBt and DIPEA afforded the title compound as a black gum (36 mg, 35\%). $\mathrm{R}_{f}\left(\mathrm{CH}_{2} \mathrm{Cl}_{2}: \mathrm{MeOH}, 9: 1\right)$ 0.43; IR (ATR) $v_{\max } 3318$, 3072, 2970, 2928, 2857, 1660, 1523, 1418, 1156, 826, 791, $759 \mathrm{~cm}^{-1} ;{ }^{1} \mathrm{H} \mathrm{NMR}\left(400 \mathrm{MHz}, \mathrm{CDCl}_{3}\right) \delta 9.92(2 \mathrm{H}$, br s, NH-9), 8.79 (2H, dd, $J=4.2,1.5 \mathrm{~Hz}, \mathrm{H}-2), 8.73(2 \mathrm{H}, \mathrm{d}, J=6.5 \mathrm{~Hz}, \mathrm{H}-7), 8.13$ (2H, dd, $J=8.4,1.5 \mathrm{~Hz}, \mathrm{H}-$ 4), 7.52-7.46 (4H, m, H-5, H-6), 7.43 (2H, dd, J = 8.4, 4.2 Hz, H-3), 7.01-6.92 (2H, m, NH-14), 3.30-3.19 (8H, m, $\left.\mathrm{H}_{2}-15, \mathrm{H}_{2}-17\right), 3.13-3.03\left(4 \mathrm{H}, \mathrm{m}, \mathrm{H}_{2}-19\right), 2.93$ (4H, t, $J=6.9 \mathrm{~Hz}, \mathrm{H}_{2}-11$ or $\left.\mathrm{H}_{2}-12\right), 2.69(4 \mathrm{H}, \mathrm{t}, J=6.9 \mathrm{~Hz}$, $\mathrm{H}_{2}-11$ or $\left.\mathrm{H}_{2}-12\right)$, 1.7 1-1.60 (4H, m, $\left.\mathrm{H}_{2}-16\right), 1.52-1.44$ (4H, m, $\left.\mathrm{H}_{2}-20\right), 1.44$ (18H, br s, $\left.t-\mathrm{Bu}\right), 1.28-1.19(4 \mathrm{H}$, $\left.\mathrm{m}, \mathrm{H}_{2}-21\right) ;{ }^{13} \mathrm{C}$ NMR $\left(100 \mathrm{MHz}, \mathrm{CDCl}_{3}\right) \delta 171.8$ (C-13), 170.8 (C-10), 156.4 (C-22), $148.3(\mathrm{C}-2), 138.4(\mathrm{C}-8 \mathrm{a})$, 136.3 (C-4), 134.6 (C-8), 128.0 (C-4a), 127.3, 121.7, 121.5 (C-3, C-5, C-6), 116.5 (C-7), 79.6 (C-23), 47.0 (C19), 43.6 (C-17), 36.0 (C-15), 33.2, 31.6 (C-11, C-12), 28.5 (C-20, t-Bu), 27.8 (C-16), 26.7 (C-21); (+)HRESIMS $m / z 883.5058[\mathrm{M}+\mathrm{H}]^{+}\left(\right.$calcd for $\left.\mathrm{C}_{48} \mathrm{H}_{67} \mathrm{~N}_{8} \mathrm{O}_{8}, 883.5076\right)$.

5.2.5.15. Di-tert-butyl heptane-1,7-diylbis((3-(4-oxo-4-(quinolin-8-ylamino)butanamido) propyl)carbamate) (30)

Following general procedure B, reaction of 4-oxo-4-(quinolin-8-ylamino)butanoic acid (60 mg, $0.26 \mathrm{mmol}$ ) with di-tert-butyl heptane-1,7-diylbis((3-aminopropyl)carbamate) (50 mg, $0.11 \mathrm{mmol})$, EDC.HCl, HOBt and DIPEA afforded the title compound as a black gum (32 mg, 32\%). $\mathrm{R}_{f}\left(\mathrm{CH}_{2} \mathrm{Cl}_{2}: \mathrm{MeOH}, 9: 1\right)$ 0.40; IR (ATR) ) $v_{\max } 3298$, 2927, 2855, 1652, 1498, 1424, 1318, 1155, $753 \mathrm{~cm}^{-1}$; ${ }^{1} \mathrm{H}$ NMR (400 MHz, $\left.\mathrm{CDCl}_{3}\right) \delta 9.92$ (2H, br s, NH-9), 8.79 $(2 \mathrm{H}, \mathrm{dd}, J=4.2,1.5 \mathrm{~Hz}, \mathrm{H}-2), 8.73(2 \mathrm{H}, \mathrm{d}, J=6.8 \mathrm{~Hz}, \mathrm{H}-7), 8.13(2 \mathrm{H}, \mathrm{dd}, J=8.5,1.5 \mathrm{~Hz}, \mathrm{H}-4), 7.52-7.46(4 \mathrm{H}$, m, H-5, H-6), 7.43 (2H, dd, $J=8.5,4.2$ Hz, H-3), 7.01-6.89 (2H, m, NH-14), 3.32-3.16 (8H, m, H2-15, H $2-17$ ), 3.14-3.02 (4H, m, H $\left.\mathrm{H}_{2}-19\right), 2.93\left(4 \mathrm{H}, \mathrm{t}, J=7.0 \mathrm{~Hz}, \mathrm{H}_{2}-11\right.$ or $\left.\mathrm{H}_{2}-12\right), 2.69$ (4H, t, $J=7.0 \mathrm{~Hz}, \mathrm{H}_{2}-11$ or $\left.\mathrm{H}_{2}-12\right)$, 1.72-1.60 (4H, m, $\left.\mathrm{H}_{2}-16\right), 1.52-1.44$ (4H, m, H $\left.\mathrm{H}_{2}-20\right)$, 1.44 (18H, br s, $t$-Bu), 1.32-1.16 (6H, m, $\left.\mathrm{H}_{2}-21, \mathrm{H}_{2}-22\right)$; ${ }^{13} \mathrm{C}$ NMR (100 MHz, $\mathrm{CDCl}_{3}$ ) $\delta 171.8$ (C-13), 170.8 (C-10), 156.5 (C-23), 148.3 (C-2), 138.4 (C-8a), 136.3 (C4), 134.6 (C-8), 128.0 (C-4a), 127.3, 121.7, 121.5 (C-3, C-5, C-6), 116.5 (C-7), 79.6 (C-24), 47.0 (C-19), 43.5 (C-17), 36.0 (C-15), 33.2, 31.7 (C-11, C-12), 29.2 (C-21 or C-22), 28.5 (C-20, $t$-Bu), 27.8 (C-16), 26.9 (C-21 or C-22); (+)-HRESIMS $m / z 939.5694[\mathrm{M}+\mathrm{H}]^{+}$(calcd for $\mathrm{C}_{52} \mathrm{H}_{75} \mathrm{~N}_{8} \mathrm{O}_{8}, 939.5702$ ). 
Following general procedure B, reaction of 4-oxo-4-(quinolin-8-ylamino)butanoic acid (59 mg, $0.24 \mathrm{mmol}$ ) with di-tert-butyl octane-1,8-diylbis((3-aminopropyl)carbamate) $(50 \mathrm{mg}, 0.11 \mathrm{mmol})$, EDC.HCl, HOBt and DIPEA afforded the title compound as a black gum (30 mg, 30\%). $\mathrm{R}_{f}\left(\mathrm{CH}_{2} \mathrm{Cl}_{2}: \mathrm{MeOH}, 9: 1\right)$ 0.40; IR (ATR) $v_{\max } 3334$, 3073, 2969, 2927, 2856, 1661, 1523, 1418, 1155, 826, $791 \mathrm{~cm}^{-1} ;{ }^{1} \mathrm{H}$ NMR $\left(400 \mathrm{MHz}, \mathrm{CDCl}_{3}\right) \delta 9.92(2 \mathrm{H}, \mathrm{br} \mathrm{s}$, NH-9), 8.79 (2H, dd, $J=4.2,1.5 \mathrm{~Hz}, \mathrm{H}-2), 8.73(2 \mathrm{H}, \mathrm{dd}, J=6.5 \mathrm{~Hz}, \mathrm{H}-7), 8.13$ (2H, dd, $J=8.5,1.5 \mathrm{~Hz}, \mathrm{H}-4)$, 7.52-7.46 (4H, m, H-5, H-6), 7.43 (2H, dd, $J=8.5,4.2 \mathrm{~Hz}, \mathrm{H}-3), 7.00-6.90$ (2H, m, NH-14), 3.32-3.14 (8H, m, $\left.\mathrm{H}_{2}-15, \mathrm{H}_{2}-17\right), 3.14-3.03$ (4H, m, $\left.\mathrm{H}_{2}-19\right), 2.93\left(4 \mathrm{H}, \mathrm{t}, J=7.0 \mathrm{~Hz}, \mathrm{H}_{2}-2\right.$ or $\left.\mathrm{H}_{2}-3\right), 2.69$ (4H, t, $J=7.0 \mathrm{~Hz}, \mathrm{H}_{2}-2$ or $\left.\mathrm{H}_{2}-3\right), 1.72-1.59$ (4H, m, H $\left.\mathrm{H}_{2}-16\right), 1.52-1.44$ (4H, m, $\left.\mathrm{H}_{2}-20\right), 1.44$ (18H, br s, $\left.t-\mathrm{Bu}\right), 1.31-1.16\left(8 \mathrm{H}, \mathrm{m}, \mathrm{H}_{2}-21\right.$, $\left.\mathrm{H}_{2}-22\right) ;{ }^{13} \mathrm{C}$ NMR $\left(100 \mathrm{MHz}, \mathrm{CDCl}_{3}\right) \delta 171.8$ (C-13), 170.8 (C-10), 156.5 (C-23), 148.3 (C-2), 138.4 (C-8a), 136.3 (C-4), 134.6 (C-8), 128.0 (C-4a), 127.4, 121.7, 121.5 (C-3, C-5, C-6), 116.5 (C-7), 79.6 (C-24), 47.1 (C19), 43.5 (C-17), 36.0 (C-15), 33.2, 31.7 (C-11, C-12), 29.4 (C-21 or C-22), 28.5 (C-20, $t$-Bu), 27.8 (C-16), 26.9 (C-21 or C-22); (+)-HRESIMS m/z $933.5198[\mathrm{M}+\mathrm{Na}]^{+}$(calcd for $\mathrm{C}_{50} \mathrm{H}_{70} \mathrm{~N}_{8} \mathrm{NaO}_{8}, 933.5209$ ).

5.2.5.17. Di-tert-butyl decane-1,10-diylbis((3-(4-oxo-4-(quinolin-8-ylamino)butanamido)propyl)carbamate) (32)

To a solution of 4-oxo-4-(quinolin-8-ylamino)butanoic acid $(63 \mathrm{mg}, 0.258 \mathrm{mmol})$ dissolved in anhydrous $\mathrm{CH}_{2} \mathrm{Cl}_{2}(1.5 \mathrm{~mL})$ was added EDC. $\mathrm{HCl}(55 \mathrm{mg}, 0.288 \mathrm{mmol})$ and DMAP $(63 \mathrm{mg}, 0.515 \mathrm{mmol})$. The reaction was left to stir for $10 \mathrm{~min}$ under nitrogen atmosphere at $0{ }^{\circ} \mathrm{C}$. Then di-tert-butyl decane-1,10-diylbis((3aminopropyl)carbamate) $(50 \mathrm{mg}, 0.103 \mathrm{mmol})$ dissolved in anhydrous $\mathrm{CH}_{2} \mathrm{Cl}_{2}(1.5 \mathrm{~mL})$ was added and the reaction was left to stir under nitrogen atmosphere at room temperature for $12 \mathrm{~h} . \mathrm{CH}_{2} \mathrm{Cl}_{2}(30 \mathrm{~mL})$ was added and the mixture was washed with $\mathrm{NaHCO}_{3}(2 \times 20 \mathrm{~mL})$ and deionised water $(2 \times 30 \mathrm{~mL})$. The organic layer was collected and dried with $\mathrm{MgSO}_{4}$ salts and then in vacuo. The crude oil was purified with silica gel flash column chromatography $\left(10 \% \mathrm{MeOH} / \mathrm{CH}_{2} \mathrm{Cl}_{2}\right)$ to afford the product as a brown oil $(88 \mathrm{mg}, 91 \%) . \mathrm{R}_{f}(5 \%$ $\mathrm{MeOH} / \mathrm{CH}_{2} \mathrm{Cl}_{2}$ ) 0.36; IR (ATR) $v_{\max } 3342,2927,2856,1669,1524,1419,1158,827,793 \mathrm{~cm}^{-1} ;{ }^{1} \mathrm{H}$ NMR (400 $\left.\mathrm{MHz}, \mathrm{CDCl}_{3}\right) \delta 9.92(2 \mathrm{H}, \mathrm{br} \mathrm{s}, \mathrm{NH}-9), 8.79(2 \mathrm{H}, \mathrm{dd}, J=4.5,2.0 \mathrm{~Hz}, \mathrm{H}-2), 8.73(2 \mathrm{H}, \mathrm{d}, J=6.5 \mathrm{~Hz}, \mathrm{H}-7), 8.14$ (2H, dd, $J=8.0,1.5 \mathrm{~Hz}, \mathrm{H}-4), 7.53-7.46$ (4H, m, H-5, H-6), 7.45-7.42 (2H, m, H-3), 6.96 (2H, br s, NH-14), 3.26-3.21 (8H, m, $\left.\mathrm{H}_{2}-15, \mathrm{H}_{2}-17\right), 3.11-3.04\left(4 \mathrm{H}, \mathrm{m}, \mathrm{H}_{2}-19\right) 2.93$ (4H, t, $\left.J=7.0 \mathrm{~Hz}, \mathrm{H}_{2}-12\right), 2.72-2.65$ (4H, m, $\left.\mathrm{H}_{2}-11\right), 1.64\left(4 \mathrm{H}\right.$, br s, $\left.\mathrm{H}_{2}-16\right), 1.45$ (22H, br s, $\left.\mathrm{H}_{2}-22, t-\mathrm{Bu}\right), 1.24\left(12 \mathrm{H}\right.$, br s, $\left.\mathrm{H}_{2}-21, \mathrm{H}_{2}-22, \mathrm{H}_{2}-23\right) ;{ }^{13} \mathrm{C}$ NMR (100 MHz, $\left.\mathrm{CDCl}_{3}\right) \delta 171.8$ (C-13), 170.8 (C-10), 156.5 (C-24), 148.3 (C-2), 138.5 (C-8a), 136.4 (C-4), 134.6 (C-8), 128.0 (C-4a), 127.4 (C-5), 121.7 (C-6), 121.5 (C-5), 116.6, (C-7), 79.6 (C-26), 47.1 (C-19), 43.5 (C-17), 36.0 (C-15), 33.3 (C-12), 31.7 (C-11), 29.5 (C-23), 29.4 (C-22), 28.5 (C-20, t-Bu), 27.8 (C-16), 26.9 (C-21); (+)-HRESIMS $m / z, 961.5521[\mathrm{M}+\mathrm{Na}]^{+}\left(\right.$calcd for $\left.\mathrm{C}_{52} \mathrm{H}_{74} \mathrm{~N}_{8} \mathrm{NaO}_{8}, 961.5522\right)$.

5.2.5.18. Di-tert-butyl butane-1,4-diylbis((3-(4-oxo-4(quinoline-2-ylamino)butanamido)propyl)carbamate) (33)

To a solution of 4-oxo-4-(quinoline-2-ylamino) butanoic acid (62 $\mathrm{mg}, 0.255 \mathrm{mmol})$ dissolved in anhydrous $\mathrm{CH}_{2} \mathrm{Cl}_{2}(1.5 \mathrm{~mL})$ was added EDC $\cdot \mathrm{HCl}(55 \mathrm{mg}, 0.286 \mathrm{mmol}$, ) and DMAP (62 $\mathrm{mg}, 0.510 \mathrm{mmol})$ and the reaction 
was left to stir for $10 \mathrm{~min}$ under nitrogen atmosphere at $0{ }^{\circ} \mathrm{C}$. Then di-tert-butyl butane 1,4-diylbis((3aminopropyl)carbamate) (41 mg, $0.041 \mathrm{mmol})$ dissolved in anhydrous $\mathrm{CH}_{2} \mathrm{Cl}_{2}(1.5 \mathrm{~mL})$ was added and the reaction was left to stir under nitrogen atmosphere at room temperature for $12 \mathrm{~h}$. The reaction mixture was diluted with $\mathrm{CH}_{2} \mathrm{Cl}_{2}(30 \mathrm{~mL})$, washed with $\mathrm{NaHCO}_{3}(2 \times 20 \mathrm{~mL})$ and deionised water $(2 \times 30 \mathrm{~mL})$ and the organic layer was collected, dried with $\mathrm{MgSO}_{4}$, and removed in vacuo. The crude product was purified with silica gel flash column chromatography $\left(10 \% \mathrm{MeOH} / \mathrm{CH}_{2} \mathrm{Cl}_{2}\right)$ to afford the title compound as a colourless oil (55 mg, 51\%). $\mathrm{R}_{f}\left(5 \% \mathrm{MeOH} / \mathrm{CH}_{2} \mathrm{Cl}_{2}\right.$ ) 0.31; IR (ATR) $v_{\max } 3300,2928,1662,1600,1500,1426,1319,1163$, $832,757 \mathrm{~cm}^{-1} ;{ }^{1} \mathrm{H}$ NMR $\left(400 \mathrm{MHz}, \mathrm{CDCl}_{3}\right) \delta 9.71(2 \mathrm{H}, \mathrm{br} \mathrm{s}, \mathrm{NH}-9), 8.36(2 \mathrm{H}, \mathrm{d}, J=8.5 \mathrm{~Hz}, \mathrm{H}-3), 8.10(2 \mathrm{H}, \mathrm{d}$, $J=9.0 \mathrm{~Hz}, \mathrm{H}-4), 7.80(2 \mathrm{H}, \mathrm{d}, J=8.5 \mathrm{~Hz}, \mathrm{H}-8), 7.74-7.72(2 \mathrm{H}, \mathrm{m}, \mathrm{H}-5), 7.64-7.59$ (2H, m, H-7), 7.43-7.39 (2H, m, H-6), 7.02 (2H, br s, NH-14), 3.27-3.09 (12H, m, H $\left.\mathrm{H}_{2}-15, \mathrm{H}_{2}-17, \mathrm{H}_{2}-19\right), 2.85-2.84$ (4H, m, $\mathrm{H}_{2}-12$ ), 2.67-2.66 (4H, m, $\left.\mathrm{H}_{2}-11\right), 1.66$ (4H, br s, $\left.\mathrm{H}_{2}-16\right), 1.43$ (18H, br s, $\left.t-\mathrm{Bu}\right), 1.42\left(4 \mathrm{H}, \mathrm{br} \mathrm{s}, \mathrm{H}_{2}-20\right) ;{ }^{13} \mathrm{C}$ NMR (100 MHz, CDCl $)_{3} \delta 171.9$ (C-13), 171.7 (C-10), 156.3 (C-21), 151.1 (C-2), 146.7 (C-8a), 138.3 (C-4), 129.8 (C-7), 127.5 (C-5, C-8), 126.2 (C-4a), 125.0 (C-6), 114.5, (C-3), 79.7 (C-23), 46.8 (C-19), 43.6 (C-17), 36.1 (C-15), 32.9 (C-12), 31.2 (C-11), 28.4 (t-Bu), 27.8 (C-16), 26.0 (C-20); (+)-HRESIMS m/z $855.4769[\mathrm{M}+\mathrm{H}]^{+}$(calcd $^{-1}$ for $\left.\mathrm{C}_{46} \mathrm{H}_{63} \mathrm{~N}_{8} \mathrm{O}_{8}, 855.4763\right)$.

5.2.5.19. Di-tert-butyl decane-1,10-diylbis((3-(4-oxo-4-(quinolin-2-ylamino)butanamido)propyl)carbamate) (34)

To a solution of 4-oxo-4-(quinoline-2-ylamino) butanoic acid $(63 \mathrm{mg}, 0.258 \mathrm{mmol}$ ) dissolved in anhydrous $\mathrm{CH}_{2} \mathrm{Cl}_{2}(1.5 \mathrm{~mL})$ was added EDC $\cdot \mathrm{HCl}(55 \mathrm{mg}, 0.288 \mathrm{mmol})$ and DMAP $(63 \mathrm{mg}, 0.515 \mathrm{mmol})$. The reaction was left to stir for $10 \mathrm{~min}$ under nitrogen atmosphere at $0{ }^{\circ} \mathrm{C}$. Then di-tert-butyl decane-1,10-diylbis((3aminopropyl)carbamate) (50 mg, $0.103 \mathrm{mmol})$ dissolved in anhydrous $\mathrm{CH}_{2} \mathrm{Cl}_{2}(1.5 \mathrm{~mL})$ was added and the reaction was left to stir under nitrogen atmosphere at room temperature for $12 \mathrm{~h} . \mathrm{CH}_{2} \mathrm{Cl}_{2}(30 \mathrm{~mL})$ was added and the mixture was washed with $\mathrm{NaHCO}_{3}(2 \times 20 \mathrm{~mL})$ and deionised water $(2 \times 30 \mathrm{~mL})$. The organic layer was collected and dried with $\mathrm{MgSO}_{4}$ then in vacuo. The crude product was purified with silica gel flash column chromatography $\left(10 \% \mathrm{MeOH} / \mathrm{CH}_{2} \mathrm{Cl}_{2}\right.$ ) to afford the product as a pale yellow oil (102 $\left.\mathrm{mg}, 100 \%\right) . \mathrm{R}_{f}(5 \%$ $\mathrm{MeOH} / \mathrm{CH}_{2} \mathrm{Cl}_{2}$ ) 0.42; IR (ATR) $v_{\max } 3298,2929,2856,1669,1500,1426,1320,1165,832,756 \mathrm{~cm}^{-1} ;{ }^{1} \mathrm{H}$ NMR $\left(400 \mathrm{MHz}, \mathrm{CDCl}_{3}\right) \delta 9.37(2 \mathrm{H}, \mathrm{br} \mathrm{s}, \mathrm{NH}-9), 8.37(2 \mathrm{H}, \mathrm{d}, J=8.7 \mathrm{~Hz}, \mathrm{H}-3), 8.10(2 \mathrm{H}, \mathrm{d}, J=9.0 \mathrm{~Hz}, \mathrm{H}-4), 7.81$ (2H, d, $J=8.4 \mathrm{~Hz}, \mathrm{H}-8), 7.73$ (2H, dd, $J=8.30,1.0 \mathrm{~Hz}, \mathrm{H}-5), 7.64-7.60$ (2H, m, H-7), 7.43-7.39 (2H, m, H-6), 7.02 (2H, br s, NH-14), 3.28-3.24 (8H, m, $\left.\mathrm{H}_{2}-15, \mathrm{H}_{2}-17\right), 3.08$ (4H, br s, $\left.\mathrm{H}_{2}-19\right) 2.85$ (4H, t, $J=6.0 \mathrm{~Hz}, \mathrm{H}_{2}-12$ ), $2.66\left(4 \mathrm{H}, \mathrm{s}, \mathrm{H}_{2}-11\right), 1.66$ (4H, br s, $\left.\mathrm{H}_{2}-16\right), 1.43\left(22 \mathrm{H}\right.$, br s, $\left.\mathrm{H}_{2}-20, t-\mathrm{Bu}\right), 1.24\left(12 \mathrm{H}\right.$, br s, $\left.\mathrm{H}_{2}-21, \mathrm{H}_{2}-22, \mathrm{H}_{2}-23\right)$; ${ }^{13} \mathrm{C}$ NMR (100 MHz, $\left.\mathrm{CDCl}_{3}\right) \delta 171.9$ (C-13), 171.7 (C-10), 156.3 (C-24), 151.2 (C-2), 146.7 (C-8a), 138.3 (C4), 129.8 (C-7), 127.5 (C-5, C-8), 126.3 (C-4a), 125.0 (C-6), 114.5, (C-3), 79.6 (C-26), 47.1 (C-19), 43.4 (C-17), 36.0 (C-15), 33.0 (C-12), 31.3 (C-11), 29.5 (C-23), 29.3 (C-22), 28.5 (C-20, t-Bu), 27.7 (C-16), 26.9 (C-21); (+)-HRESIMS $m / z 939.5684[\mathrm{M}+\mathrm{H}]^{+}\left(\right.$calcd for $\mathrm{C}_{52} \mathrm{H}_{75} \mathrm{~N}_{8} \mathrm{O}_{8}, 939.5702$ ). 
To a solution of 4-oxo-4-(quinolin-5-ylamino)butanoic acid (76 mg, $0.3125 \mathrm{mmol}$ ) dissolved in anhydrous $\mathrm{CH}_{2} \mathrm{Cl}_{2}(1.5 \mathrm{~mL})$ was added EDC. $\mathrm{HCl}(67 \mathrm{mg}, 0.35 \mathrm{mmol})$ and DMAP $(76 \mathrm{mg}, 0.625 \mathrm{mmol})$ and the reaction was left to stir for $10 \mathrm{~min}$ under nitrogen atmosphere at $0{ }^{\circ} \mathrm{C}$. Then di-tert-butyl butane 1,4-diylbis((3aminopropyl)carbamate) $(50 \mathrm{mg}, 0.125 \mathrm{mmol})$ dissolved in anhydrous $\mathrm{CH}_{2} \mathrm{Cl}_{2}(1.5 \mathrm{~mL})$ was added and the reaction was left to stir under nitrogen atmosphere at room temperature for $12 \mathrm{~h} . \mathrm{CH}_{2} \mathrm{Cl}_{2}(30 \mathrm{~mL})$ was added and the mixture was washed with $\mathrm{NaHCO}_{3}(2 \times 20 \mathrm{~mL})$ and deionised water $(2 \times 30 \mathrm{~mL})$. The organic layer was collected and dried with $\mathrm{MgSO}_{4}$, then in vacuo. The crude product was purified with silica gel flash column chromatography $\left(10 \% \mathrm{MeOH} / \mathrm{CH}_{2} \mathrm{Cl}_{2}\right.$ ) to afford the product as a pale yellow oil (86 $\left.\mathrm{mg}, 80 \%\right) . \mathrm{R}_{f}(10 \%$ $\mathrm{MeOH} / \mathrm{CH}_{2} \mathrm{Cl}_{2}$ ) 0.56; IR (ATR) $v_{\max } 3289,2925,1661,1539,1260,1160,801,733 \mathrm{~cm}^{-1} ;{ }^{1} \mathrm{H} \mathrm{NMR}(400 \mathrm{MHz}$, $\left.\mathrm{CDCl}_{3}\right) \delta 9.34(2 \mathrm{H}, \mathrm{br} \mathrm{s}, \mathrm{NH}-9), 8.86(2 \mathrm{H}, \mathrm{d}, J=3.0 \mathrm{~Hz}, \mathrm{H}-2), 8.41$ (2H, s, H-4), 7.95-7.87 (4H, m, H-6, H-8), 7.64-7.62 (2H, m, H-7), 7.37-7.36 (2H, m, H-3), 7.24 (2H, br s, NH-14), 3.25-3.06 (12H, m, H $\mathrm{H}_{2}-15, \mathrm{H}_{2}-17, \mathrm{H}_{2}-$ 19), 2.85 (4H, t, $\left.J=6.0, \mathrm{H}_{2}-12\right), 2.70\left(4 \mathrm{H}\right.$, br s, $\left.\mathrm{H}_{2}-11\right), 1.61$ (4H, br s, $\left.\mathrm{H}_{2}-16\right), 1.42(18 \mathrm{H}, \mathrm{br} \mathrm{s}, t-\mathrm{Bu}), 1.39(4 \mathrm{H}$, br s, $\left.\mathrm{H}_{2}-20\right) ;{ }^{13} \mathrm{C}$ NMR $\left(100 \mathrm{MHz}, \mathrm{CDCl}_{3}\right) \delta 172.9(\mathrm{C}-13), 171.9(\mathrm{C}-10), 156.5(\mathrm{C}-21), 150.2(\mathrm{C}-2), 148.5(\mathrm{C}-$ 8a), 133.4 (C-5), 130.8 (C-4), 129.4 (C-7), 126.5 (C-8), 122.6 (C-4a), 120.9, (C-3), 120.6 (C-6), 80.0 (C-23), 46.9 (C-19), 43.7 (C-17), 36.3 (C-15), 33.0 (C-12), 31.9 (C-11), 28.5 (t-Bu), 27.9 (C-16), 26.0 (C-20); (+)HRESIMS $m / z 877.4602[\mathrm{M}+\mathrm{Na}]^{+}$(calcd for $\mathrm{C}_{46} \mathrm{H}_{62} \mathrm{~N}_{8} \mathrm{NaO}_{8}, 877.4583$ ).

\subsubsection{Di-tert-butyl decane-1,10-diylbis((3-(4-oxo-4-(quinolin-5-ylamino)butanamido)propyl)carbamate)}

(36)

To a solution of 4-oxo-4-(quinolin-5-ylamino)butanoic acid (63 mg, $0.258 \mathrm{mmol})$ dissolved in anhydrous $\mathrm{CH}_{2} \mathrm{Cl}_{2}(1.5 \mathrm{~mL})$ was added $\mathrm{EDC} \cdot \mathrm{HCl}(55 \mathrm{mg}, 0.288 \mathrm{mmol})$ and DMAP $(63 \mathrm{mg}, 0.515 \mathrm{mmol})$. The reaction was left to stir for $10 \mathrm{~min}$ under nitrogen atmosphere at $0{ }^{\circ} \mathrm{C}$ then di-tert-butyl decane-1,10-diylbis((3aminopropyl)carbamate) $(50 \mathrm{mg}, 0.103 \mathrm{mmol})$ dissolved in anhydrous $\mathrm{CH}_{2} \mathrm{Cl}_{2}(1.5 \mathrm{~mL})$ was added and the reaction was left to stir under nitrogen atmosphere at room temperature for $12 \mathrm{~h} . \mathrm{CH}_{2} \mathrm{Cl}_{2}(30 \mathrm{~mL})$ was added and the mixture was washed with $\mathrm{NaHCO}_{3}(2 \times 20 \mathrm{~mL})$ and deionised water $(2 \times 30 \mathrm{~mL})$. The organic layer was collected, dried with $\mathrm{MgSO}_{4}$ and then in vacuo. The crude oil was purified with silica gel flash column chromatography $\left(15 \% \mathrm{MeOH} / \mathrm{CH}_{2} \mathrm{Cl}_{2}\right)$ to afford the product as a pale yellow oil (70 $\left.\mathrm{mg}, 72 \%\right) . \mathrm{R}_{f}(5 \%$ $\mathrm{MeOH} / \mathrm{CH}_{2} \mathrm{Cl}_{2}$ ) 0.08; IR (ATR) $v_{\max } 3287,2928,1663,1542,1419,1158,803 \mathrm{~cm}^{-1}$; ${ }^{1} \mathrm{H} \mathrm{NMR}(400 \mathrm{MHz}$, $\left.\mathrm{CDCl}_{3}\right) \delta 9.81(2 \mathrm{H}$, br s, NH-9), $8.87(2 \mathrm{H}, \mathrm{d}, J=3.0 \mathrm{~Hz}, \mathrm{H}-2), 8.44(2 \mathrm{H}, \mathrm{d}, J=7.5 \mathrm{~Hz}, \mathrm{H}-4), 7.98(2 \mathrm{H}, \mathrm{s}, \mathrm{H}-6)$, 7.90, (2H, d, $J=8.5 \mathrm{~Hz}, \mathrm{H}-8), 7.64$ (2H, t, $J=8.0, \mathrm{H}-7), 7.39-7.34$ (2H, m, H-3), 7.32 (2H, br s, NH-14), 3.263.21 (8H, m, H $\left.\mathrm{H}_{2}-15, \mathrm{H}_{2}-17\right), 3.07$ (4H, t, $\left.7.2 \mathrm{~Hz}, \mathrm{H}_{2}-19\right), 2.85$ (4H, t, J = 6.0, H $\left.\mathrm{H}_{2}-12\right), 2.71$ (4H, br s, $\left.\mathrm{H}_{2}-11\right), 1.62$ (4H, br s, $\left.\mathrm{H}_{2}-16\right), 1.43$ (22H, br s, $\left.\mathrm{H}_{2}-20, t-\mathrm{Bu}\right), 1.24\left(12 \mathrm{H}\right.$, br s, $\left.\mathrm{H}_{2}-21, \mathrm{H}_{2}-22, \mathrm{H}_{2}-23\right) ;{ }^{13} \mathrm{C} \mathrm{NMR}(100 \mathrm{MHz}$, $\left.\mathrm{CDCl}_{3}\right) \delta 172.9(\mathrm{C}-13), 171.8$ (C-10), 156.7 (C-24), 150.2 (C-2), 148.6 (C-8a), 133.4 (C-5), 130.7 (C-4), 129.4 (C-7), 126.5 (C-8), 122.6 (C-4a), 120.9, (C-3), 120.5 (C-6), 79.9 (C-26), 47.2 (C-19), 43.4 (C-17), 36.1 (C-15), 33.1 (C-12), 32.0 (C-11), 29.5 (C-23), 29.4 (C-22), 28.5 (C-20, $t$-Bu), 27.8 (C-16), 26.9 (C-21); (+)-HRESIMS $m / z 961.5519[\mathrm{M}+\mathrm{Na}]^{+}$(calcd for $\mathrm{C}_{52} \mathrm{H}_{74} \mathrm{~N}_{8} \mathrm{NaO}_{8}, 961.5522$ ). 
To a solution of 4-oxo-4-(quinolin-6-ylamino)butanoic acid (76 mg, $0.3125 \mathrm{mmol}$ ) dissolved in anhydrous $\mathrm{CH}_{2} \mathrm{Cl}_{2}(1.5 \mathrm{~mL})$ was added EDC. $\mathrm{HCl}(67 \mathrm{mg}, 0.35 \mathrm{mmol})$ and DMAP $(76 \mathrm{mg}, 0.625 \mathrm{mmol})$ and the reaction was left to stir for $10 \mathrm{~min}$ under nitrogen atmosphere at $0{ }^{\circ} \mathrm{C}$. Then di-tert-butyl butane 1,4-diylbis((3aminopropyl)carbamate) $(50 \mathrm{mg}, 0.125 \mathrm{mmol})$ dissolved in anhydrous $\mathrm{CH}_{2} \mathrm{Cl}_{2}(1.5 \mathrm{~mL})$ was added and the reaction was left to stir under nitrogen atmosphere at room temperature for $12 \mathrm{~h} . \mathrm{CH}_{2} \mathrm{Cl}_{2}(30 \mathrm{~mL})$ was added and the mixture was washed with $\mathrm{NaHCO}_{3}(2 \times 20 \mathrm{~mL})$ and deionised water $(2 \times 30 \mathrm{~mL})$. The organic layer was collected and dried with $\mathrm{MgSO}_{4}$ salts, then in vacuo. The crude oil was purified with silica gel flash column chromatography $\left(10 \% \mathrm{MeOH} / \mathrm{CH}_{2} \mathrm{Cl}_{2}\right)$ to afford the product as a pale yellow oil $(74 \mathrm{mg}, 69 \%) . \mathrm{R}_{f}(10 \%$ $\mathrm{MeOH} / \mathrm{CH}_{2} \mathrm{Cl}_{2}$ ) 0.55; IR (ATR) $v_{\max } 3280,2928,1665,1559,1421,1165,800 \mathrm{~cm}^{-1} ;{ }^{1} \mathrm{H}$ NMR $(400 \mathrm{MHz}$, $\left.\mathrm{CDCl}_{3}\right) \delta 9.72(2 \mathrm{H}, \mathrm{br} \mathrm{s}, \mathrm{NH}-9), 8.86(2 \mathrm{H}, \mathrm{dd}, J=4.0,2.5 \mathrm{~Hz}, \mathrm{H}-2), 8.31$ (2H, s, H-5), 8.00-7.94 (4H, m, H-4, H-8), 7.62 (2H, dd, $J=9.0,6.5 \mathrm{~Hz}, \mathrm{H}-7), 7.33-7.28$ (2H, m, H-3), 7.21 (2H, br s, NH-14), 3.26-3.08 (12H, m, $\left.\mathrm{H}_{2}-15, \mathrm{H}_{2}-17, \mathrm{H}_{2}-19\right), 2.79\left(4 \mathrm{H}, \mathrm{t}, J=5.5 \mathrm{~Hz}, \mathrm{H}_{2}-12\right), 2.70\left(4 \mathrm{H}, \mathrm{t}, J=5.5 \mathrm{~Hz}, \mathrm{H}_{2}-11\right), 1.66$ (4H, br s, $\left.\mathrm{H}_{2}-16\right)$, $1.43\left(18 \mathrm{H}\right.$, br s, $t$-Bu), 1.41 (4H, br s, $\left.\mathrm{H}_{2}-20\right) ;{ }^{13} \mathrm{C}$ NMR (100 MHz, $\left.\mathrm{CDCl}_{3}\right) \delta 172.8$ (C-13), $171.4(\mathrm{C}-10), 156.5$ (C-21), 149.1 (C-2), 145.3 (C-8a), 136.7 (C-6), 136.0 (C-4), 129.8 (C-8), 128.9 (C-4a), 123.5 (C-7), 121.5, (C3), 115.8 (C-5) 80.0 (C-23), 47.0 (C-19), 43.8 (C-17), 36.3 (C-15), 33.1 (C-12), 31.7 (C-11), 28.5 (t-Bu), 27.9 (C-16), 26.1 (C-20); (+)-HRESIMS m/z $877.4560[\mathrm{M}+\mathrm{Na}]^{+}$(calcd for $\mathrm{C}_{46} \mathrm{H}_{62} \mathrm{~N}_{8} \mathrm{NaO}_{8}, 877.4564$ ).

\subsubsection{Di-tert-butyl decane-1,10-diylbis((3-(4-oxo-4-(quinolin-6-ylamino)butanamido)propyl)carbamate)} (38)

To a solution of 4-oxo-4-(quinolin-6-ylamino)butanoic acid (63 $\mathrm{mg}, 0.258 \mathrm{mmol}$ ) dissolved in anhydrous $\mathrm{CH}_{2} \mathrm{Cl}_{2}(1.5 \mathrm{~mL})$ was added EDC. $\mathrm{HCl}(55 \mathrm{mg}, 0.288 \mathrm{mmol})$ and DMAP (63 $\left.\mathrm{mg}, 0.515 \mathrm{mmol}\right)$. The reaction was left to stir for $10 \mathrm{~min}$ under nitrogen atmosphere at $0{ }^{\circ} \mathrm{C}$, then di-tert-butyl decane-1,10-diylbis $((3$ aminopropyl)carbamate) $(50 \mathrm{mg}, 0.103 \mathrm{mmol})$ dissolved in anhydrous $\mathrm{CH}_{2} \mathrm{Cl}_{2}(1.5 \mathrm{~mL})$ was added and the reaction was left to stir under nitrogen atmosphere at room temperature for $12 \mathrm{~h} . \mathrm{CH}_{2} \mathrm{Cl}_{2}(30 \mathrm{~mL})$ was added and the mixture was washed with $\mathrm{NaHCO}_{3}(2 \times 20 \mathrm{~mL})$ and deionised water $(2 \times 30 \mathrm{~mL})$. The organic layer was collected, dried with $\mathrm{MgSO}_{4}$ salts then in vacuo. The crude oil was purified with silica gel flash column chromatography $\left(15 \% \mathrm{MeOH} / \mathrm{CH}_{2} \mathrm{Cl}_{2}\right)$ to afford the product as a pale yellow oil (94 $\left.\mathrm{mg}, 97 \%\right)$. $\mathrm{R}_{f} \quad(5 \%$ $\mathrm{MeOH} / \mathrm{CH}_{2} \mathrm{Cl}_{2}$ ) 0.08; IR (ATR) $v_{\max } 3299,2928,2856,1657,1554,1419,1158,881,836,771 \mathrm{~cm}^{-1} ;{ }^{1} \mathrm{H}$ NMR $\left(400 \mathrm{MHz} \mathrm{CDCl}_{3}\right) \delta 9.79$ (2H, br s, NH-9), $8.76(2 \mathrm{H}, \mathrm{d}, J=3.0 \mathrm{~Hz}, \mathrm{H}-2), 8.32(2 \mathrm{H}, \mathrm{s}, \mathrm{H}-5), 8.01(2 \mathrm{H}, \mathrm{d}, J=8.0$ Hz, H-4), 7.95 (2H, d, J = 9.0 Hz, H-8), 7.62 (2H, dd, J = 9.0, 2.5 Hz, H-7), 7.31-7.28 (4H, m, NH-14), 3.27-

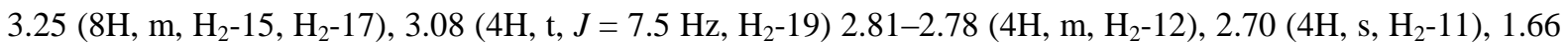
(4H, br s, $\left.\mathrm{H}_{2}-16\right), 1.45\left(22 \mathrm{H}\right.$, br s, $\left.\mathrm{H}_{2}-20, t-\mathrm{Bu}\right), 1.23\left(12 \mathrm{H}\right.$, br s, $\left.\mathrm{H}_{2}-21, \mathrm{H}_{2}-22, \mathrm{H}_{2}-23\right) ;{ }^{13} \mathrm{C} \mathrm{NMR}(100 \mathrm{MHz}$, $\left.\mathrm{CDCl}_{3}\right) \delta 172.7$ (C-13), 171.4 (C-10), 156.8 (C-24), 149.1 (C-2), 145.4 (C-8a), 136.7 (C-6), $135.9(\mathrm{C}-4), 129.8$ (C-8), 128.9 (C-4a), 123.5 (C-7), 121.5, (C-3), 115.8 (C-5) 79.9 (C-26), 47.2 (C-19), 43.5 (C-17), 36.2 (C-15), 33.2 (C-12), 31.7 (C-11), 29.5 (C-23), 29.4 (C-22), 28.5 (C-20, $t$-Bu), 27.8 (C-16), 26.9 (C-21); (+)-HRESIMS $m / z 961.5522[\mathrm{M}+\mathrm{Na}]^{+}$(calcd for $\mathrm{C}_{52} \mathrm{H}_{74} \mathrm{~N}_{8} \mathrm{NaO}_{8}, 961.5522$ ). 
ylmethyl)amino)butanamido)propyl)carbamate) (39)

Following general procedure B, 4-oxo-4-(pyridin-2-ylamino)butanoic acid (54 mg, $0.26 \mathrm{mmol}$ ), di-tert-butyl butane 1,4-diylbis((3-aminopropyl)carbamate) (49 mg, $0.12 \mathrm{mmol})$, EDC.HCl, HOBt and DIPEA afforded the title compound as an orange oil (38 mg, 40\%). $\mathrm{R}_{f}(10 \% \mathrm{MeOH}) 0.33$; IR (ATR) $v_{\max } 3288,3075,2973,2929$, 1652, 1544, 1418, $1160 \mathrm{~cm}^{-1} ;{ }^{1} \mathrm{H}$ NMR (400 MHz, DMSO-d $)_{6} \delta 8.48(2 \mathrm{H}, \mathrm{d}, J=6.0 \mathrm{~Hz}, \mathrm{H}-6), 8.42(2 \mathrm{H}, \mathrm{t}, J=$ $5.9 \mathrm{~Hz}, \mathrm{NH}-8), 7.80$ (2H, brs, NH-13), 7.72 (2H, ddd, J=7.5, 7.5, $1.8 \mathrm{~Hz}, \mathrm{H}-4), 7.27$ (2H, d, J = 7.5 Hz, H-3), $7.23(2 \mathrm{H}, \mathrm{dd}, J=7.5,5.0 \mathrm{~Hz}, \mathrm{H}-5), 4.33(4 \mathrm{H}, \mathrm{d}, J=6.0 \mathrm{~Hz}, \mathrm{H}-7), 3.13-3.05\left(8 \mathrm{H}, \mathrm{m}, \mathrm{H}_{2}-16, \mathrm{H}_{2}-18\right), 3.00(4 \mathrm{H}$, $\left.\mathrm{dt}, J=6.7,6.2 \mathrm{~Hz}, \mathrm{H}_{2}-14\right), 2.44-2.38\left(4 \mathrm{H}, \mathrm{m}, \mathrm{H}_{2}-10\right.$ or $\left.\mathrm{H}_{2}-11\right), 2.36-2.30\left(4 \mathrm{H}, \mathrm{m}, \mathrm{H}_{2}-10\right.$ or $\left.\mathrm{H}_{2}-11\right), 1.62-1.51$ $\left(4 \mathrm{H}, \mathrm{m}, \mathrm{H}_{2}-15\right), 1.43-1.34\left(4 \mathrm{H}, \mathrm{m}, \mathrm{H}_{2}-19\right), 1.37$ (18H, m, $t$-Bu); ${ }^{13} \mathrm{C}$ NMR (100 MHz, DMSO-d $) \delta 171.6(\mathrm{C}-$ 12), 171.1 (C-9, 158.8 (C-2), 154.6 (C-20), 148.7 (C-6), 136.6 (C-4), 121.9 (C-5), 120.8 (C-3), 78.2 (C-21), 46.2 (C-18), 44.4 (C-16), 44.1 (C-7), 36.3 (C-14), 30.7 (C-10, C-11), 28.0 (C-15, $t$-Bu), 25.1 (C-19); (+)-HRESIMS $[\mathrm{M}+\mathrm{Na}]^{+} m / z 805.4608$ (calcd for $\mathrm{C}_{40} \mathrm{H}_{62} \mathrm{~N}_{8} \mathrm{NaO}_{8}$ ).

5.2.5.25

Di-tert-butyl

decane-1,10-diylbis((3-(4-oxo-4-((pyridin-2-

ylmethyl)amino)butanamido)propyl)carbamate) (40)

Following general procedure B, 4-oxo-4-(pyridin-2-ylamino)butanoic acid (48 mg, $0.23 \mathrm{mmol}$ ), di-tert-butyl decane 1,10-diylbis((3-aminopropyl)carbamate) (49 mg, $0.10 \mathrm{mmol})$, HBTU and DIPEA afforded the title compound as an orange gum (23 mg, 35\%). $\mathrm{R}_{f}(10 \% \mathrm{MeOH})$ 0.40; IR (ATR) $v_{\max } 3286,3075,2927,2856$, $1652,1418,1156,1025 \mathrm{~cm}^{-1}$; ${ }^{1} \mathrm{H}$ NMR (400 MHz, DMSO- $\left.d_{6}\right) \delta 8.47(2 \mathrm{H}, \mathrm{d}, J=5.0 \mathrm{~Hz}, \mathrm{H}-6), 8.41(2 \mathrm{H}, \mathrm{t}, J=$ $6.0 \mathrm{~Hz}, \mathrm{NH}-8), 7.82-7.76$ (2H, m, NH-13), 7.72 (2H, ddd, J= 7.8, 7.8, 2.0 Hz, H-4), 7.27 (2H, d, J = 7.8 Hz, H3), $7.23(2 \mathrm{H}, \mathrm{dd}, J=5.0,7.8 \mathrm{~Hz}, \mathrm{H}-5), 4.33$ (4H, d, $J=6.0 \mathrm{~Hz}, \mathrm{H}-7), 3.13-3.04\left(8 \mathrm{H}, \mathrm{m}_{,} \mathrm{H}_{2}-16, \mathrm{H}_{2}-18\right), 3.00$ $\left(4 \mathrm{H}, \mathrm{dt}, J=6.8,6.1 \mathrm{~Hz}, \mathrm{H}_{2}-14\right), 2.44-2.38\left(4 \mathrm{H}, \mathrm{m}, \mathrm{H}_{2}-10\right.$ or $\left.\mathrm{H}_{2}-11\right), 2.36-2.30\left(4 \mathrm{H}, \mathrm{m}, \mathrm{H}_{2}-10\right.$ or $\left.\mathrm{H}_{2}-11\right), 1.61-$ 1.52 (4H, m, H $\left.{ }_{2}-15\right), 1.46-1.34$ (4H, m, H $\left.\mathrm{H}_{2}-19\right), 1.37$ (18H, br s, $t$-Bu), 1.28-1.13 (12H, m, H ${ }_{2}-20, \mathrm{H}_{2}-21, \mathrm{H}_{2}-$ 22); ${ }^{13} \mathrm{C}$ NMR (100 MHz, DMSO- $\left.d_{6}\right) \delta 171.6,171.1$ (C-9, C-12), 158.8 (C-2), 154.6 (C-23), 148.7 (C-6), 136.6 (C-4), 121.9 (C-5), 120.8 (C-3), 78.1 (C-24), 46.3 (C-18), 44.3 (C-16), 44.1 (C-7), 36.3 (C-14), 30.7 (C-10, C11), 28.9, 28.7, 26.2 (C-20, C-21, C-22), 28.3 (C-15), 28.0 ( $t$-Bu), 27.6 (C-19); (+)-HRESIMS [M + Na $]^{+} \mathrm{m} / z$ 889.5488 (calcd for $\mathrm{C}_{46} \mathrm{H}_{74} \mathrm{~N}_{8} \mathrm{NaO}_{8}, 889.5522$ ).

5.2.5.26

Di-tert-butyl

butane-1,4-diylbis((3-(4-oxo-4-((pyridin-3-

ylmethyl)amino)butanamido)propyl)carbamate) (41)

Following general procedure B, 4-oxo-4-(pyridin-3-ylamino)butanoic acid (54 mg, $0.26 \mathrm{mmol}$ ), di-tert-butyl butane 1,4-diylbis((3-aminopropyl)carbamate) (49 mg, $0.12 \mathrm{mmol})$, EDC.HCl, HOBt and DIPEA afforded the title compound as an orange oil $(29 \mathrm{mg}, 31 \%) . \mathrm{R}_{f}(10 \% \mathrm{MeOH})$ 0.33; IR (ATR) $v_{\max } 3277,2934,2252,2126$, 1652, 1419, 1162, 1024, $1005 \mathrm{~cm}^{-1}$; ${ }^{1} \mathrm{H}$ NMR (400 MHz, DMSO- $\left.d_{6}\right) \delta 8.46(2 \mathrm{H}, \mathrm{d}, J=1.7 \mathrm{~Hz}, \mathrm{H}-2), 8.43(2 \mathrm{H}$, $\mathrm{dd}, J=1.5,4.7 \mathrm{~Hz}, \mathrm{H}-5), 8.04$ (2H, t, $J=7.0 \mathrm{~Hz}, \mathrm{NH}-8), 7.89-7.82$ (2H, m, NH-13), 7.63 (2H, dt, $J=1.9,7.8$ Hz, H-4), 7.32 (2H, dd, $J=4.7,7.8$ Hz, H-5), 4.27 (4H, d, $\left.J=6.0 \mathrm{~Hz}, \mathrm{H}_{2}-7\right), 3.14-3.05$ (8H, m, $\left.\mathrm{H}_{2}-16, \mathrm{H}_{2}-18\right)$, 
$3.00\left(4 \mathrm{H}, \mathrm{dt}, J=6.1,6.7 \mathrm{~Hz}, \mathrm{H}_{2}-14\right), 2.40-2.35\left(4 \mathrm{H}, \mathrm{m}, \mathrm{H}_{2}-10\right.$ or $\left.\mathrm{H}_{2}-11\right), 2.35-2.29\left(4 \mathrm{H}, \mathrm{m}, \mathrm{H}_{2}-10\right.$ or $\left.\mathrm{H}_{2}-11\right)$, $1.56\left(4 \mathrm{H}, \mathrm{tt}, J=6.7,6.9 \mathrm{~Hz}, \mathrm{H}_{2}-15\right), 1.44-1.34\left(4 \mathrm{H}, \mathrm{m}, \mathrm{H}_{2}-19\right), 1.37$ (18H, brs, $t$-Bu); ${ }^{13} \mathrm{C}$ NMR $(100 \mathrm{MHz}$, DMSO- $d_{6}$ ) $\delta 171.6$ (C-9), 171.1 (C-12), 154.6 (C-20), 148.6 (C-2), 148.0 (C-6), 135.1 (C-3), 134.9 (C-4), 123.3 (C-5), 78.2 (C-21), 46.3 (C-18), 44.5 (C-16), 39.7 (C-7), 36.3 (C-14), 30.7 (C-10, C-11), 28.7 (C-15). 28.0 (t$\mathrm{Bu}), 25.4(\mathrm{C}-19) ;(+)$-HRESIMS [M + Na] ${ }^{+} \mathrm{m} / 2.805 .4599$ (calcd for $\mathrm{C}_{40} \mathrm{H}_{62} \mathrm{~N}_{8} \mathrm{NaO}_{8}, 805.4583$ ).

5.2.5.27.

Di-tert-butyl

decane-1,10-diylbis((3-(4-oxo-4-((pyridin-3-

ylmethyl)amino)butanamido)propyl)(arbamate) (42)

Following general procedure B, 4-oxo-4-(pyridin-3-ylamino)butanoic acid (54 mg, $0.26 \mathrm{mmol})$, di-tert-butyl decane 1,10-diylbis((3-aminopropyl)carbamate) $(56 \mathrm{mg}, 0.12 \mathrm{mmol})$, EDC.HCl, HOBt and DIPEA afforded the title compound as an orange oil (21 mg, 24\%). $\mathrm{R}_{f}(10 \% \mathrm{MeOH}) 0.33$; IR (ATR) $v_{\max } 3288,2928,2856,2254$, $1652,1579,1418,1024,1003 \mathrm{~cm}^{-1} ;{ }^{1} \mathrm{H}$ NMR $\left(400 \mathrm{MHz}, \mathrm{DMSO}-d_{6}\right) \delta 8.45(2 \mathrm{H}, \mathrm{d}, J=1.5 \mathrm{~Hz}, \mathrm{H}-2), 8.43(2 \mathrm{H}$, d, $J=4.8 \mathrm{~Hz}, \mathrm{H}-6), 8.39(2 \mathrm{H}, \mathrm{t}, J=6.0 \mathrm{~Hz}, \mathrm{NH}-8), 7.79(2 \mathrm{H}, \mathrm{t}, J=5.2 \mathrm{~Hz}, \mathrm{NH}-13), 7.62(2 \mathrm{H}, \mathrm{dt}, J=7.9,2.0 \mathrm{~Hz}$, $\mathrm{H}-4), 7.32$ (2H, dd, $J=7.9,4.8 \mathrm{~Hz}, \mathrm{H}-5), 4.27$ (4H, d, $J=5.8 \mathrm{~Hz}, \mathrm{H}_{2}-7$ ), 3.12-3.04 (8H, m, $\mathrm{H}_{2}-16, \mathrm{H}_{2}-18$ ), 3.00 $\left(4 \mathrm{H}, \mathrm{dt}, 6.2,6.8 \mathrm{~Hz}, \mathrm{H}_{2}-14\right), 2.40-2.34\left(4 \mathrm{H}, \mathrm{m}, \mathrm{H}_{2}-10\right.$ or $\left.\mathrm{H}_{2}-11\right), 2.34-2.29$ (4H, m, $\mathrm{H}_{2}-10$ or $\left.\mathrm{H}_{2}-11\right), 1.62-1.51$ (4H, m, $\left.\mathrm{H}_{2}-15\right), 1.46-1.35$ (4H, m, $\left.\mathrm{H}_{2}-19\right), 1.37$ (18H, br s, $t$-Bu), 1.29-1.13 (12H, m, $\left.\mathrm{H}_{2}-20, \mathrm{H}_{2}-21, \mathrm{H}_{2}-22\right)$; ${ }^{13} \mathrm{C}$ NMR (100 MHz, DMSO- $\left.d_{6}\right) \delta$ 171.6, 171.1 (C-9, C-12), 154.6 (C-23), 148.6 (C-2), 148.0 (C-6), 135.1 (C-3), 134.9 (C-4), 123.3 (C-5), 78.1 (C-24), 46.3 (C-18), 44.3 (C-16), 39.7 (C-7), 36.3 (C-14), 30.7 (C-10, C-11), 28.2 (C-15), 28.9, 28.7, 26.2 (C-20, C-21, C-22) 28.0 ( $t$-Bu), 27.7 (C-19); (+)-HRESIMS [M + Na] $]^{+} \mathrm{m} / z$ 899.5535 (calcd for $\mathrm{C}_{46} \mathrm{H}_{74} \mathrm{~N}_{8} \mathrm{NaO}_{8}, 889.5522$ ).

5.2.5.28. $N^{l}, N^{4}$-Bis(3-(4-((6-methoxyquinolin-8-yl)amino)-4-oxobutanamido)propyl)butane-1,4-diaminium (43)

Following general procedure C, di-tert-butyl butane-1,4-diylbis((3-(4-((6-methoxyquinolin-8-yl)amino)-4oxobutanamido)propyl)carbamate) $(15 \mathrm{mg}, 0.016 \mathrm{mmol})$ was reacted with TFA in $\mathrm{CH}_{2} \mathrm{Cl}_{2}$. Purification was achieved by $\mathrm{C}_{8}$ reversed-phase column chromatography $30 \% \mathrm{MeOH} / \mathrm{H}_{2} \mathrm{O}(0.05 \% \mathrm{TFA})$, affording the title compound as a clear oil $(11 \mathrm{mg}, 73 \%) . \mathrm{R}_{f}\left(\mathrm{MeOH}: 10 \% \mathrm{HCl}, 7: 3, \mathrm{C}_{18}\right)$ 0.80; IR (ATR) $v_{\max } 3334,3072,2955$, 2844, 1677, 1638, 1531, 1203, 1159, 1133, $721 \mathrm{~cm}^{-1}$; ${ }^{1} \mathrm{H}$ NMR (400 MHz, DMSO- $\left.d_{6}\right) \delta 10.07$ (2H, br s, NH-9), $8.74(2 \mathrm{H}, \mathrm{dd}, J=4.2,1.5 \mathrm{~Hz}, \mathrm{H}-2), 8.46-8.34\left(4 \mathrm{H}, \mathrm{m}, \mathrm{NH}_{2}-18\right), 8.30-8.28$ (2H, m, H-7), 8.30-8.26 (2H, m, H4), $8.12(2 \mathrm{H}, \mathrm{t}, J=5.8 \mathrm{~Hz}, \mathrm{NH}-14), 7.57$ (2H, dd, $J=8.4,4.2 \mathrm{~Hz}, \mathrm{H}-3), 7.06(2 \mathrm{H}, \mathrm{d}, J=2.8 \mathrm{~Hz}, \mathrm{H}-5), 3.87$ (6H, br s, OMe), 3.14 (4H, dt, $\left.J=6.4,6.2 \mathrm{~Hz}, \mathrm{H}_{2}-15\right), 2.91-2.80\left(8 \mathrm{H}, \mathrm{m}, \mathrm{H}_{2}-17, \mathrm{H}_{2}-19\right), 2.85-2.80\left(4 \mathrm{H}, \mathrm{m}, \mathrm{H}_{2}-11\right.$ or $\left.\mathrm{H}_{2}-12\right)$, 2.50-2.45 (4H, m, $\mathrm{H}_{2}-11$ or $\left.\mathrm{H}_{2}-12\right), 1.71\left(4 \mathrm{H}, \mathrm{tt}, J=7.4,7.0 \mathrm{~Hz}, \mathrm{H}_{2}-16\right), 1.60-1.50\left(4 \mathrm{H}, \mathrm{m}_{,} \mathrm{H}_{2}-20\right) ;{ }^{13} \mathrm{C}$ NMR (100 MHz, DMSO- $\left.d_{6}\right) \delta 172.0$ (C-13), 171.2 (C-10), 157.4 (C-6), 146.1 (C-2), 135.4, 135.3, 134.5 (C-8 C-8a, C-4), 128.9 (C-4a), 122.5 (C-3), 99.6 (C-5), 55.5 (OMe), 46.1 (C-19), 44.5 (C-17), 35.5 (C-15), 31.9, 30.1 (C-11, C-12), 26.2 (C-16), 22.6 (C-20); (+)-HRESIMS [M+ H] $]^{+} \mathrm{m} / 2.715 .3952$ (calcd for $\mathrm{C}_{38} \mathrm{H}_{51} \mathrm{~N}_{8} \mathrm{O}_{6}, 714.87$ ). 
Following general procedure C, di-tert-butyl hexane-1,6-diylbis((3-(4-((6-methoxyquinolin-8-yl)amino)-4oxobutanamido)propyl)carbamate) $\left(20 \mathrm{mg}, 0.021 \mathrm{mmol}\right.$ ) was reacted with TFA in $\mathrm{CH}_{2} \mathrm{Cl}_{2}$. Purification was achieved by $\mathrm{C}_{8}$ reversed-phase column chromatography $30 \% \mathrm{MeOH} / \mathrm{H}_{2} \mathrm{O}(0.05 \% \mathrm{TFA})$, affording the title compound as a clear oil (11 mg, 55\%). $\mathrm{R}_{f}\left(\mathrm{MeOH}: 10 \% \mathrm{HCl}, 7: 3, \mathrm{C}_{18}\right)$ 0.80; IR (ATR) $v_{\max } 3346,3074,2941$, $2859,1673,1627,1527,1199,1175,1129,1025,720 \mathrm{~cm}^{-1} ;{ }^{1} \mathrm{H}$ NMR (400 MHz, DMSO-d $\left.d_{6}\right) \delta 10.08$ (2H, br s, NH-9), 8.74 (2H, dd, $J=4.2,1.6 \mathrm{~Hz}, \mathrm{H}-2), 8.38-8.30$ (4H, m, NH $\left.{ }_{2}-18\right), 8.29-8.28$ (2H, m, H-7), 8.29-8.25 (2H, m, H-4), 8.15 (2H, t, $J=6.0 \mathrm{~Hz}, \mathrm{NH}-14), 7.57$ (2H, dd, $J=8.4,4.2 \mathrm{~Hz}, \mathrm{H}-3), 7.06$ (2H, d, $J=2.8 \mathrm{~Hz}, \mathrm{H}-5), 3.87$ (6H, br s, OMe), 3.15 (4H, dt, $\left.J=6.3,6.0 \mathrm{~Hz}, \mathrm{H}_{2}-15\right), 2.92-2.80\left(4 \mathrm{H}, \mathrm{m}, \mathrm{H}_{2}-17\right), 2.86-2.81\left(4 \mathrm{H}, \mathrm{m}_{2} \mathrm{H}_{2}-11\right.$ or H$_{2}$ 12), 2.79-2.69 (4H, m, $\left.\mathrm{H}_{2}-19\right)$, 2.50-2.45 (4H, $\mathrm{m}, \mathrm{H}_{2}-11$ or $\left.\mathrm{H}_{2}-12\right), 1.71$ (4H, tt, J = 7.0, 7.0 Hz, $\left.\mathrm{H}_{2}-176\right), 1.48-$ 1.37 (4H, m, $\left.\mathrm{H}_{2}-20\right), 1.15-1.07$ (4H, m, $\left.\mathrm{H}_{2}-21\right) ;{ }^{13} \mathrm{C}$ NMR (100 MHz, DMSO- $d_{6}$ ) $\delta 172.2$ (C-13), 171.3 (C-10), 157.5 (C-6), 146.1 (C-2), 135.43, 135.36, 134.5 (C-68, C-4, C-68a), 128.9 (C-4a), 122.6 (C-3), 108.8 (C-7), 99.6 (C-5), 55.5 (OMe), 46.7 (C-19), 44.4 (C-17), 35.4 (C-15), 31.9, 30.1 (C-11, C-12), 26.3 (C-16), 25.3, 25.3 (C-20, C-21); (+)-HRESIMS [M + H] $]^{+} \mathrm{m} / \mathrm{z} 743.4236$ (calcd for $\mathrm{C}_{40} \mathrm{H}_{55} \mathrm{~N}_{8} \mathrm{O}_{6}, 743.4239$ ).

5.2.5.30. $N^{1}, N^{7}$-Bis(3-(4-((6-methoxyquinolin-8-yl)amino)-4-oxobutanamido)propyl)heptane-1,7-diaminium (45)

Following general procedure C, di-tert-butyl heptane-1,7-diylbis((3-(4-((6-methoxyquinolin-8-yl)amino)-4oxobutanamido)propyl)carbamate) $\left(20 \mathrm{mg}, 0.02 \mathrm{mmol}\right.$ ) was reacted with TFA in $\mathrm{CH}_{2} \mathrm{Cl}_{2}$. Purification was achieved by $\mathrm{C}_{8}$ reversed-phase column chromatography $30 \% \mathrm{MeOH} / \mathrm{H}_{2} \mathrm{O}(0.05 \% \mathrm{TFA})$, affording the title compound as a clear oil (15 mg, 75\%). $\mathrm{R}_{f}\left(\mathrm{MeOH}: 10 \% \mathrm{HCl}, 7: 3, \mathrm{C}_{18}\right)$ 0.80; IR (ATR) $v_{\max } 3331,3072,2938$, 2850, 1674, 1634, 1528, 1200, 1177, 1132, $720 \mathrm{~cm}^{-1}$; ${ }^{1} \mathrm{H}$ NMR (400 MHz, DMSO-d $\left.d_{6}\right) \delta 10.08$ (2H, br s, NH-9), $8.74(2 \mathrm{H}, \mathrm{dd}, J=4.4,1.5 \mathrm{~Hz}, \mathrm{H}-2), 8.40-8.30\left(4 \mathrm{H}, \mathrm{m}, \mathrm{NH}_{2}-18\right), 8.30-8.28(2 \mathrm{H}, \mathrm{m}, \mathrm{H}-7), 8.28-8.25$ (2H, m, H4), 8.16 (2H, t, $J=5.8 \mathrm{~Hz}, \mathrm{NH}-14), 7.57$ (2H, dd, $J=8.4,4.4 \mathrm{~Hz}, \mathrm{H}-3), 7.06$ (2H, d, $J=2.8 \mathrm{~Hz}, \mathrm{H}-5), 3.87$ (6H, br s, OMe), $3.15\left(4 \mathrm{H}, \mathrm{dt}, J=6.4,6.2 \mathrm{~Hz}, \mathrm{H}_{2}-15\right), 2.92-2.81\left(4 \mathrm{H}, \mathrm{m}, \mathrm{H}_{2}-17\right), 2.87-2.81\left(4 \mathrm{H}, \mathrm{m}, \mathrm{H}_{2}-11\right.$ or H$\left._{2}-12\right)$, 2.79-2.71 (4H, m, $\left.\mathrm{H}_{2}-19\right), 2.50-2.45$ (4H, m, $\mathrm{H}_{2}-11$ or $\mathrm{H}_{2}-12$ ), 1.71 (4H, tt, $\left.J=7.0,6.5 \mathrm{~Hz}, \mathrm{H}_{2}-16\right), 1.51-1.38$ (4H, m, $\left.\mathrm{H}_{2}-20\right), 1.12-1.04\left(6 \mathrm{H}, \mathrm{m}, \mathrm{H}_{2}-21, \mathrm{H}_{2}-22\right) ;{ }^{13} \mathrm{C}$ NMR (100 MHz, DMSO- $\left.d_{6}\right) \delta 172.2(\mathrm{C}-13), 171.3$ (C10), 157.5 (C-6), 146.1 (C-2), 135.4 (C-8 or C-8a), 135.3 (C-4), 134.5 (C-8 or C-8a), 128.9 (C-4a), 122.5 (C-3), 108.8 (C-7), 99.5 (C-5), 55.5 (OMe), 46.7 (C-19), 44.4 (C-17), 35.3 (C-15), 31.9, 30.1 (C-11, C-12), 26.2(C16), 25.6 (C-21, C-22), 25.4 (C-20); (+)-HRESIMS $[\mathrm{M}+\mathrm{H}]^{+} \mathrm{m} / \mathrm{z} .757 .4411$ (calcd for $\mathrm{C}_{41} \mathrm{H}_{57} \mathrm{~N}_{8} \mathrm{O}_{6}, 757.4396$ ).

\subsubsection{1. $N^{l}, N^{8}$-Bis(3-(4-((6-methoxyquinolin-8-yl)amino)-4-oxobutanamido)propyl)octane-1,8-diaminium (46)}

Following general procedure C, di-tert-butyl octane-1,8-diylbis((3-(4-((6-methoxyquinolin-8-yl)amino)-4oxobutanamido) propyl)carbamate) $\left(20 \mathrm{mg}, 0.02 \mathrm{mmol}\right.$ ) was reacted with TFA in $\mathrm{CH}_{2} \mathrm{Cl}_{2}$. Purification was achieved by $\mathrm{C}_{8}$ reversed-phase column chromatography $50 \% \mathrm{MeOH} / \mathrm{H}_{2} \mathrm{O}(0.05 \% \mathrm{TFA})$, affording the title compound as a yellow oil (12 mg, 59\%). $\mathrm{R}_{f}\left(\mathrm{MeOH}: 10 \% \mathrm{HCl}, 7: 3, \mathrm{C}_{18}\right)$ 0.80; IR (ATR) $v_{\max } 3330,3072,2937$, $2858,1674,1631,1530,1201,1179,1133,721 \mathrm{~cm}^{-1}$; ${ }^{1} \mathrm{H}$ NMR (400 MHz, DMSO-d 6 ) $\delta 10.08$ (2H, br s, NH-9), $8.74(2 \mathrm{H}, \mathrm{d}, J=4.2 \mathrm{~Hz}, \mathrm{H}-2), 8.36-8.27$ (4H, m, $\left.\mathrm{NH}_{2}-18\right), 8.30-8.27$ (2H, m, H-7), 8.30-8.25 (2H, m, H-4), 
$8.16(2 \mathrm{H}, \mathrm{t}, J=5.8 \mathrm{~Hz}, \mathrm{NH}-14), 7.57(2 \mathrm{H}, \mathrm{dd}, J=8.4,4.2 \mathrm{~Hz}, \mathrm{H}-3), 7.06$ (2H, d, $J=2.8 \mathrm{~Hz}, \mathrm{H}-5), 3.87$ (6H, br $\mathrm{s}, \mathrm{OMe}), 3.16\left(4 \mathrm{H}, \mathrm{dt}, J=6.2,6.2 \mathrm{~Hz}, \mathrm{H}_{2}-15\right), 2.92-2.81\left(4 \mathrm{H}, \mathrm{m}, \mathrm{H}_{2}-17\right), 2.87-2.81\left(4 \mathrm{H}, \mathrm{m}, \mathrm{H}_{2}-11\right.$ or $\left.\mathrm{H}_{2}-12\right)$, 2.79-2.70 (4H, m, $\left.\mathrm{H}_{2}-19\right), 2.50-2.45$ (4H, m, $\mathrm{H}_{2}-11$ or $\left.\mathrm{H}_{2}-12\right), 1.71$ (4H, tt, $\left.J=6.5,6.5 \mathrm{~Hz}, \mathrm{H}_{2}-16\right), 1.49-1.38$ (4H, m, H $2-20), 1.11-1.00\left(8 \mathrm{H}, \mathrm{m}, \mathrm{H}_{2}-21, \mathrm{H}_{2}-22\right)$; ${ }^{13} \mathrm{C}$ NMR (100 MHz, DMSO-d $) \delta 172.3$ (C-13), $171.3(\mathrm{C}-$ 10), 157.5 (C-6), 146.1 (C-2), 135.3, 135.3 (C-8, C-4), 134.5 (C-8a), 128.9 (C-4a), 122.5 (C-3), 108.7 (C-7), 99.5 (C-5), 55.5 (OMe), 46.8 (C-19), 44.4 (C-17), 35.3 (C-15), 31.9, 30.0 (C-11, C-12), 28.2 (C-21 or C-22), 26.3 (C-16), 25.7 (C-21 or C-22), 25.4 (C-20); (+)-HRESIMS [M + H] $]^{+} \mathrm{m} / z .771 .4594$ (calcd for $\mathrm{C}_{42} \mathrm{H}_{59} \mathrm{~N}_{8} \mathrm{O}_{6}$, 771.4550 .

5.2.5.32. $\quad N^{l}, N^{10}$-Bis(3-(4-((6-methoxyquinolin-8-yl)amino)-4-oxobutanamido)propyl)decane-1,10-diaminium (47)

Following general procedure $\mathrm{C}$, di-tert-butyl decane-1,10-diylbis((3-(4-((6-methoxyquinolin-8-yl)amino)-4oxobutanamido)propyl)carbamate) $\left(20 \mathrm{mg}, 0.020 \mathrm{mmol}\right.$ ) was reacted with TFA in $\mathrm{CH}_{2} \mathrm{Cl}_{2}$. Purification was achieved by $\mathrm{C}_{8}$ reversed-phase column chromatography $30 \% \mathrm{MeOH} / \mathrm{H}_{2} \mathrm{O}(0.05 \% \mathrm{TFA})$, affording the title compound as a clear oil (12 mg, 59\%). $\mathrm{R}_{f}\left(\mathrm{MeOH}: 10 \% \mathrm{HCl}, 5: 1, \mathrm{C}_{18}\right)$ 0.74; IR (ATR) $v_{\max } 3332,3061,2933$, 2856, 1669, 1628, 1526, 1454, 1423, 1198, 1175, 1157, 1128, 833, 798, $719 \mathrm{~cm}^{-1} ;{ }^{1} \mathrm{H}$ NMR (400 MHz, DMSO$\left.d_{6}\right) \delta 10.08\left(2 \mathrm{H}\right.$, br s, NH-9), $8.74(2 \mathrm{H}, \mathrm{dd}, J=4.2,1.5 \mathrm{~Hz}, \mathrm{H}-2), 8.40-8.30\left(4 \mathrm{H}, \mathrm{m}, \mathrm{NH}_{2}-18\right), 8.29(2 \mathrm{H}, \mathrm{d}, J=$ $2.5 \mathrm{~Hz}, \mathrm{H}-7), 8.27$ (2H, dd, $J=8.4,1.5 \mathrm{~Hz}, \mathrm{H}-4), 8.17$ (2H, t, $J=5.9 \mathrm{~Hz}, \mathrm{NH}-14), 7.57$ (2H, dd, $J=8.4,4.2 \mathrm{~Hz}$, H-3), 7.06 (2H, d, J=2.5 Hz, H-5), 3.87 (6H, br s, OMe), 3.16 (4H, dt, J = 6.4, 6.2 Hz, H -15$), 2.91-2.81$ (4H, $\mathrm{m}, \mathrm{H}_{2}-17$ ), 2.86-2.82 (4H, m, $\mathrm{H}_{2}-11$ or $\mathrm{H}_{2}-12$ ), 2.80-2.73 (4H, m, $\left.\mathrm{H}_{2}-19\right), 2.50-2.46$ (4H, m, $\mathrm{H}_{2}-11$ or $\mathrm{H}_{2}-12$ ), $1.72\left(4 \mathrm{H}, \mathrm{tt}, J=7.2,6.8 \mathrm{~Hz}, \mathrm{H}_{2}-16\right), 1.49-1.42\left(4 \mathrm{H}, \mathrm{m}, \mathrm{H}_{2}-20\right), 1.31-1.06\left(12 \mathrm{H}, \mathrm{m}, \mathrm{H}_{2}-21, \mathrm{H}_{2}-22, \mathrm{H}_{2}-23\right) ;{ }^{13} \mathrm{C}$ NMR (100 MHz, DMSO- $\left.d_{6}\right) \delta 172.3$ (C-13), 171.3 (C-10), 157.5 (C-6), 146.0 (C-2), 135.4, 135.3, 134.5 (C-8, C-8a, C-4), 128.9 (C-4a), 122.5 (C-3), 108.8 (C-7), 99.6 (C-5), 55.5 (OMe), 46.8 (C-19), 44.4 (C-17), 35.3 (C15), 31.9, 30.0 (C-11, C-12), 28.6, 28.4, 25.8 (C-21, C-22, C-23), 26.3 (C-16), 25.4 (C-20); (+)-HRESIMS [M + $\mathrm{H}]^{+} m / z, 799.4933$ (calcd for $\mathrm{C}_{44} \mathrm{H}_{63} \mathrm{~N}_{8} \mathrm{O}_{6}, 799.4870$ ).

\subsubsection{3. $N^{l}, N^{l^{\prime}}-(($ Butane-1,4-diylbis(azanediyl) $)$ bis(propane-3,1-diyl $\left.)\right)$ bis $\left(N^{4}\right.$-(quinolin-8-yl)succinamide) (48)}

Using general procedure C, di-tert-butyl butane-1,4-diylbis((3-(4-oxo-4-(quinolin-8ylamino)butanamido)propyl)carbamate) (34 mg, $0.040 \mathrm{mmol}$ ) was treated with TFA in $\mathrm{CH}_{2} \mathrm{Cl}_{2}$. The solvent was removed under reduced pressure and the crude product was purified with C8 reversed-phased column chromatography eluting with $50 \% \mathrm{MeOH} / \mathrm{H}_{2} \mathrm{O}(0.05 \% \mathrm{TFA})$ to yield the product as a purple oil $(20 \mathrm{mg}, 57 \%)$. $\mathrm{R}_{f}\left(\mathrm{MeOH} / 10 \% \mathrm{HCl}_{(\mathrm{aq})}, 9: 1, \mathrm{C}_{18}\right)$ 0.24; IR (ATR) $v_{\max } 3336,3055,2839,1675,1528,1201,1130,830,799$, $721 \mathrm{~cm}^{-1} ;{ }^{1} \mathrm{H}$ NMR (400 MHz, CD $\left.3 \mathrm{OD}\right) \delta 8.94$ (2H, dd, $\left.J=4.5,1.5 \mathrm{~Hz}, \mathrm{H}-2\right), 8.49-8.45$ (4H, m, H-4, H-7), 7.73 $(2 \mathrm{H}, \mathrm{dd}, J=8.0,1.0 \mathrm{~Hz}, \mathrm{H}-5), 7.67-7.64(2 \mathrm{H}, \mathrm{m}, \mathrm{H}-3), 7.60(2 \mathrm{H}, \mathrm{t}, 8.0 \mathrm{~Hz}, \mathrm{H}-6) 3.34-3.30\left(4 \mathrm{H}, \mathrm{m}, \mathrm{H}_{2}-15\right)$, 2.97-2.92 (8H, m, H $\left.{ }_{2}-12, \mathrm{H}_{2}-17\right), 2.80$ (4H, br s, $\left.\mathrm{H}_{2}-19\right)$ 2.68-2.65 (4H, m, H $\left.\mathrm{H}_{2}-11\right), 1.88-1.82$ (4H, m, H $\left.\mathrm{H}_{2}-16\right)$, 1.58-1.55 (4H, m, $\left.\mathrm{H}_{2}-20\right)$ ) ${ }^{13} \mathrm{C}$ NMR (100 MHz, CD $\left.3 \mathrm{OD}\right) \delta 176.3$ (C-13), 173.5 (C-10), 149.2 (C-2), 140.2 (C4), 138.8 (C-8a), 134.5 (C-8), 130.0 (C-4a), 128.7 (C-6), 124.6 (C-5), 123.2, (C-3), 121.2 (C-7), 48.0 (C-19), 
46.0 (C-17), 36.6 (C-15), 32.8 (C-12), 31.5 (C-11), 27.7 (C-16), 24.1 (C-20); (+)-HRESIMS m/z 655.3713 [M + $\mathrm{H}]^{+}$(calcd for $\mathrm{C}_{36} \mathrm{H}_{47} \mathrm{~N}_{8} \mathrm{O}_{4}, 655.3715$ ).

\subsubsection{4. $N^{l}, N^{6}$-Bis(3-(4-oxo-4-(quinolin-8-ylamino)butanamido)propyl)hexane-1,6-diaminium (49)}

Following general procedure $\mathrm{C}$, di-tert-butyl hexane-1,6-diylbis((3-(4-oxo-4-(quinolin-8ylamino)butanamido)propyl) carbamate) $(20 \mathrm{mg}, 0.017 \mathrm{mmol})$ was reacted with TFA in $\mathrm{CH}_{2} \mathrm{Cl}_{2}$. Purification was achieved by $\mathrm{C}_{8}$ reversed-phase column chromatography $30 \% \mathrm{MeOH} / \mathrm{H}_{2} \mathrm{O}(0.05 \% \mathrm{TFA})$, affording the title compound as a clear oil $(9 \mathrm{mg}, 58 \%) . \mathrm{R}_{f}\left(\mathrm{MeOH}: 10 \% \mathrm{HCl}, 7: 3, \mathrm{C}_{18}\right)$ 0.83; IR (ATR) $v_{\max } 3332,3060,2941$, $2851,1671,1525,1199,1174,1126,827,797,719 \mathrm{~cm}^{-1}$; ${ }^{1} \mathrm{H}$ NMR (400 MHz, DMSO-d $\left.d_{6}\right) \delta 10.10(2 \mathrm{H}, \mathrm{br} \mathrm{s}$, NH-9), 8.93 (2H, dd, $J=4.2,1.6 \mathrm{~Hz}, \mathrm{H}-2), 8.59(2 \mathrm{H}, \mathrm{dd}, J=7.8,1.3 \mathrm{~Hz}, \mathrm{H}-7), 8.41(2 \mathrm{H}, \mathrm{dd}, J=8.4,1.6 \mathrm{~Hz}, \mathrm{H}-$ 4), 8.37-8.27 (4H, m, NH $\left.\mathrm{NH}_{2}-18\right), 8.16(2 \mathrm{H}, \mathrm{t}, J=5.9 \mathrm{~Hz}, \mathrm{NH}-14), 7.86-7.62$ (4H, m, H-3, H-5), 7.55 (2H, dd, $J=$ 8.6, 7.8 Hz, H-6), $3.15\left(4 \mathrm{H}, \mathrm{dt}, J=6.5,6.2 \mathrm{~Hz}, \mathrm{H}_{2}-15\right), 2.91-2.82\left(4 \mathrm{H}, \mathrm{m}, \mathrm{H}_{2}-17\right), 2.86-2.82\left(4 \mathrm{H}, \mathrm{m}, \mathrm{H}_{2}-11\right.$ or $\left.\mathrm{H}_{2}-12\right), 2.76-2.69\left(4 \mathrm{H}, \mathrm{m}, \mathrm{H}_{2}-19\right), 2.51-2.48\left(4 \mathrm{H}, \mathrm{m}, \mathrm{H}_{2}-11\right.$ or $\left.\mathrm{H}_{2}-12\right), 1.71\left(4 \mathrm{H}, \mathrm{tt}, J=7.0,6.8 \mathrm{~Hz}, \mathrm{H}_{2}-16\right)$, $1.46-1.36$ (4H, m, H $\left.\mathrm{H}_{2}-20\right), 1.12-1.04\left(4 \mathrm{H}, \mathrm{m}, \mathrm{H}_{2}-21\right) ;{ }^{13} \mathrm{C}$ NMR (100 MHz, DMSO- $\left.d_{6}\right) \delta 172.2(\mathrm{C}-13), 171.0$ (C-10), 148.8 (C-2), 138.0 (C-8a), 136.6 (C-4), 134.5 (C-8), 127.8 (C-4a), 126.9 (C-6), 122.1 (C-3), 121.7 (C-5), 116.4 (C-7), 46.6 (C-19), 44.4 (C-17), 35.4 (C-15), 31.9, 30.2 (C-11, C-12), 26.2 (C-16), 25.3 (C-21), 25.3 (C20); (+)-HRESIMS $m / z 683.4015[\mathrm{M}+\mathrm{H}]^{+}$(calcd for $\mathrm{C}_{38} \mathrm{H}_{51} \mathrm{~N}_{8} \mathrm{O}_{4}, 683.4028$ ).

\subsubsection{5. $N^{l}, N^{7}$-Bis(3-(4-oxo-4-(quinolin-8-ylamino)butanamido)propyl)heptane-1,7-diaminium (50)}

Following general procedure C, di-tert-butyl heptane-1,7-diylbis((3-(4-oxo-4-(quinolin-8-ylamino)butanamido) propyl)carbamate) $\left(20 \mathrm{mg}, 0.017 \mathrm{mmol}\right.$ ) was reacted with TFA in $\mathrm{CH}_{2} \mathrm{Cl}_{2}$. Purification was achieved by $\mathrm{C}_{8}$ reversed-phase column chromatography $30 \% \mathrm{MeOH} / \mathrm{H}_{2} \mathrm{O}(0.05 \%$ TFA), affording the title compound as a clear oil (11 mg, 70\%). $\mathrm{R}_{f}\left(\mathrm{MeOH}: 10 \% \mathrm{HCl}, 7: 3, \mathrm{C}_{18}\right)$ 0.83; IR (ATR) $v_{\max } 3332,3061,2939,2859,1671,1525$, $1199,1175,1127,828,797,719 \mathrm{~cm}^{-1} ;{ }^{1} \mathrm{H}$ NMR $\left(400 \mathrm{MHz}\right.$, DMSO- $\left.d_{6}\right) \delta 10.11(2 \mathrm{H}, \mathrm{br} \mathrm{s}, \mathrm{NH}-9), 8.93(2 \mathrm{H}, \mathrm{dd}, J$ $=4.2,1.6 \mathrm{~Hz}, \mathrm{H}-2), 8.60(2 \mathrm{H}, \mathrm{dd}, J=7.8,1.2 \mathrm{~Hz}, \mathrm{H}-7), 8.40(2 \mathrm{H}, \mathrm{dd}, J=8.4,1.6 \mathrm{~Hz}, \mathrm{H}-4), 8.38-8.30(4 \mathrm{H}, \mathrm{m}$, $\left.\mathrm{H}_{2}-18\right), 8.17$ (2H, t, $\left.J=6.0 \mathrm{~Hz}, \mathrm{NH}-14\right), 7.68-7.62(4 \mathrm{H}, \mathrm{m}, \mathrm{H}-3, \mathrm{H}-5), 7.55$ (2H, dd, $\left.J=8.6,7.8 \mathrm{~Hz}, \mathrm{H}-6\right), 3.15$ (4H, dt, $\left.J=6.3,6.3 \mathrm{~Hz}, \mathrm{H}_{2}-15\right), 2.91-2.81$ (4H, m, $\mathrm{H}_{2}-17$ ), 2.87-2.82 (4H, m, $\mathrm{H}_{2}-11$ or $\left.\mathrm{H}_{2}-12\right), 2.78-2.69$ (4H, m, $\left.\mathrm{H}_{2}-19\right), 2.51-2.47\left(4 \mathrm{H}, \mathrm{m}, \mathrm{H}_{2}-11\right.$ or $\left.\mathrm{H}_{2}-12\right), 1.71\left(4 \mathrm{H}, \mathrm{tt}, J=7.0,6.7 \mathrm{~Hz}, \mathrm{H}_{2}-16\right), 1.46-1.36\left(4 \mathrm{H}, \mathrm{m}, \mathrm{H}_{2}-20\right)$, 1.09-1.00 (6H, m, H $\left.\mathrm{H}_{2}-21, \mathrm{H}_{2}-22\right) ;{ }^{13} \mathrm{C}$ NMR (100 MHz, DMSO- $d_{6}$ ) $\delta 172.3$ (C-13),171.0 (C-10), 148.8 (C-2), 138.0 (C-8a), 136.6 (C-4), 134.6 (C-8), 127.8 (C-4a), 126.9 (C-6), 122.1 (C-3), 121.7 (C-5), 116.4 (C-7), 46.7 (C-19), 44.4 (C-17), 35.4 (C-15), 31.9, 30.2 (C-11, C-12), 27.9, 25.6 (C-21, C-22), 26.2 (C-16), 25.3 (C-20); (+)-HRESIMS $m / z 697.4159[\mathrm{M}+\mathrm{H}]^{+}\left(\right.$calcd for $\left.\mathrm{C}_{39} \mathrm{H}_{53} \mathrm{~N}_{8} \mathrm{O}_{4}, 697.4184\right)$.

\subsubsection{6. $N^{l}, N^{8}$-Bis(3-(4-oxo-4-(quinolin-8-ylamino)butanamido)propyl)octane-1,8-diaminium (51)}

Following general procedure C, di-tert-butyl octane-1,8-diylbis((3-(4-oxo-4-(quinolin-8-ylamino)butanamido) propyl)carbamate) $(20 \mathrm{mg}, 0.016 \mathrm{mmol})$ was reacted with TFA in $\mathrm{CH}_{2} \mathrm{Cl}_{2}$. Purification was achieved by $\mathrm{C}_{8}$ 
reversed-phase column chromatography $30 \% \mathrm{MeOH} / \mathrm{H}_{2} \mathrm{O}(0.05 \%$ TFA), affording the title compound as a clear oil (8 mg, 53\%). $\mathrm{R}_{f}$ (MeOH:10\% HCl, 7:3, $\mathrm{C}_{18}$ ) 0.83; IR (ATR) $v_{\max } 3316,3263,3097,2934,2858,2443,1671$, $1523,1198,1163,1127,829,797,717 \mathrm{~cm}^{-1} ;{ }^{1} \mathrm{H}$ NMR (400 MHz, DMSO- $\left.d_{6}\right) \delta 10.11$ (2H, br s, NH-9), 8.93 $(2 \mathrm{H}, \mathrm{dd}, J=4.2,1.7 \mathrm{~Hz}, \mathrm{H}-2), 8.60(2 \mathrm{H}, \mathrm{dd}, J=7.8,1.2 \mathrm{~Hz}, \mathrm{H}-7), 8.40(2 \mathrm{H}, \mathrm{dd}, J=8.2,1.7 \mathrm{~Hz}, \mathrm{H}-4), 8.37-8.27$ (4H, m, $\left.\mathrm{NH}_{2}-18\right), 8.17(2 \mathrm{H}, \mathrm{t}, J=6.0 \mathrm{~Hz}, \mathrm{NH}-14), 7.67-7.64(2 \mathrm{H}, \mathrm{m}, \mathrm{H}-5), 7.66-7.62(2 \mathrm{H}, \mathrm{m}, \mathrm{H}-3), 7.55(2 \mathrm{H}$, dd, $J=8.8,7.8 \mathrm{~Hz}, \mathrm{H}-6), 3.16\left(4 \mathrm{H}, \mathrm{dt}, J=6.5,6.0 \mathrm{~Hz}, \mathrm{H}_{2}-15\right), 2.92-2.81\left(4 \mathrm{H}, \mathrm{m}, \mathrm{H}_{2}-17\right), 2.88-2.81\left(4 \mathrm{H}, \mathrm{m}, \mathrm{H}_{2}-\right.$ 11 or $\left.\mathrm{H}_{2}-12\right), 2.78-2.68\left(4 \mathrm{H}, \mathrm{m}, \mathrm{H}_{2}-19\right), 2.50-2.46\left(4 \mathrm{H}, \mathrm{m}, \mathrm{H}_{2}-11\right.$ or $\left.\mathrm{H}_{2}-12\right), 1.71\left(4 \mathrm{H}, \mathrm{tt}, J=7.0,7.0 \mathrm{~Hz}, \mathrm{H}_{2}-\right.$ 16), $1.48-1.37$ (4H, m, $\left.\mathrm{H}_{2}-20\right), 1.09-1.00\left(8 \mathrm{H}, \mathrm{m}, \mathrm{H}_{2}-21, \mathrm{H}_{2}-22\right) ;{ }^{13} \mathrm{C}$ NMR (100 MHz, DMSO- $\left.d_{6}\right) \delta 172.3$ (C13), 171.0 (C-10), 148.8 (C-2), 138.0 (C-8a), 136.6 (C-4), 134.6 (C-8), 127.8 (C-4a), 126.9 (C-6), 122.1 (C-3), 121.7 (C-11), 116.4 (C-13), 46.8 (C-19), 44.4 (C-17), 35.3 (C-15), 31.9, 30.1 (C-2, C-3), 28.2, 25.7 (C-21, C22), 26.3 (C-16), 25.4 (C-20); (+)-HRESIMS $m / 2.711 .4333[\mathrm{M}+\mathrm{H}]^{+}$(calcd for $\mathrm{C}_{40} \mathrm{H}_{55} \mathrm{~N}_{8} \mathrm{O}_{4}, 711.4341$ ).

5.2.5.37. $N^{l}, N^{I^{\prime}}$-((Decane-1,10-diylbis(azanediyl))bis(propane-3,1-diyl))bis $\left(N^{4}-(\right.$ quinolin-8-yl)succinamide) (52) Using general procedure $\mathrm{C}$, di-tert-butyl decane-1,10-diylbis((3-(4-oxo-4-(quinolin-8ylamino)butanamido)propyl)carbamate) $\left(41 \mathrm{mg}, 0.044 \mathrm{mmol}\right.$,) was treated with $\mathrm{TFA}$ in $\mathrm{CH}_{2} \mathrm{Cl}_{2}$. The solvent was removed under reduced pressure and the crude product was purified with $\mathrm{C} 8$ reversed-phased column chromatography eluting with $30 \% \mathrm{MeOH} / \mathrm{H}_{2} \mathrm{O}(0.05 \%$ TFA) to yield the product as a purple oil (40 mg, $93 \%)$. $\mathrm{R}_{f}\left(\mathrm{MeOH} / 10 \% \mathrm{HCl}_{(\mathrm{aq})}, 9: 1, \mathrm{C}_{18}\right) \quad 0.73$; IR (ATR) $v_{\max } 2935,1680,1528,1201,1132,829,798,721 \mathrm{~cm}^{-1} ;{ }^{1} \mathrm{H}$ NMR (400 MHz, CD 30 OD) $\delta 8.92(2 \mathrm{H}, \mathrm{dd}, J=4.5,1.5 \mathrm{~Hz}, \mathrm{H}-2), 8.53(2 \mathrm{H}, \mathrm{dd}, J=7.5,1.0 \mathrm{~Hz}, \mathrm{H}-7), 8.43(2 \mathrm{H}$, dd, $J=8.5,1.5 \mathrm{~Hz}, \mathrm{H}-4), 7.70$ (2H, dd, $J=8.5,1.5 \mathrm{~Hz}, \mathrm{H}-5), 7.65-7.57$ (2H, m, H-3, H-6), 3.37-3.34 (4H, m, $\mathrm{H}_{2}-15$ ), 3.03 (4H, t, $J=6.75 \mathrm{~Hz}, \mathrm{H}_{2}-17$ ), 2.97-2.94 (4H, m, H ${ }_{2}-12$ ), 2.79 (4H, t, $\left.J=7.75 \mathrm{~Hz}, \mathrm{H}_{2}-19\right) 2.69-2.66$ (4H, m, $\left.\mathrm{H}_{2}-11\right), 1.91-1.85$ (4H, m, H $\left.\mathrm{H}_{2}-16\right), 1.51-1.43$ (4H, m, $\left.\mathrm{H}_{2}-20\right), 1.00-0.93\left(12 \mathrm{H}, \mathrm{m}, \mathrm{H}_{2}-21, \mathrm{H}_{2}-22, \mathrm{H}_{2}-23\right)$; ${ }^{13} \mathrm{C}$ NMR (100 MHz, CD 3 OD) $\delta 176.5$ (C-13), 173.3 (C-10), 149.6 (C-2), 139.4 (C-8a), 139.0 (C-4), 135.2 (C8), 129.9 (C-4a), 128.4 (C-6), 124.0 (C-5), 123.2, (C-3), 119.5 (C-7), 49.1 (C-19), 45.9 (C-17), 36.4 (C-15), 32.8 (C-12), 31.3 (C-11), 30.2 (C-23), 30.0 (C-22) 27.9 (C-16), 27.3 (C-21), 27.2 C-20); (+)-HRESIMS m/z $739.4675[\mathrm{M}+\mathrm{H}]^{+}$(calcd for $\mathrm{C}_{42} \mathrm{H}_{59} \mathrm{~N}_{8} \mathrm{O}_{4}, 739.4653$ ).

\subsubsection{8. $N^{1}, N^{4}$-Bis(3-(4-oxo-4-(quinolin-2-ylamino)butanamido)propyl)butane-1,4-diaminium (53)}

Following general procedure $\mathrm{C}$, di-tert-butyl butane-1,4-diylbis((3-(4-oxo-4(quinoline-2ylamino)butanamido)propyl)carbamate) $\left(15 \mathrm{mg}, 0.018 \mathrm{mmol}\right.$ ) was reacted with TFA in $\mathrm{CH}_{2} \mathrm{Cl}_{2}$. Purification was achieved by $\mathrm{C}_{8}$ reversed-phase column chromatography $50 \% \mathrm{MeOH}: \mathrm{H}_{2} \mathrm{O}(0.05 \%$ TFA), affording the title compound as a clear oil in quantitative yield. $\mathrm{R}_{f}\left(\mathrm{MeOH}: 10 \% \mathrm{HCl}, 7: 3, \mathrm{C}_{18}\right)$ 0.77; IR (ATR) $v_{\max } 3387,3282$, $3064,2847,1673,1500,1427,1199,1175,1127,1024,719 \mathrm{~cm}^{-1} ;{ }^{1} \mathrm{H}$ NMR (400 MHz, DMSO- $\left.d_{6}\right) \delta 10.85(2 \mathrm{H}$, br s, NH-9), 8.51-8.40 (4H, m, NH $\left.\mathrm{N}_{2}-18\right), 8.33(2 \mathrm{H}, \mathrm{d}, J=9.0 \mathrm{~Hz}, \mathrm{H}-4), 8.26(2 \mathrm{H}, \mathrm{d}, J=9.0 \mathrm{~Hz}, \mathrm{H}-3), 8.11(2 \mathrm{H}$, t, $J=5.8 \mathrm{~Hz}, \mathrm{NH}-14), 7.90(2 \mathrm{H}, \mathrm{d}, J=8.4 \mathrm{~Hz}, \mathrm{H}-5), 7.80(2 \mathrm{H}, \mathrm{d}, J=8.4 \mathrm{~Hz}, \mathrm{H}-8), 7.71(2 \mathrm{H}, \mathrm{ddd}, J=8.4,7.5$, $1.5 \mathrm{~Hz}, \mathrm{H}-7), 7.48$ (2H, ddd, $J=8.4,7.5,1.5 \mathrm{~Hz}, \mathrm{H}-6), 3.13$ (4H, dt, $\left.J=6.5,5.8 \mathrm{~Hz}, \mathrm{H}_{2}-15\right), 2.92-2.81(8 \mathrm{H}, \mathrm{m}$, $\left.\mathrm{H}_{2}-17, \mathrm{H}_{2}-19\right), 2.72\left(4 \mathrm{H}, \mathrm{t}, J=6.8 \mathrm{~Hz}, \mathrm{H}_{2}-11\right.$ or $\left.\mathrm{H}_{2}-12\right), 2.44\left(4 \mathrm{H}, \mathrm{t}, J=6.8 \mathrm{~Hz}, \mathrm{H}_{2}-11\right.$ or $\left.\mathrm{H}_{2}-12\right), 1.71(4 \mathrm{H}, \mathrm{tt}, J$ $\left.=7.2,6.8 \mathrm{~Hz}, \mathrm{H}_{2}-16\right), 1.62-1.53\left(4 \mathrm{H}, \mathrm{m}, \mathrm{H}_{2}-20\right) ;{ }^{13} \mathrm{C}$ NMR $\left(100 \mathrm{MHz}\right.$, DMSO- $\left.d_{6}\right) \delta 172.04(\mathrm{C}-10$ or $\mathrm{C}-$ 
13), 171.98 (C-10 or C-13), 151.6 (C-2), 146.2 (C-8a), 138.3 (C-4), 130.0 (C-7), 127.7 (C-5), 126.8 (C-8), 125.5 (C-4a), 124.9 (C-6), 114.2 (C-3), 46.1 (C-19), 44.5 (C-17), 35.5 (C-15), 31.4, 29.8 (C-11, C-12), 26.1 (C-16), 22.6 (C-20); (+)-HRESIMS $m / z 655.3736[\mathrm{M}+\mathrm{H}]^{+}$(calcd for $\mathrm{C}_{36} \mathrm{H}_{47} \mathrm{~N}_{8} \mathrm{O}_{4}, 655.3715$ ).

\subsubsection{9. $N^{l}, N^{I 0}$-Bis(3-(4-oxo-4-(quinolin-2-ylamino)butanamido)propyl)decane-1,10-diaminium (54)}

Following general procedure $\mathrm{C}$, di-tert-butyl decane-1,10-diylbis((3-(4-oxo-4-(quinolin-2-ylamino)butanamido) propyl)carbamate) $(15 \mathrm{mg}, 0.016 \mathrm{mmol})$ was reacted with TFA in $\mathrm{CH}_{2} \mathrm{Cl}_{2}$. Purification was achieved by $\mathrm{C}_{8}$ reversed-phase column chromatography $50 \% \mathrm{MeOH}: \mathrm{H}_{2} \mathrm{O}(0.05 \%$ TFA) affording the title compound as a white gum (12 mg, 78\%). $\mathrm{R}_{f}$ (MeOH:10\% HCl, 7:3, $\mathrm{C}_{18}$ ) 0.77; IR (ATR) $v_{\max } 3315,3054,2930,2856,1617,1427$, $1198,1173,1126,719 \mathrm{~cm}^{-1} ;{ }^{1} \mathrm{H}$ NMR (400 MHz, DMSO- $\left.d_{6}\right) \delta 10.91(2 \mathrm{H}, \mathrm{br} \mathrm{s}, \mathrm{NH}-9), 8.45-8.36\left(4 \mathrm{H}, \mathrm{m}, \mathrm{NH}_{2^{-}}\right.$ 18), 8.33 (2H, d, $J=9.0 \mathrm{~Hz}, \mathrm{H}-4), 8.26$ (2H, d, $J=9.0 \mathrm{~Hz}, \mathrm{H}-3), 8.15$ (2H, t, $J=5.8 \mathrm{~Hz}, \mathrm{NH}-14), 7.90$ (2H, dd, $J=8.2,1.6 \mathrm{~Hz}, \mathrm{H}-5), 7.80(2 \mathrm{H}, \mathrm{d}, J=8.2 \mathrm{~Hz}, \mathrm{H}-8), 7.70(2 \mathrm{H}, \mathrm{ddd}, J=8.2,6.8,1.6 \mathrm{~Hz}, \mathrm{H}-7), 7.48$ (2H, ddd, $J=$ 8.2, 6.8, $1.6 \mathrm{~Hz}, \mathrm{H}-6), 3.15\left(4 \mathrm{H}, \mathrm{dt}, J=6.5,5.8 \mathrm{~Hz}, \mathrm{H}_{2}-15\right), 2.88\left(4 \mathrm{H}, \mathrm{tt}, J=7.2,6.0 \mathrm{~Hz}, \mathrm{H}_{2}-17\right), 2.82-2.75(4 \mathrm{H}$, $\left.\mathrm{m}, \mathrm{H}_{2}-19\right), 2.75-2.70\left(4 \mathrm{H}, \mathrm{m}, \mathrm{H}_{2}-11\right.$ or $\left.\mathrm{H}_{2}-12\right), 2.45\left(4 \mathrm{H}, \mathrm{t}, J=6.6 \mathrm{~Hz}, \mathrm{H}_{2}-11\right.$ or $\left.\mathrm{H}_{2}-12\right), 1.72(4 \mathrm{H}, \mathrm{tt}, J=6.8,7.2$ $\left.\mathrm{Hz}, \mathrm{H}_{2}-16\right), 1.47\left(4 \mathrm{H}, \mathrm{tt}, J=7.5,7.0 \mathrm{~Hz}, \mathrm{H}_{2}-20\right), 1.16-0.99\left(12 \mathrm{H}, \mathrm{m}, \mathrm{H}_{2}-21, \mathrm{H}_{2}-22, \mathrm{H}_{2}-23\right) ;{ }^{13} \mathrm{C}$ NMR (100 MHz, DMSO- $d_{6}$ ) $\delta 172.3$ (C-10 or C-13), 172.2 (C-10 or C-13), 151.6 (C-2), 146.0 (C-8a), 138.5 (C-4), 130.1 (C-7), 127.8 (C-5), 126.6 (C-8), 125.5 (C-4a), 124.9 (C-6), 114.2 (C-3), 46.9 (C-19), 44.4 (C-17), 35.4 (C-15), 28.7, 28.5, 25.9 (C-21, C-22, C-23), 26.2 (C-16), 25.5 (C-20); (+)-HRESIMS m/z 739.4648 [M + H] (calcd for $\left.\mathrm{C}_{42} \mathrm{H}_{59} \mathrm{~N}_{8} \mathrm{O}_{4}, 739.4654\right)$.

5.2.5.40. $N^{l}, N^{I^{\prime}}-\left((\right.$ Butane-1,4-diylbis(azanediyl) $)$ bis(propane-3,1-diyl))bis $\left(N^{4}-(\right.$ quinolin-5-yl $)$ succinamide) (55)

Using general procedure C, di-tert-butyl butane-1,4-diylbis((3-(4-oxo-4(quinoline-5ylamino)butanamido)propyl)carbamate) (16 mg, $0.019 \mathrm{mmol}$ ) was treated with TFA in $\mathrm{CH}_{2} \mathrm{Cl}_{2}$. The crude product was purified with $\mathrm{C}_{8}$ reversed-phased column chromatography eluting with $50 \% \mathrm{MeOH} / \mathrm{H}_{2} \mathrm{O}(0.05 \%$ TFA) to yield the product as an orange oil $(14 \mathrm{mg}, 82 \%) . \mathrm{R}_{f}\left(\mathrm{MeOH} / 10 \% \mathrm{HCl}_{(\mathrm{aq}}, 9: 1, \mathrm{C}_{18}\right) 0.64$; IR (ATR) $v_{\max }$ $3285,1675,1540,1202,1131,801,722 \mathrm{~cm}^{-1} ;{ }^{1} \mathrm{H}$ NMR (400 MHz, $\left.\mathrm{CD}_{3} \mathrm{OD}\right) \delta 9.20-9.15$ (4H, m, H-2, H-4), 8.08-8.03 (6H, m, H-6, H-7, H-8), 7.99-7.97 (2H, m, H-3), 3.35-3.30 (4H, m, $\mathrm{H}_{2}-157$ ), 3.02 (4H, t, J = 7.5 Hz, $\left.\mathrm{H}_{2}-17\right), 2.92\left(8 \mathrm{H}, \mathrm{t}, J=6.5 \mathrm{~Hz}, \mathrm{H}_{2}-12, \mathrm{H}_{2}-19\right), 2.67\left(4 \mathrm{H}, \mathrm{t}, J=6.8 \mathrm{~Hz}, \mathrm{H}_{2}-11\right), 1.91-1.85\left(4 \mathrm{H}, \mathrm{m}, \mathrm{H}_{2}-16\right), 1.70-$ $1.66\left(4 \mathrm{H}, \mathrm{m}, \mathrm{H}_{2}-20\right) ;{ }^{13} \mathrm{C}$ NMR (100 MHz, $\left.\mathrm{CD}_{3} \mathrm{OD}\right) \delta 175.8$ (C-13), 174.4 (C-10), 147.2 (C-2), 142.3 (C-8a), 141.6 (C-4), 136.5 (C-5), 135.2 (C-7), 125.7 (C-4a), 125.6 (C-8), 122.4 (C-3), 120.5 (C-6), 48.0 (C-19), 46.3 (C17), 36.9 (C-15), 32.2 (C-12), 31.4 (C-11), 27.6 (C-16), 24.2 (C-20); (+)-HRESIMS m/z $655.3700[\mathrm{M}+\mathrm{H}]^{+}$ (calcd for $\mathrm{C}_{36} \mathrm{H}_{47} \mathrm{~N}_{8} \mathrm{O}_{4}, 655.3715$ ).

5.2.5.41. $N^{l}, N^{I^{\prime}}-\left(\left(\right.\right.$ Decane-1,10-diylbis(azanediyl))bis(propane-3,1-diyl))bis $\left(N^{4}-(\right.$ quinolin-5-yl)succinamide) (56)

Using general procedure $\mathrm{C}$, di-tert-butyl decane-1,10-diylbis((3-(4-oxo-4-(quinolin-5ylamino)butanamido)propyl)carbamate) (31 $\mathrm{mg}, 0.033 \mathrm{mmol}$ ) was treated with TFA in $\mathrm{CH}_{2} \mathrm{Cl}_{2}$. The solvent 
was removed under reduced pressure and the product was purified with $\mathrm{C}_{8}$ reversed-phased column chromatography eluting with $50 \% \mathrm{MeOH} / \mathrm{H}_{2} \mathrm{O}(0.05 \%$ TFA) to yield the product as a yellow oil $(31 \mathrm{mg}, 97 \%)$. $\mathrm{R}_{f}\left(\mathrm{MeOH} / 10 \% \mathrm{HCl}_{(\mathrm{aq})}, 9: 1, \mathrm{C}_{18}\right)$ 0.79; IR (ATR) $v_{\max } 3279,1677,1538,1202,1133,802,721 \mathrm{~cm}^{-1} ;{ }^{1} \mathrm{H} \mathrm{NMR}$ (400 MHz, CD 3 OD) $\delta$ 9.17-9.14 (4H, m, H-2, H-4), 8.06-8.03 (6H, m, H-6, H-7, H-8), 7.98-7.95 (2H, m, H-3), 3.35-3.30 (4H, m, $\left.\mathrm{H}_{2}-15\right), 3.02\left(4 \mathrm{H}, \mathrm{t}, J=7.5 \mathrm{~Hz}, \mathrm{H}_{2}-17\right), 2.92\left(4 \mathrm{H}, \mathrm{t}, J=6.5 \mathrm{~Hz}, \mathrm{H}_{2}-12\right), 2.86(4 \mathrm{H}, \mathrm{t}, J=8.0$ $\left.\mathrm{Hz}, \mathrm{H}_{2}-19\right)$, 2.69-2.66 (4H, m, H $\left.{ }_{2}-11\right), 1.91-1.84$ (4H, m, $\left.\mathrm{H}_{2}-16\right), 1.59-1.55$ (4H, m, H $\left.{ }_{2}-20\right), 1.20$ (12H, br s, $\left.\mathrm{H}_{2}-21, \mathrm{H}_{2}-22, \mathrm{H}_{2}-23\right) ;{ }^{13} \mathrm{C}$ NMR (100 MHz, CD $\left.3 \mathrm{OD}\right) \delta 175.9$ (C-13), 174.4 (C-10), 148.3 (C-2), 143.7 (C-8a), 140.0 (C-4), 136.1 (C-5), 134.0 (C-7), 125.6 (C-4a), 125.0 (C-8), 122.4, (C-3), 122.2 (C-6), 49.1 (C-19), 46.1 (C-17), 36.8 (C-15), 32.1 (C-12), 31.3 (C-11), 30.3 (C-23), 30.1 (C-22) 27.7 (C-16), 27.4 (C-20), 27.2 (C-21); (+)-HRESIMS $m / z, 739.4657[\mathrm{M}+\mathrm{H}]^{+}$(calcd for $\mathrm{C}_{42} \mathrm{H}_{59} \mathrm{~N}_{8} \mathrm{O}_{4}, 739.4653$ ).

5.2.5.42. $N^{1}, N^{1}-((B u t a n e-1,4-d i y l b i s($ azanediyl $))$ bis(propane-3,1-diyl $\left.)\right)$ bis $\left(N^{4}\right.$-(quinolin-6-yl) succinamide) (57)

Using general procedure C, di-tert-butyl butane-1,4-diylbis((3-(4-oxo-4-(quinolin-6ylamino)butanamido)propyl)carbamate) $(18 \mathrm{mg}, 0.021 \mathrm{mmol})$ was treated with $\mathrm{TFA}$ in $\mathrm{CH}_{2} \mathrm{Cl}_{2}$. The solvent was removed under reduced pressure and the crude product was purified with C8 reversed-phased column chromatography eluting with $50 \% \mathrm{MeOH} / \mathrm{H}_{2} \mathrm{O}(0.05 \% \mathrm{TFA})$ to yield the product as an orange oil $(15 \mathrm{mg}, 83 \%)$. $\mathrm{R}_{f}\left(\mathrm{MeOH} / 10 \% \mathrm{HCl}_{(\mathrm{aq})}, 9: 1, \mathrm{C}_{18}\right)$ 0.53; IR (ATR) $v_{\max } 3287,3082,2823,1672,1558,1200,1131,835,800$, $721 \mathrm{~cm}^{-1}$; ${ }^{1} \mathrm{H}$ NMR (400 MHz, CD 3 OD) $\delta 9.03(2 \mathrm{H}, \mathrm{dd}, J=5.5,1.5 \mathrm{~Hz}, \mathrm{H}-2), 8.98$ (2H, d, $\left.J=8.5 \mathrm{~Hz}, \mathrm{H}-4\right)$, 8.67 (2H, d, J = 1.5 Hz, H-5), 8.20-8.14 (4H, m, H-7, H-8), 7.99-7.96 (2H, m, H-3), 3.35-3.30 (4H, m, H2-15), $3.05\left(4 \mathrm{H}, \mathrm{t}, J=7.1 \mathrm{~Hz}, \mathrm{H}_{2}-17\right), 2.98-2.85\left(4 \mathrm{H}, \mathrm{m}, \mathrm{H}_{2}-19\right), 2.83\left(4 \mathrm{H}, \mathrm{t}, J=6.5 \mathrm{~Hz}, \mathrm{H}_{2}-12\right) 2.63(4 \mathrm{H}, \mathrm{t}, J=6.7$ $\left.\mathrm{Hz}, \mathrm{H}_{2}-11\right), 1.93-1.86$ (4H, m, H $\left.2-16\right), 1.73-1.69$ (4H, m, $\left.\mathrm{H}_{2}-20\right) ;{ }^{13} \mathrm{C}$ NMR (100 MHz, CD 3 OD) $\delta 176.0$ (C-13), 173.7 (C-10), 146.6 (C-4), 144.4 (C-2), 141.4 (C-6), 136.7 (C-8a), 131.5 (C-4a), 129.4 (C-7), 123.3 (C-3), 123.0 (C-8), 116.5 (C-5), 48.0 (C-19), 46.1 (C-17), 36.7 (C-15), 32.7 (C-12), 31.2 (C-11), 27.7 (C-16), 24.2 (C-20); (+)-HRESIMS $m / z, 655.3703[\mathrm{M}+\mathrm{H}]^{+}$(calcd for $\mathrm{C}_{36} \mathrm{H}_{47} \mathrm{~N}_{8} \mathrm{O}_{4}, 655.3715$ ).

5.2.5.43. $N^{1}, N^{l^{\prime}}-(($ Decane-1,10-diylbis(azanediyl $))$ bis(propane-3,1-diyl $\left.)\right)$ bis $\left(N^{4}\right.$-(quinolin-6-yl $)$ succinamide) (58) Using general procedure C, di-tert-butyl decane-1,10-diylbis((3-(4-oxo-4-(quinolin-6ylamino)butanamido)propyl)carbamate) $\left(33 \mathrm{mg}, 0.035 \mathrm{mmol}\right.$ ) was treated with TFA in $\mathrm{CH}_{2} \mathrm{Cl}_{2}$. The solvent was removed under reduced pressure and the crude product was purified with $\mathrm{C} 8$ reversed-phased column chromatography eluting with $50 \% \mathrm{MeOH} / \mathrm{H}_{2} \mathrm{O}(0.05 \%$ TFA) to yield the product as a yellow oil $(29 \mathrm{mg}, 85 \%)$. $\mathrm{R}_{f}\left(\mathrm{MeOH} / 10 \% \mathrm{HCl}_{(\mathrm{aq})}, 9: 1, \mathrm{C}_{18}\right)$ 0.73; IR (ATR) $v_{\max } 3273,1679,1538,1202,1133,800,723 \mathrm{~cm}^{-1} ;{ }^{1} \mathrm{H} \mathrm{NMR}$ $\left(400 \mathrm{MHz}, \mathrm{CD}_{3} \mathrm{OD}\right) \delta 9.04(2 \mathrm{H}, \mathrm{dd}, J=5.0,1.0 \mathrm{~Hz}, \mathrm{H}-2), 8.97(2 \mathrm{H}, \mathrm{d}, J=8.0 \mathrm{~Hz}, \mathrm{H}-4), 8.70(2 \mathrm{H}, \mathrm{d}, J=2.0 \mathrm{~Hz}$, H-5), 8.21-8.14 (4H, m, H-7, H-8), 7.99-7.96 (2H, m, H-3), 3.36-3.30 (4H, m, H2-15), 3.05 (4H, t, J= $7.0 \mathrm{~Hz}$, $\left.\mathrm{H}_{2}-17\right), 2.86\left(8 \mathrm{H}, \mathrm{t}, J=6.5 \mathrm{~Hz}, \mathrm{H}_{2}-12, \mathrm{H}_{2}-20\right), 2.66-2.62$ (4H, m, H $\left.\mathrm{H}_{2}-11\right), 1.93-1.86\left(4 \mathrm{H}, \mathrm{m}, \mathrm{H}_{2}-16\right), 1.61-1.54$ (4H, m, H $2-20), 1.20-1.08$ (12H, m, H $\left.2-21, \mathrm{H}_{2}-22, \mathrm{H}_{2}-23\right) ;{ }^{13} \mathrm{C}$ NMR (100 MHz, CD 3 OD) $\delta 176.1$ (C-13), 173.7 (C-10), 146.0 (C-4), 144.8 (C-2), 141.2 (C-6), 137.4 (C-8a), 131.4 (C-4a), 129.1 (C-7), 123.6 (C-8), 123.3 (C3), 116.5 (C-5), 49.0 (C-19), 46.0 (C-17), 36.6 (C-15), 32.5 (C-12), 31.0 (C-11), 30.2 (C-23), 30.1 (C-22) 27.7 (C-16), $27.4(\mathrm{C}-20), 27.2(\mathrm{C}-21)$; (+)-HRESIMS $m / z$ 739.4656 [M + H] $]^{+}$(calcd for $\mathrm{C}_{42} \mathrm{H}_{59} \mathrm{~N}_{8} \mathrm{O}_{4}, 739.4653$ ). 
Following general procedure $\mathrm{C}$, reaction of di-tert-butyl butane-1,4-diylbis((3-(4-oxo-4-((pyridin-2ylmethyl)amino)butanamido)propyl)carbamate) (38 $\mathrm{mg}, 0.049 \mathrm{mmol}$ ) with TFA in $\mathrm{CH}_{2} \mathrm{Cl}_{2}$ afforded the pure compound as a clear oil. Purification was achieved by $\mathrm{C}_{8}$ reversed-phase column chromatography eluting with $50 \% \mathrm{MeOH} / \mathrm{H}_{2} \mathrm{O}(0.05 \% \mathrm{TFA})(38 \mathrm{mg}, 100 \%) . \mathrm{R}_{t}=4.80 \mathrm{mins}$; IR (ATR) $v_{\max } 3301,2935,2818,2127,1671$, $1645,1196,1177,1122 \mathrm{~cm}^{-1}$; ${ }^{1} \mathrm{H}$ NMR (400 MHz, DMSO- $\left.d_{6}\right) \delta 8.66-8.62(2 \mathrm{H}, \mathrm{m}, \mathrm{H}-6), 8.63-8.57(12 \mathrm{H}, \mathrm{m}$, NH-8, $\left.\mathrm{NH}_{2}-17\right), 8.10-8.04$ (4H, m, H-4, NH-13), 7.56-7.51 (4H, m, H-5, H-3), 4.46 (4H, d, J = 5.7 Hz, H ${ }_{2}-7$ ), $3.12\left(4 \mathrm{H}, \mathrm{dt}, J=6.6,6.2 \mathrm{~Hz}, \mathrm{H}_{2}-14\right), 2.93-2.84\left(8 \mathrm{H}, \mathrm{m}, \mathrm{H}_{2}-16, \mathrm{H}_{2}-18\right), 2.46\left(4 \mathrm{H}, \mathrm{t}, J=6.8 \mathrm{~Hz}, \mathrm{H}_{2}-10\right.$ or H$\left._{2}-11\right)$, $2.36\left(4 \mathrm{H}, \mathrm{t}, J=6.8 \mathrm{~Hz}, \mathrm{H}_{2}-10\right.$ or $\left.\mathrm{H}_{2}-11\right), 1.71\left(4 \mathrm{H}, \mathrm{tt}, J=7.5,6.6 \mathrm{~Hz}, \mathrm{H}_{2}-15\right), 1.64-1.58\left(4 \mathrm{H}, \mathrm{m}, \mathrm{H}_{2}-19\right) ;{ }^{13} \mathrm{C}$ NMR (100 MHz, DMSO- $\left.d_{6}\right) \delta 172.1$ (C-9 or C-12), $172.0\left(\mathrm{C}-9\right.$ or C-12), $158.5\left(\mathrm{q},{ }^{2} \mathrm{~J}_{\mathrm{FC}}=34.3 \mathrm{~Hz}, \mathrm{CF}_{3} \mathrm{COO}\right)$ 157.1 (C-2), 145.8 (C-6), 140.6 (C-4), 123.4 (C-5), 122.6 (C-3), 46.1 (C-18), 44.6 (C-16), 42.6 (C-7), 35.6 (C14), 30.4 (C-10, C-11), 26.1 (C-15), 22.7 (C-19); (+)-HRESIMS m/z 607.3715 [M + Na $]^{+}$(calcd for $\left.\mathrm{C}_{30} \mathrm{H}_{48} \mathrm{~N}_{8} \mathrm{NaO}_{4}, 607.3969\right)$.

5.2.5.45 $N^{1}, N^{I^{\prime}}-\left((\right.$ Decane-1,10-diylbis(azanediyl) $)$ bis(propane-3,1-diyl))bis $\left(N^{4}\right.$-(pyridin-2ylmethyl)succinamide) $(\mathbf{6 0})$

Following general procedure $\mathrm{C}$, reaction of di-tert-butyl decane-1,10-diylbis((3-(4-oxo-4-((pyridin-2ylmethyl)amino)butanamido)propyl)carbamate) $\left(20 \mathrm{mg}, 0.023 \mathrm{mmol}\right.$ ) with TFA in $\mathrm{CH}_{2} \mathrm{Cl}_{2}$ afforded the pure compound as a clear oil. Purification was achieved by $\mathrm{C}_{8}$ reversed-phase column chromatography eluting with $25 \% \mathrm{MeOH} / \mathrm{H}_{2} \mathrm{O}(0.05 \% \mathrm{TFA})(8 \mathrm{mg}, 40 \%) . \mathrm{R}_{t}=5.36 \mathrm{mins}$; IR (ATR) $v_{\max } 3285,2931,2850,1668,1198$, $1175,1128,1025,719 \mathrm{~cm}^{-1} ;{ }^{1} \mathrm{H}$ NMR $\left(400 \mathrm{MHz}\right.$, DMSO- $\left.d_{6}\right) \delta 8.64-8.61(2 \mathrm{H}, \mathrm{m}, \mathrm{H}-6), 8.58(2 \mathrm{H}, \mathrm{t}, J=5.8 \mathrm{~Hz}$, NH-8), 8.49-8.31 (4H, m, NH-17), 8.08-8.02 (4H, m, NH-13, H-4), 7.55-7.49 (4H, m, H-5, H-3), 4.44 (4H, d, $J$ $\left.=5.7 \mathrm{~Hz}, \mathrm{H}_{2}-7\right), 3.12\left(4 \mathrm{H}, \mathrm{dt}, J=6.1,6.4 \mathrm{~Hz}, \mathrm{H}_{2}-14\right), 2.93-2.78\left(8 \mathrm{H}, \mathrm{m}, \mathrm{H}_{2}-16, \mathrm{H}_{2}-18\right), 2.49-2.42\left(4 \mathrm{H}, \mathrm{m}, \mathrm{H}_{2^{-}}\right.$ 10 or $\left.\mathrm{H}_{2}-11\right), 2.39-2.30\left(4 \mathrm{H}, \mathrm{m}, \mathrm{H}_{2}-10\right.$ or $\left.\mathrm{H}_{2}-11\right), 1.70\left(4 \mathrm{H}, \mathrm{tt}, J=7.3,6.4 \mathrm{~Hz}, \mathrm{H}_{2}-15\right), 1.59-1.49\left(4 \mathrm{H}, \mathrm{m}, \mathrm{H}_{2}-\right.$ 19), 1.33-1.21 (12H, m, $\left.\mathrm{H}_{2}-20, \mathrm{H}_{2}-21, \mathrm{H}_{2}-22\right) ;{ }^{13} \mathrm{C}$ NMR (100 MHz, DMSO- $\left.d_{6}\right) \delta 172.1$ (C-9 or C-12), 172.0 (C-9 or C-12), 157.2 (C-2), 146.0 (C-6), 140.2 (C-4), 123.2, 122.4 (C-5, C-3), 46.8 (C-18), 44.5 (C-16), 42.7 (C7), 35.5 (C-14), 30.4 (C-10, C-11), 28.7, 28.4, 25.5 (C-20, C-21, C-22), 26.1 (C-15), 25.9 (C-19); (+)-HRESIMS $\mathrm{m} / \mathrm{z} 667.4654[\mathrm{M}+\mathrm{H}]^{+}$(calcd for $\mathrm{C}_{36} \mathrm{H}_{59} \mathrm{~N}_{8} \mathrm{O}_{4}, 667.4647$ ).

\subsubsection{6. $N^{l}, N^{4}$-Bis(3-(4-oxo-4-((pyridin-3-ylmethyl)amino)butanamido)propyl)butane-1,4-diaminium (61)}

Following general procedure $\mathrm{C}$, reaction of di-tert-butyl butane-1,4-diylbis((3-(4-oxo-4-((pyridin-3ylmethyl)amino)butanamido)propyl)carbamate) $\left(29 \mathrm{mg}, 0.037 \mathrm{mmol}\right.$ ) with TFA in $\mathrm{CH}_{2} \mathrm{Cl}_{2}$ afforded the pure compound as a clear oil. Purification was achieved by $\mathrm{C}_{8}$ reversed-phase column chromatography eluting with $50 \% \mathrm{MeOH} / \mathrm{H}_{2} \mathrm{O}\left(0.05 \% \mathrm{TFA}\right.$ ) (38 mg, 100\%). $\mathrm{R}_{t}=4.73 \mathrm{mins}$; IR (ATR) $v_{\max } 3278,3061,2824,2130,1668$, $1549,1197,1175,1025 \mathrm{~cm}^{-1} ;{ }^{1} \mathrm{H}$ NMR (400 MHz, DMSO- $\left.d_{6}\right) \delta 8.75-8.67$ (4H, m, H-2, H-6), 8.66-8.56 (6H, m, NH-8, $\left.\mathrm{NH}_{2}-17\right), 8.17(2 \mathrm{H}, \mathrm{d}, J=7.9 \mathrm{~Hz}, \mathrm{H}-4), 8.05(2 \mathrm{H}, \mathrm{t} J=5.8 \mathrm{~Hz}, \mathrm{NH}-13), 7.80(2 \mathrm{H}, \mathrm{dd}, J=7.9,5.6 \mathrm{~Hz}$, 
H-5), 4.39 (4H, d, $\left.J=5.8 \mathrm{~Hz}, \mathrm{H}_{2}-7\right), 3.11$ (4H, dt, $\left.J=6.4,6.2 \mathrm{~Hz}, \mathrm{H}_{2}-14\right), 2.94-2.83\left(8 \mathrm{H}, \mathrm{m}, \mathrm{H}_{2}-16, \mathrm{H}_{2}-18\right)$, 2.45-2.39 (4H, m, $\mathrm{H}_{2}-10$, or $\left.\mathrm{H}_{2}-11\right), 2.38-2.33$ (4H, m, $\mathrm{H}_{2}-10$ or $\left.\mathrm{H}_{2}-11\right), 1.71$ (4H, tt, J = 7.5, 6.4 Hz, $\left.\mathrm{H}_{2}-15\right)$, 1.64-1.58 (4H, m, $\left.\mathrm{H}_{2}-19\right)$ ) ${ }^{13} \mathrm{C}$ NMR (100 MHz, DMSO-d $)_{6} \delta 172.0$ (C-9 or C-12), 171.9 (C-9 or C-12), 158.2 $\left(\mathrm{q},{ }^{2} \mathrm{~J}_{\mathrm{FC}}=34.5 \mathrm{~Hz}, \mathrm{CF}_{3} \mathrm{COO}\right) 143.3,143.1$ (C-2, C-6), 141.2 (C-4), 138.2 (C-3), 125.7 (C-5), 46.1 (C-18), 44.6 (C-16), 39.1 (C-7), 35.6 (C-14), 30.4 (C-10, C-11), 26.1 (C-15), 22.7 (C-19); (+)-HRESIMS m/z 585.3864 [M + $\mathrm{H}]^{+}$(calcd for $\mathrm{C}_{30} \mathrm{H}_{49} \mathrm{~N}_{8} \mathrm{O}_{4}, 585.3861$ ).

\subsubsection{7. $N^{1}, N^{10}$-Bis(3-(4-oxo-4-((pyridin-3-ylmethyl)amino)butanamido)propyl)decane-1,10-diaminium (62)}

Following general procedure $\mathrm{C}$, reaction of di-tert-butyl decane-1,10-diylbis((3-(4-oxo-4-((pyridin-3ylmethyl)amino)butanamido)propyl)carbamate) (21 mg, $0.024 \mathrm{mmol}$ ) with TFA in $\mathrm{CH}_{2} \mathrm{Cl}_{2}$ afforded the title compound as a clear oil. Purification was achieved by $\mathrm{C}_{8}$ reversed-phase column chromatography eluting with $25 \% \mathrm{MeOH} / \mathrm{H}_{2} \mathrm{O}(0.05 \% \mathrm{TFA})(16 \mathrm{mg}, 76 \%) . \mathrm{R}_{t}=5.55 \mathrm{mins}$; IR (ATR) $v_{\max } 3283,3062,2933,2859,1670$, 1551, 1199, 1178, $1129 \mathrm{~cm}^{-1} ;{ }^{1} \mathrm{H}$ NMR (400 MHz, DMSO-d $)_{6} \delta$ 8.75-8.67 (4H, m, H-2, H-6), 8.61-8.53 (2H, m, NH-8), 8.46-8.32 (4H, m, NH-17$), 8.28-8.11$ (2H, m, H-4), 8.03 (2H, t, J = 5.8 Hz, NH-13), 7.89-7.75 (2H, m, H-5), 4.42-4.37 (4H, m, H2-7), 3.11 (4H, dt, J=65, $\left.6.0 \mathrm{~Hz}, \mathrm{H}_{2}-14\right), 2.92-2.79$ (8H, m, H $\left.\mathrm{H}_{2}-16, \mathrm{H}_{2}-18\right), 2.45-$ $2.40\left(4 \mathrm{H}, \mathrm{m}, \mathrm{H}_{2}-10\right.$ or $\left.\mathrm{H}_{2}-11\right), 2.38-2.33$ (4H, m, $\mathrm{H}_{2}-10$ or $\left.\mathrm{H}_{2}-11\right), 1.70$ (4H, tt, J = 7.4, $\left.6.5 \mathrm{~Hz}, \mathrm{H}_{2}-15\right), 1.59-$ 1.49 (4H, m, H $\left.\mathrm{H}_{2}-19\right), 1.31-1.21\left(12 \mathrm{H}, \mathrm{m}, \mathrm{H}_{2}-20, \mathrm{H}_{2}-21, \mathrm{H}_{2}-22\right) ;{ }^{13} \mathrm{C}$ NMR (100 MHz, DMSO-d $) \delta 172.0(\mathrm{C}-9$ or C-12), 171.9 (C-9 or C-12), 143.2* $142.3^{*}$ (C-2, C-6), $141.4^{*}$ (C-4), 139.3 (C-3), 125.7 (C-5), 46.8 (C-18), 44.5 (C-16), 39.8 (C-7), 35.5 (C-14), 30.0 (C-10, C-11), 28.7, 28.5, 25.5 (C-20, C-21, C-22), 26.1 (C-15), 25.9 (C-19); (+)-HRESIMS $m / z 667.4641[\mathrm{M}+\mathrm{H}]^{+}$(calcd for $\mathrm{C}_{36} \mathrm{H}_{59} \mathrm{~N}_{8} \mathrm{O}_{4}, 667.4654$ ).

*assigned by HSQC

\subsection{Antimicrobial assays}

The susceptibility of bacterial strains S. aureus (ATCC 25923), E. coli (ATCC 25922) and P. aeruginosa (ATCC 27853) to antibiotics and compounds was determined in microplates using the standard broth dilution method in accordance with the recommendations of the Comité de l'AntibioGramme de la Société Française de Microbiologie (CA-SFM). Briefly, the minimal inhibitory concentrations (MICs) were determined with an inoculum of $10^{5} \mathrm{CFU}$ in $200 \mu \mathrm{L}$ of $\mathrm{MH}$ broth containing two-fold serial dilutions of each drug. The MIC was defined as the lowest concentration of drug that completely inhibited visible growth after incubation for $18 \mathrm{~h}$ at $37^{\circ} \mathrm{C}$. To determine all MICs, the measurements were independently repeated in triplicate.

Additional antimicrobial evaluation against Klebsiella pneumoniae (ATCC 700603), Acinetobacter baumannii (ATCC 19606), Candida albicans (ATCC 90028), and Cryptococcus neoformans (ATCC 208821) was undertaken at the Community for Open Antimicrobial Drug Discovery at The University of Queensland (Australia) according to their standard protocols. ${ }^{31}$ For antimicrobial assays, the tested strains were cultured in either Luria broth (LB) (In Vitro Technologies, USB75852), nutrient broth (NB) (Becton Dickson, 234000), or MHB at $37{ }^{\circ} \mathrm{C}$ overnight. A sample of culture was then diluted 40 -fold in fresh MHB and incubated at $37{ }^{\circ} \mathrm{C}$ for 1.5-2 h. The compounds were serially diluted 2-fold across the wells of 96-well plates (Corning 3641, 
nonbinding surface), with compound concentrations ranging from 0.015 to $64 \mu \mathrm{g} / \mathrm{mL}$, plated in duplicate. The resultant mid $\log$ phase cultures were diluted to the final concentration of $1 \times 106 \mathrm{CFU} / \mathrm{mL}$; then, $50 \mu \mathrm{L}$ was added to each well of the compound containing plates giving a final compound concentration range of 0.008 to $32 \mu \mathrm{g} / \mathrm{mL}$ and a cell density of $5 \times 105 \mathrm{CFU} / \mathrm{mL}$. All plates were then covered and incubated at $37^{\circ} \mathrm{C}$ for $18 \mathrm{~h}$. Resazurin was added at $0.001 \%$ final concentration to each well and incubated for $2 \mathrm{~h}$ before MICs were read by eye.

For the antifungal assay, fungi strains were cultured for 3 days on YPD agar at $30{ }^{\circ} \mathrm{C}$. A yeast suspension of $1 \times$ $10^{6}$ to $5 \times 10^{6} \mathrm{CFU} / \mathrm{mL}$ was prepared from five colonies. These stock suspensions were diluted with yeast nitrogen base (YNB) (Becton Dickinson, 233520) broth to a final concentration of $2.5 \times 10^{3} \mathrm{CFU} / \mathrm{mL}$. The compounds were serially diluted 2-fold across the wells of 96-well plates (Corning 3641, nonbinding surface), with compound concentrations ranging from 0.015 to $64 \mu \mathrm{g} / \mathrm{mL}$ and final volumes of $50 \mu \mathrm{L}$, plated in duplicate. Then, $50 \mu \mathrm{L}$ of the fungi suspension that was previously prepared in YNB broth to the final concentration of 2.5 $\times 10^{3} \mathrm{CFU} / \mathrm{mL}$ was added to each well of the compound-containing plates, giving a final compound concentration range of 0.008 to $32 \mu \mathrm{g} / \mathrm{mL}$. Plates were covered and incubated at $35{ }^{\circ} \mathrm{C}$ for $36 \mathrm{~h}$ without shaking. C. albicans MICs were determined by measuring the absorbance at $\mathrm{OD}_{530}$. For C. neoformans, resazurin was added at $0.006 \%$ final concentration to each well and incubated for a further $3 \mathrm{~h}$ before MICs were determined by measuring the absorbance at $\mathrm{OD}_{570-600}$.

Colistin and vancomycin were used as positive bacterial inhibitor standards for Gram-negative and Grampositive bacteria, respectively. Fluconazole was used as a positive fungal inhibitor standard for C. albicans and C. neoformans. The antibiotics were provided in 4 concentrations, with 2 above and 2 below its MIC value, and plated into the first 8 wells of column 23 of the 384-well NBS plates. The quality control (QC) of the assays was determined by the antimicrobial controls and the Z'-factor (using positive and negative controls). Each plate was deemed to fulfil the quality criteria (pass QC), if the Z'-factor was above 0.4 , and the antimicrobial standards showed full range of activity, with full growth inhibition at their highest concentration, and no growth inhibition at their lowest concentration.

\subsection{Determination of the MICs of antibiotics in the presence of synergising compounds}

Briefly, restoring enhancer concentrations were determined with an inoculum of $5 \times 10^{5} \mathrm{CFU}$ in $200 \mu \mathrm{L}$ of $\mathrm{MH}$ broth containing two-fold serial dilutions of each derivative in the presence of doxycycline at $2 \mu \mathrm{g} / \mathrm{mL}$. The lowest concentration of the polyamine adjuvant that completely inhibited visible growth after incubation for 18 $\mathrm{h}$ at $37^{\circ} \mathrm{C}$ was determined. These measurements were independently repeated in triplicate.

\subsection{Cytotoxicity assays}

The L6 cell line cytotoxicity assays were performed in 96-well microtiter plates, each well containing $100 \mu \mathrm{L}$ of RPMI 1640 medium supplemented with $1 \%$ L-glutamine (200 mM) and 10\% fetal bovine serum, and 4 x $10^{4}$ L6 cells (a primary cell line derived from rat skeletal myoblasts). Serial drug dilutions of seven 3 -fold dilution steps 
covering a range from 90 to $0.123 \mu \mathrm{g} / \mathrm{mL}$ were prepared. After $72 \mathrm{~h}$ of incubation, the plates were inspected under an inverted microscope to assure growth of the controls and sterile conditions. Alamar Blue solution (10 $\mu \mathrm{L}$ ) was then added to each well and the plates incubated for another $2 \mathrm{~h}$. Then the plates were read with a Spectramax Gemini XS microplate fluorometer using an excitation wavelength of $536 \mathrm{~nm}$ and an emission wavelength of $588 \mathrm{~nm}$. Data were analysed using the microplate reader software Softmax Pro. Podophyllotoxin was the reference drug used. ${ }^{32}$

HEK293 cells were counted manually in a Neubauer haemocytometer and plated at a density of 5000 cells/well into each well of the 384-well plates containing the $25 \mathrm{x}(2 \mu \mathrm{L})$ concentrated compounds. The medium used was Dulbecco's modified eagle medium (DMEM) supplemented with $10 \%$ foetal bovine serum (FBS). Cells were incubated together with the compounds for $20 \mathrm{~h}$ at $37{ }^{\circ} \mathrm{C}, 5 \% \mathrm{CO}_{2}$. To measure cytotoxicity, $5 \mu \mathrm{L}$ (equals 100 $\mu \mathrm{M}$ final) of resazurin was added to each well after incubation, and incubated for further $3 \mathrm{~h}$ at $37{ }^{\circ} \mathrm{C}$ with $5 \%$ $\mathrm{CO}_{2}$. After final incubation fluorescence intensity was measured as Fex 560/10 nm, em 590/10 nm $\left(\mathrm{F}_{560 / 590}\right)$ using a Tecan M1000 Pro monochromator plate reader. $\mathrm{CC}_{50}$ values (concentration at 50\% cytotoxicity) were calculated by normalizing the fluorescence readout, with $74 \mu \mathrm{g} / \mathrm{mL}$ tamoxifen as negative control (0\%) and normal cell growth as positive control (100\%). The concentration-dependent percentage cytotoxicity was fitted to a dose response function (using Pipeline Pilot) and $\mathrm{CC}_{50}$ values determined.

\subsection{Haemolytic assays}

Human whole blood was washed three times with 3 volumes of $0.9 \% \mathrm{NaCl}$ and then resuspended in same to a concentration of $0.5 \times 10^{8}$ cells $/ \mathrm{mL}$, as determined by manual cell count in a Neubauer haemocytometer. The washed cells were then added to the 384-well compound-containing plates for a final volume of $50 \mu \mathrm{L}$. After a $10 \mathrm{~min}$ shake on a plate shaker the plates were then incubated for $1 \mathrm{~h}$ at $37^{\circ} \mathrm{C}$. After incubation, the plates were centrifuged at $1000 \mathrm{~g}$ for $10 \mathrm{~min}$ to pellet cells and debris, $25 \mu \mathrm{L}$ of the supernatant was then transferred to a polystyrene 384-well assay plate. Haemolysis was determined by measuring the supernatant absorbance at 405 $\mathrm{mm}\left(\mathrm{OD}_{405}\right)$. The absorbance was measured using a Tecan M1000 Pro monochromator plate reader. $\mathrm{HC}_{10}$ and $\mathrm{HC}_{50}$ (concentration at $10 \%$ and $50 \%$ haemolysis, respectively) were calculated by curve fitting the inhibition values vs. $\log$ (concentration) using a sigmoidal dose-response function with variable fitting values for top, bottom and slope.

\section{Acknowledgements}

We acknowledge financial support from the Catalyst: Seeding Dumont d'Urville NZ-France Science \& Technology Support Programme (19-UOA-057-DDU) provided by the New Zealand Ministry of Business, Innovation and Employment and administered by the Royal Society Te Apārangi, and the Maurice and Phyllis Paykel Trust. We thank Dr. Michael Schmitz and Tony Chen for their assistance with the NMR and mass spectrometric data. Some of the antimicrobial screening was performed by CO-ADD (The Community for Antimicrobial Drug Discovery), funded by the Wellcome Trust (UK) and The University of Queensland (Australia) 


\section{Supplementary information}

Supplementary data related to this article can be found at

\section{References}

1. Hay M, Thomas DW, Craighead JL, Economides C, Rosenthal J. Clinical Development Success Rates for Investigational Drugs. Nat Biotechnol. 2014;32:40-51. doi:10.1038/nbt.2786.

2. Singh SB. Confronting the Challenges of Discovery of Novel Antibacterial Agents. Bioorg Med Chem Let. 2014;24:3683-3689. doi:10.1016/j.bmcl.2014.06.053

3. Silver LL, Challenges of Antibacterial Discovery. Clin Microbiol Rev. 2011;24:71-109. doi:10.1128/CMR.00030-10

4. Payne DJ, Gwynn MN, Holmes DJ, Pompliano DL. Drugs for Bad Bugs: Confronting the Challenges of Antibacterial Discovery. Nat Rev Drug Discov. 2007;6:29-40. doi:10.1038/nrd2201.

5. Alekshun MN, Levy SB. Molecular Mechanisms of Antibacterial Multidrug Resistance. Cell. 2007;128:1037-1050. doi:10.1016/j.cell.2007.03.004.

6. Melander RJ, Melander C. The Challenge of Overcoming Antibiotic Resistance: An Adjuvant Approach? ACS Infectious Diseases. 2017;3:559-563. doi: 10.1021/acsinfecdis.7b00071

7. Ejim L, Farha MA, Falconer SB, Wildenhain J, Coombes BK, Tyers M, Brown ED, Wright GD. Combinations of Antibiotics and Nonantibiotic Drugs Enhance Antimicrobial eEficacy. Nat Chem Biol. 2011;7:348-350. doi: 10.1038/NChemBio.559.

8. González-Bello C. Antibiotic adjuvants - A strategy to Unlock Bacterial Resistance to Antibiotics. Bioorg Med Chem Lett. 2017;27:4221-4228. doi:10.1016/j.bmcl.2017.08.027.

9. Zhang N, Ma S. Recent Development of Membrane-active Molecules as Antibacterial Agents. Eur J Med Chem. 2019;184:111743-111755. Doi: org/10.1016/j.ejmech.2019.111743.

10. Kwon D-H, Lu C-D. Polyamine Effects on Antibiotic Susceptibility in Bacteria. Antimicrob Agents Chemother. 2007;51:2070-2077. doi:10.1128/AAC.01472-06.

11. Blanchet M, Borselli D, Brunel JM. Polyamine Derivatives: a Revival of an Old Neglected Scaffold to Fight Resistant Gram-negative Bacteria? Future Med Chem. 2016;8:963-973. doi:10.4155/fmc-20160011.

12. Böttcher T, Kolodkin-Gal I, Kolter R, Losick R, Clardy J. Synthesis and Activity of Biomimetic Biofilm Disruptors. JACS. 2013;135:2927-2930. dx.doi.org/10.1021/ja3120955.

13. Pieri C, Borselli D, Di Giorgio C, De Méo M, Bolla J-M, Vidal N, Combes S, Brunel JM. New Ianthelliformisamine Derivatives as Antibiotic Enhancers against Resistant Gram-Negative Bacteria. $J$ Med Chem. 2014;57:4263-4272. doi:10.1021/jm500194e.

14. Wang B, Pachaiyappan B, Gruber JD, Schmidt MG, Zhang Y-M, Woster PM. Antibacterial Diamines Targeting Bacterial Membranes. J Med Chem. 2016;59:3140-3151. doi:10.1021/acs.jmedchem.5b01912. 
15. Balakrishna R, Wood SJ, Nguyen TB, Miller KA, Kumar EVKS, Datta A, David SA. Structural Correlates of Antibacterial and Membrane-Permeabilizing Activities in Acylpolyamines. Antimicrob Agents Chemother. 2006;50:852-861. doi:10.1128/AAC.50.3.852-861.2006.

16. Hoque J, Konai MM, Sequeira SS, Samaddar S, Haldar J. Antibacterial and Antibiofilm Activity of Cationic Small Molecules with Spatial Positioning of Hydrophobicity: An in Vitro and in Vivo Evaluation. J Med Chem. 2016;59:10750-10762. doi:10.1021/acs.jmedchem.6b01435.

17. Finlayson R, Pearce AN, Page MJ, Kaiser M, Bourguet-Kondracki M-L, Harper JL, Webb VL, Copp BR. Didemnidines A and B, Indole Spermidine Alkaloids from the New Zealand Ascidian Didemnum sp. J Nat Prod. 2011;74:888-892. doi:10.1021/np1008619.

18. Liew LPP, Pearce AN, Kaiser M, Copp BR. Synthesis and In Vitro and In Vivo Evaluation of Antimalarial Polyamines. Euro J Med Chem. 2013;69:22-31. doi:10.1016/j.ejmech.2013.07.055

19. Wang J, Kaiser M, Copp BR. Investigation of Indolglyoxamide and Indolacetamide Analogues of Polyamines as Antimalarial and Antitrypanosomal Agents. Mar Drugs. 2014;12:3138-3160. doi:10.3390/md12063138.

20. Pearce AN, Kaiser M, Copp BR. Synthesis and Antimalarial Evaluation of Artesunate-polyamine and Trioxolane-polyamine Conjugates. Euro J Med Chem. 2017;140:595-603. doi:10.1016/j.ejmech.2017.09.040.

21. Li SA, Cadelis MM, Sue K, Blanchet M, Vidal N, Brunel JM, Bourguet-Kondracki M-L, Copp BR, 6Bromoindolglyoxylamido Derivatives as Antimicrobial Agents and Antibiotic Enhancers. Bioorg Med Chem. 2019;27:2090-2099. doi:10.1016/j.bmc.2019.04.004.

22. Klenke B, Stewart M, Barrett MP, Brun R, Gilbert IH. Synthesis and Biological Evaluation of S-Triazine Substituted Polyamines as Potential new Anti-Trypanosomal drugs. J Med Chem. 2001;44:3440-3452. doi:10.1021/jm010854.

23. Klenke B, Gilbert IH, Nitrile Reduction in the Presence of Boc-protected Amino Groups by Catalytic Hydrogenation over Palladium-activated Raney-Nickel. J Org Chem. 2001;66:2480-2483. doi:10.1021/jo005637f.

24. Israel M, Rosenfiled JS, Modest EJ. Analogs of Spermine and Spermidine. 1. Synthesis of Polymethyleneplloyamones by Reduction of Cyanoethylated $\alpha, \omega$-Alkylediamines. J Med Chem. 1964;7:710-716. doi:org/10.1021/jm00336a006.

25. Forman ME, Jennings MC, Wuest WM, Minbiole KPC. Building a Better Quaternary Ammonium Compound (QAC): Branched Tetracationic Antiseptic Amphiphiles. ChemMedChem. 2016;11:13011405. doi: 10.1002/cmdc.201600176.

26. Yang T, Moreira W, Nyantakyi A, Chen H, binte Aziz D, Go M-L, Dick T. Amphiphilic Indole Derivatives as Antimycobacterial Agents: Structure-Activity Relationships and Membrane Targeting Properties. J Med Chem. 2017;60:2745-2763. doi: 10.1021/acs/jmedchem.6b01530.

27. Hufford CD, McChesney JD. Assignments of Dissociation Constants of Primaquine by ${ }^{13} \mathrm{C}-\mathrm{NMR}$ Spectroscopy. J Heterocyclic Chem. 1983;20:273-25. doi:org/10.1002/jhet.5570200203.

28. Basso LGM, Rodrigues RZ, Naal RMZG, Costa-Filho AJ. Effects of the Antimalarial Drug Primaquine on the Dynamic Structure of Lipid Model Membranes. Biochimica et Biophysica Acta. 2011;1808:55-64. doi:10.1016/j.bbamem.2010.08.009. 
29. La-Scalea MA, Menezes CMS, Matsutami GC, Polli MC, Serrano SHP, Ferreira EI. Molecular Modelling of the Votammetric Oxidation at a Glassy Carbon Electrode of the Antimalarial drug Primaquine and its Prodrugs Succinylprimaquine and Maleylprimaquine. Electrochimica Acta. 2006;51:5103-5111. doi:10.1016/j.electacta.2006.03.085.

30. McChesney JD, Sarangan S. Rapid Aromatic Hydrogen Exchange in the Antimalarial Primaquine. Pharmaceutical Research. 1984;184-186. doi:org/10.1023/A:1016356926714.

31. Blaskovich M.A., Zuegg J., Elliott A.G., Cooper M.A. Helping Chemists Discover New Antibiotics. ACS Infect. Dis. 2015;1:285-287. doi:10.1021/acsinfecdis.5b00044.

32. Orhan I., Şener B., Kaiser M., Brun R., Tasdemir, D. Inhibitory Activity of Marine Sponge-Derived Natural Products against Parasitic Protozoa. Mar. Drugs 2010;8:47-58. doi:10.3390/md8010047. 